\title{
Ice-sheet model sensitivities to environmental forcing and their use in projecting future sea level (the SeaRISE project)
}

\author{
Robert A. BINDSCHADLER, ${ }^{1}$ Sophie NOWICKI, ${ }^{1}$ Ayako Abe-OUCHI, ${ }^{2}$ \\ Andy ASCHWANDEN, ${ }^{3}$ Hyeungu CHOI, ${ }^{4}$ Jim FASTOOK, ${ }^{5}$ Glen GRANZOW, ${ }^{6}$ \\ Ralf GREVE, ${ }^{7}$ Gail GUTOWSKI, ${ }^{8}$ Ute HERZFELD, ${ }^{9}$ Charles JACKSON, ${ }^{8}$ \\ Jesse JOHNSON, ${ }^{6}$ Constantine KHROULEV, ${ }^{3}$ Anders LEVERMANN, ${ }^{10}$ \\ William H. LIPSCOMB, ${ }^{11}$ Maria A. MARTIN, ${ }^{12}$ Mathieu MORLIGHEM, ${ }^{13}$ \\ Byron R. PARIZEK, ${ }^{14}$ David POLLARD, ${ }^{15}$ Stephen F. PRICE, ${ }^{11}$ Diandong REN, ${ }^{16}$ \\ Fuyuki SAITO, ${ }^{17}$ Tatsuru SATO, ${ }^{7}$ Hakime SEDDIK, ${ }^{7}$ Helene SEROUSSI, ${ }^{18}$ \\ Kunio TAKAHASHI, ${ }^{17}$ Ryan WALKER, ${ }^{19}$ Wei Li WANG ${ }^{1}$ \\ ${ }^{1}$ NASA Goddard Space Flight Center, Greenbelt, MD, USA \\ E-mail: robert.a.bindschadler@nasa.gov \\ ${ }^{2}$ Atmosphere and Ocean Research Institute, University of Tokyo, Kashiwa, Chiba, Japan \\ ${ }^{3}$ Geophysical Institute, University of Alaska Fairbanks, Fairbanks, AK, USA \\ ${ }^{4}$ Sigma Space Corporation, Lanham, MD, USA \\ ${ }^{5}$ Computer Science/Quaternary Institute, University of Maine, Orono, ME, USA \\ ${ }^{6}$ College of Arts and Sciences, University of Montana, Missoula, MT, USA \\ ${ }^{7}$ Institute of Low Temperature Science, Hokkaido University, Sapporo, Japan \\ ${ }^{8}$ Institute for Geophysics, University of Texas at Austin, Austin, TX, USA \\ ${ }^{9}$ Department of Electrical, Computer and Energy Engineering and Cooperative Institute for Research in Environmental \\ Sciences, University of Colorado, Boulder, CO, USA \\ ${ }^{10}$ Physics Institute, Potsdam University, Potsdam, Germany \\ ${ }^{11}$ Los Alamos National Laboratory, Los Alamos, NM, USA \\ ${ }^{12}$ Potsdam Institute for Climate Impact Research, Potsdam, Germany \\ ${ }^{13}$ Department of Earth System Science, University of California, Irvine, Irvine, CA, USA \\ ${ }^{14}$ Mathematics and Geoscience, Penn State DuBois, DuBois, PA, USA \\ ${ }^{15}$ Earth and Environmental Systems Institute, The Pennsylvania State University, University Park, PA, USA \\ ${ }^{16}$ Department of Physics, Curtin University of Technology, Perth, Australia \\ ${ }^{17}$ Japan Agency for Marine-Earth Science and Technology, Research Institute for Global Change, Showamachi, Kanazawa, \\ Yokohama, Kanagawa, Japan \\ ${ }^{18}$ Jet Propulsion Laboratory, California Institute of Technology, Pasadena, CA, USA \\ ${ }^{19}$ Earth System Science Interdisciplinary Center, University of Maryland, College Park, MD, USA
}

\begin{abstract}
Ten ice-sheet models are used to study sensitivity of the Greenland and Antarctic ice sheets to prescribed changes of surface mass balance, sub-ice-shelf melting and basal sliding. Results exhibit a large range in projected contributions to sea-level change. In most cases, the ice volume above flotation lost is linearly dependent on the strength of the forcing. Combinations of forcings can be closely approximated by linearly summing the contributions from single forcing experiments, suggesting that nonlinear feedbacks are modest. Our models indicate that Greenland is more sensitive than Antarctica to likely atmospheric changes in temperature and precipitation, while Antarctica is more sensitive to increased ice-shelf basal melting. An experiment approximating the Intergovernmental Panel on Climate Change's RCP8.5 scenario produces additional first-century contributions to sea level of 22.3 and $8.1 \mathrm{~cm}$ from Greenland and Antarctica, respectively, with a range among models of 62 and $14 \mathrm{~cm}$, respectively. By 200 years, projections increase to 53.2 and $26.7 \mathrm{~cm}$, respectively, with ranges of 79 and $43 \mathrm{~cm}$. Linear interpolation of the sensitivity results closely approximates these projections, revealing the relative contributions of the individual forcings on the combined volume change and suggesting that total ice-sheet response to complicated forcings over 200 years can be linearized.
\end{abstract}

\section{INTRODUCTION}

In the Fourth Assessment Report (AR4) from the Intergovernmental Panel on Climate Change (IPCC), sea-level projections for the year 2100 ranged from 0.18 to $0.59 \mathrm{~m}$, but these values excluded 'future rapid dynamical changes in ice flow' (Solomon and others, 2007). The additional caveat that these projections do not include 'the full effects of changes in ice-sheet flow, therefore the upper values of the ranges are not to be considered upper bounds for sea level rise' further weakened the utility of the projected ranges to drive policy decisions related to climate change. This situation resulted from the fact that no ice-sheet model could reproduce recent observed rapid changes in ice-sheet elevation and velocity, so there was no means to include 
the possible future evolution of these changes in a deterministic way.

Among the leading suggested causes of these rapid, observed changes are penetration of surface meltwater to the ice-sheet bed causing enhanced acceleration of ice flow (e.g. Zwally and others, 2002; Joughin and others, 2008), sudden disintegration of floating ice shelves and the consequent acceleration of glaciers formerly flowing into the now-removed ice shelves (Rignot and others, 2004; Scambos and others, 2004) and the penetration of warm water beneath floating ice shelves causing a significant reduction in the buttressing effect of ice on the larger outlet glaciers feeding the floating ice shelves (Payne and others, 2004; Shepherd and others, 2004). First attempts to model the full effect of some of these processes demonstrated that very large losses of ice could result (Parizek and Alley, 2004; Dupont and Alley, 2005; Payne and others, 2007; Joughin and others, 2010).

The IPCC AR4 conclusions regarding the difficulties in credibly projecting future sea level have focused the glaciological community's efforts to understand the cause of the observed changes in a deterministic way so that the causal processes can be included in ice-sheet numerical models. Various workshops have been organized to discuss the necessary process studies and means to improve the capabilities of existing ice-sheet models (e.g. Little and others, 2007; Oppenheimer and others, 2007; Vaughan and others, 2007; Lipscomb and others, 2009; Van der Veen and others, 2010). The results of these discussions have made it clear that new field studies of key processes are necessary, as well as improvements to numerical models in how they incorporate fast-flowing ice and the processes driving rapid response of ice sheets. Each of these improvements, however, requires considerable time (and resources), making it unlikely that breakthroughs in predictive proficiency based on incorporation of the most advanced representation of these processes can be expected in time for the Fifth Assessment Report (AR5) of the IPCC. Nevertheless, the need for the glaciological community to contribute improvements to the limited-value sea-level projections of the IPCC AR4 report in time for AR5 (initially due in 2012, now scheduled for 2013) is undeniable.

One strategy to deal with this situation led to the project SeaRISE (Sea-level Response to Ice Sheet Evolution) described herein. The project's approach is briefly discussed in the next section, with short descriptions of the participating models provided in Appendix A. The paper continues with a presentation of, and a discussion about, the sensitivities of both the Greenland and Antarctic ice sheet contributions to sea level calculated for a series of environmental forcings prescribed both singly and in combination. This paper concludes with the presentation of model results for a scenario closely matching the RCP8.5 scenario being considered by the IPCC AR5 and its use in validating a methodology to interpolate the likely model responses of any specified environmental forcing scenario. Two companion papers present and discuss the spatial patterns of these same sensitivity experiments along with the insights these comparisons offer into the effects that different model implementations of the governing equations have on the resulting calculated ice-sheet behavior (Nowicki and others, in press a, b). In a third companion paper, a regional modeling study further investigates the impact of the spatial resolution of existing datasets, grounding-zone processes and till rheology on the dynamics of Thwaites Glacier, which drains into the Amundsen Sea Embayment of West Antarctica (Parizek and others, in press).

\section{APPROACH}

Three primary characteristics best define the SeaRISE project's approach: the use of multiple models; standardization of datasets that describe the physical setting, model initialization and sensitivity experiments; and application of an 'experiment minus control' method to isolate ice-sheet sensitivity to any environmental-forcing experiment. Each of these characteristics is discussed more fully below.

\subsection{Multiple models}

Numerical models of ice sheets must attempt to incorporate complexities of both internal flow and interactions of the ice sheet with its external environment at its upper and lower boundaries as well as along its perimeter. Many different response timescales are involved due to numerous internal and interactive processes. Numerical implementation strategies also vary. The result is that different attempts to numerically simulate the same ice sheet can produce different behaviors for what is intended to be consistent forcing. For the complex problem of simulating whole ice sheets accurately, no analytic solution is available to determine the errors of any particular model; this makes it very difficult (perhaps impossible) to determine which of many models is 'best', or most accurate. In addition, there are so many prognostic properties of an ice sheet (e.g. geometry, velocity, stress, temperature) that no one model is likely to be best in every aspect.

SeaRISE presumes that at the present time there is no single 'best' model of ice-sheet flow when it comes to projecting future ice-sheet behavior due to various climatic forcings and that more will be learned about the actual icesheet response by comparing the projected responses of many models. In this sense, SeaRISE adopts the multiplemodel 'ensemble' approach of the IPCC which attempts to capture the future behavior of the global climate by examining the projections of many models, each with its unique numerical approach to simulate the myriad complexities of global climate, but driven by similar forcing scenarios. The ensemble result is particularly illuminating, providing not only a possibly more accurate quantification of actual behavior than any single model, but also a clearer representation of the uncertainty in that behavior along with some insight into what aspects of models are more (or less) robust when simulating responses to particular forcings. As such, multi-model comparisons are also helpful to model development in pointing out regions or processes most responsible for different model behaviors.

\subsection{Standardization}

The variety of models and their numerical approaches and parameterizations of geophysical phenomena is an asset of SeaRISE. Nevertheless, there are many aspects of modeling the actual ice sheets that can be made common, thus reducing the possible sources of model-to-model variation. Increasing this commonality makes the ensemble of model results more useful by making the range of model projections more a function of their different treatments of icesheet flow and environmental interaction rather than a 
Table 1. Datasets provided for use in initializing and running all SeaRISE experiments. Sources of each dataset are given. Data files and more details about them can be found at http://websrv.cs.umt.edu/isis/index.php/Data

Data description $\quad$ Source

Greenland (5 $\mathrm{km}$ postings) Antarctica $(10 \mathrm{~km}$ postings)

Latitude/longitude

Mean annual surface temperature

Ice thickness

Accumulation

Ice surface elevation

Bed topography

Bathymetry

Basal heat flux

Thickness mask

Surface velocity (horizontal components only)

Surface balance velocity

Time rate of change of ice-sheet surface height

Land cover mask

Oxygen isotopes record and associated

temperature time series
See note 1

Ettema and others (2009)

See note 2

Ettema and others (2009)

Bamber and others (2001) with inclusions of some outlet glacier troughs from CReSIS Bamber and others (2001)

Jakobsson and others (2008)

Shapiro and Ritzwoller 2004)

Joughin and others (2010)

J. Johnson (personal communication, 2010)

Csatho and others (personal communication, 2009)

Csatho and others (personal communication, 2009)

Greenland Ice Core Project

Notes: 1 . Both data grids are polar stereographic projections of latitude and longitude. For Greenland, a standard parallel of $71^{\circ}$ is used with $90^{\circ}$ as the latitude of projection origin. False easting and northing are both zero. The straight vertical longitude from the North Pole is $39^{\circ} \mathrm{W}$ and the lower left corner $X$ and $Y$ values are $-800 \mathrm{~km}$ and $-3400 \mathrm{~km}$, respectively. For Antarctica, the only difference from Greenland is that the straight vertical longitude from the South Pole is $0^{\circ}$ and the lower left corner $X$ and $Y$ values are $-2800 \mathrm{~km}$ and $-2800 \mathrm{~km}$, respectively.

2. Grounded ice is calculated from surface elevation and topography. Ice-shelf thickness was provided by J.A. Griggs and J.L. Bamber (Bamber and others, 2009; Griggs and Bamber, 2009) who warn that 'This is a beta data product and should not be treated as a final product.' The ice-shelf thickness data are from Griggs and Bamber (2011).

3. For SeaRISE, these values should be capped at a value of $0.07 \mathrm{~W} \mathrm{~m}^{-2}$.

consequence of different models using different approximations of the ice sheets' physical setting or the past climate.

\subsubsection{Physical setting}

There are many data fields that any model must use as boundary conditions to describe the physical setting of the ice sheet. The particular data fields of Greenland and Antarctica used as standards for the SeaRISE experiments are listed in Table 1, along with the source of each dataset. These datasets can be found at http://websrv.cs.umt.edu/isis/ index.php/Data. Many of these datasets are leveraged off the effort of the Community Ice Sheet Model (CISM) that supplies gridded data associated with both the Greenland and Antarctic ice sheets (http://websrv.cs.umt.edu/isis/index. php/Main_Page).

SeaRISE's desire for up-to-date versions of these parameter fields contributed to a broad effort to improve them with the most recent observations. Glaciologists around the world, some not directly involved in SeaRISE, contributed their most current data so that SeaRISE models could work with the best datasets. The Antarctic bed elevation was updated by a prerelease version of the updated BEDMAP dataset (courtesy of $\mathrm{H}$. Pritchard) that included detailed new airborne radar data and new bathymetry in some offshore areas. This was further improved, as part of a separate modeling effort, by removing some unrealistic gridding artifacts, and the revised more 'model-friendly' data provided to SeaRISE modelers (Le Brocq and others, 2010). In Greenland, the SeaRISE database includes new compilations of the bed topography that incorporate the subglacial troughs of Jakobshavn Isbræ as well as Helheim, Kangerdlussuaq and Petermann glaciers based on new radar data collected by the Center for Remote
Sensing of Ice Sheets (CReSIS) and NASA's IceBridge mission by employing an algorithm that maintains a deep trough even when that trough is narrower than the $5 \mathrm{~km}$ grid spacing (Herzfeld and others, 2011). Use of better-defined outlet glacier troughs improves the realization of the surface flow field (Herzfeld and others, 2012).

\subsubsection{Initialization (spin-up and tuning)}

SeaRISE models initialize by 'spinning up', by 'tuning' or by a combination of the two. Both methods are designed to minimize differences between modeled and observed icesheet velocities and thickness distributions. These differences are created because required model parameters have inaccuracies caused by measurement errors, interpolations of sparsely sampled data, temporal mismatching and other sources. The initialized states often contain transients, i.e. the modeled ice sheet continues to evolve without any change in prescribed climates. As the model runs, these adjustments gradually decrease as the geometry, stress, temperature and motion fields approach equilibrium, but they can mask or influence the ice-sheet changes caused by a specific experiment's prescriptions. All models express this effect to some degree, so, as described below, the impacts of any projected environmental change are calculated as a difference from an experiment where modern climate conditions are held constant.

'Spin-up' initialization refers to running the model through one or more glacial/interglacial cycles to reach internal consistency. It requires climatic information over hundreds of thousands of years. For SeaRISE models using this initialization approach, datasets of temperature derived from the ice cores were used: a 125 ka record from the GRIP 
ice core for Greenland and a 405 ka record from the Vostok ice core for Antarctica.

Initialization by 'tuning' refers to selecting a particular data field (or fields) as a target(s) and adjusting the independent variables of the model to come acceptably close (i.e. within a specified mismatch tolerance) to this target. Generally, geometry and environmental parameters are specified and the calculated velocity field is tuned through lubrication or strain enhancement factors to match the surface velocity (or balance velocity) field. Once tuned, these tuning parameters are usually held constant. Details of specific models are given in Table 2 and Appendix A.

A goal of both types of initialization is to have the model output match reality in as many characteristics as possible at the time the experiment runs commence. The characteristics that are used as targets to match for SeaRISE models are the shape of the ice sheet (usually surface elevations or ice thickness over a static bed) and its surface flow field (see Nowicki and others, in press $a, b$, for these spatial comparisons). Rates of change of either, or both, of these fields have been used in other modeling exercises but are not used by SeaRISE models. Whether 'spinning up' or 'tuning', SeaRISE set 1 January 2004 as the starting time of all experiments.

\subsubsection{Experiments}

As mentioned above, coupling of realistically dynamic icesheet models to predictive climate models is at a very early stage, and most ice-sheet models are only beginning to include poorly understood processes that are primarily responsible for recently observed dramatic flow accelerations/decelerations and rapid ice-thickness increases/decreases. Forcing ice-sheet models with environmental conditions computed by independent climate models may not provide credible projections of ice-sheet response if those ice-sheet models contain unrealistic dynamics. The modeling community continues to work toward the goal of ice-sheet models with improved dynamics fully coupled to global climate models, but its realization is many years away.

In light of this situation, SeaRISE designed a set of experiments wherein the effect of the environment is prescribed as a common forcing to each ice-sheet model. In basic terms, the environment interacts with the ice sheet on either its upper or lower boundary or at its perimeter. This holistic view drove the definition of the experiments where a change experienced by the ice sheet was imposed at one or more of these interfaces. The need to formulate standardized experiments, applicable to all or most models, strongly influenced their simple form. It is certainly possible to contemplate experiments that capture more realistic climatic and glaciological scenarios than those used in the SeaRISE experiments. In fact, SeaRISE participants considered many forms of such scenarios but rejected experiments that could not be consistently implemented for the majority of models, to preserve the project's strength of using multiple models. In so doing, SeaRISE sacrifices some realworld complexity for the sake of increasing the number of models running each experiment. As such, these experiments represent more an attempt to measure ice-sheet sensitivity to specific forcing conditions rather than a coupled interaction of the ice sheet with the global climate. Most experiments ran 500 years into the future, thus covering the 200 year time focus of the next IPCC assessment report. The upper surface forcing uses calculated changes in atmospheric temperature and precipitation from the IPCC Fourth Assessment Report; the basal forcing amplifies basal sliding; and the perimeter forcing prescribes the melt rate beneath floating ice shelves. More details of each are given below when the specific experiment conditions and results are presented.

\subsection{Model output}

Runs of each model were conducted on the modelers' home computing platforms, and outputs were submitted to the NASA Goddard Space Flight Center using a standard output file format determined by the SeaRISE participants. The specific format, including standard parameter names and reporting intervals, can be viewed at http://websrv.cs.umt. edu/isis/index.php/Output_

Format. The specific output parameters included the scalar quantities of ice-sheet volume, area of grounded ice and area of floating ice. In addition, the following parameters were specified at each grid coordinate: surface and bed elevations, ice thickness, upper and lower surface mass balance, basal water amount and pressure, three components of both surface and basal velocity, basal ice temperature, temporal rate of ice thickness change and an integer mask that specified which gridpoints contained icefree ocean, ice-free land, grounded ice and floating ice. For Greenland, these parameters were output every 5 years, while for Antarctica they were output every 10 years. Most models of Greenland and Antarctica used spatial grids spaced at 5 and $10 \mathrm{~km}$, respectively. Typical compressed NetCDF-formatted output file sizes for a 500 year run are $1 \mathrm{~GB}$ for Greenland (at 5 year reporting and $5 \mathrm{~km}$ resolution) and $43 \mathrm{~GB}$ for Antarctica (at 10 year reporting and $10 \mathrm{~km}$ resolution). This output file standardization greatly reduced the effort required to analyze large volumes of model output.

\section{SeaRISE MODELS}

This paper focuses on results of ten full ice-sheet models that participated in SeaRISE (Table 2). Regional models also explored the response of particularly active or potentially active sites (Parizek and others, in press). Six whole ice-sheet models were applied to just one ice sheet while four simulated both the Greenland and Antarctic ice sheets. These models share various attributes, but there are also many differences among them that lead to different responses to the various experiments. As discussed above, SeaRISE strove to standardize many aspects of the physical setting as well as prescribe uniform forcings used by each model. It did not attempt to dictate the internal workings of each model, nor the manner in which each was initialized. Most models represent the ice sheets on a grid oriented and scaled to conform to the standard datasets (see Table 1, note 1 ), but some use adaptive or variable grids. All include multiple vertical layers. Each model solves equations of motion for ice flow, both internal deformation and basal sliding, using the stress field, which is calculated from the geometry. The velocity is typically converted to a strain field using an ice rheology affected by ice temperature. Boundary conditions, often prescribed for a particular experiment, complete the equation set and allow solution of the threedimensional (3-D) motion field. Mass continuity determines how ice flow changes the geometry over a given time-step, and the model advances to the next time-step.

The nonlinearity of ice rheology, the complex boundary interactions at the surface, base and perimeter of the ice 
Table 2. Characteristics of models used in SeaRISE (additional capabilities of some models may not be indicated here if not used in SeaRISE experiments; details in Appendix A)

\begin{tabular}{|c|c|c|c|c|c|}
\hline \multirow[t]{2}{*}{ Characteristics } & \multicolumn{5}{|c|}{ Model } \\
\hline & ICIES & Elmer/lce & UMISM & ISSM & SICOPOLIS \\
\hline $\begin{array}{l}\text { Numerical } \\
\text { method }\end{array}$ & $\begin{array}{l}\text { Finite difference, } \\
\text { Eulerian }\end{array}$ & $\begin{array}{l}\text { Finite element with } \\
\text { triangular prisms, Eulerian }\end{array}$ & $\begin{array}{l}\text { Finite-element } \\
\text { quadrilaterals }\end{array}$ & $\begin{array}{l}\text { Finite element; } \\
\text { arbitrary Lagrangian } \\
\text { Eulerian (ALE) }\end{array}$ & Finite difference, Eulerian \\
\hline $\begin{array}{l}\text { Grid } \\
\text { (horizontal; } \\
\text { vertical) }\end{array}$ & $\begin{array}{l}\text { H: uniform } 10 \mathrm{~km} \text {; } \\
\mathrm{V}: 26 \text { layers } \\
\text { (terrain-following) }\end{array}$ & $\begin{array}{l}\mathrm{H} \text { : adaptive (between } 1 \mathrm{~km} \\
\text { on the margins and } 70 \mathrm{~km} \\
\text { in the interior); } \mathrm{V}: 17 \text { layers } \\
\text { (terrain-following) }\end{array}$ & $\begin{array}{l}\text { H: } 20 \mathrm{~km} \text { Antarctica, } \\
10 \mathrm{~km} \text { Greenland; } \\
\text { V: } 40 \text { layers, non- } \\
\text { uniformly spaced }\end{array}$ & $\begin{array}{l}\mathrm{H} \text { : anisotropic } \\
\text { (between } 3 \mathrm{~km} \text { on } \\
\text { fast ice streams and } \\
15 \mathrm{~km} \text { in the interior); } \\
\mathrm{V}: 14 \text { layers }\end{array}$ & $\begin{array}{l}\mathrm{H}: 5 \mathrm{~km} \text { Greenland, } 10 \mathrm{~km} \\
\text { Antarctica; V: } 91 \text { layers } \\
\text { (terrain-following) }\end{array}$ \\
\hline Time-step & $\begin{array}{l}\text { Adaptive, } \\
\text { maximum of } \\
0.125 \text { years }\end{array}$ & 1 month & 1 year & 2 months & $\begin{array}{l}\text { Thickness, velocity: } 0.01-0.02 \\
\text { year (Antarctica), } 0.1-0.2 \text { year } \\
\text { (Greenland). Temperature: } \\
0.05-0.1 \text { year (Antarctica), } \\
0.1-0.2 \text { year (Greenland) }\end{array}$ \\
\hline $\begin{array}{l}\text { Spin-up/ } \\
\text { initialization }\end{array}$ & $\begin{array}{l}\text { One glacial cycle } \\
\text { from } 125 \mathrm{ka} \\
\text { steady-state }\end{array}$ & $\begin{array}{l}\text { Initial spin-up (from the } \\
\text { Eemian through the last } \\
\text { glacial period until } 200 \mathrm{BP} \text { ) } \\
\text { with the shallow-ice model } \\
\text { SICOPOLIS using fixed, } \\
\text { slightly smoothed present- }\end{array}$ & $\begin{array}{l}30 \mathrm{ka} \text {, driven by } \\
\text { ice-core temperature } \\
\text { proxy }\end{array}$ & $\begin{array}{l}\text { Data assimilation } \\
\text { to match present- } \\
\text { day velocities and } \\
\text { self-consistent } \\
\text { temperature field }\end{array}$ & $\begin{array}{l}\text { First } 125 \text { ka steady state, } \\
\text { then } 125 \text { ka transient (from } \\
\text { the Eemian through the last } \\
\text { glacial period until present); with } \\
\text { fixed, slightly smoothed present- } \\
\text { day topography }\end{array}$ \\
\hline
\end{tabular}

\begin{tabular}{|c|c|c|c|}
\hline $\begin{array}{l}\text { Ice flow } \\
\text { mechanics }\end{array}$ & Shallow ice & $\begin{array}{l}\text { Elmer/lce } \\
\text { Full Stokes }\end{array}$ & Shallow ice \\
\hline $\begin{array}{l}\text { Surface mass } \\
\text { balance }\end{array}$ & $\begin{array}{l}\text { Positive degree-da } \\
\text { (PDD) (Reeh, } 199 \\
\text { with } \\
\text { temperature- } \\
\text { dependent PDD } \\
\text { factors following } \\
\text { Tarasov and } \\
\text { Peltier (2002) }\end{array}$ & $\begin{array}{l}\text { y Present-day mean annual } \\
\text { 1)and mean summer surface } \\
\text { temperatures by Fortuin } \\
\text { and Oerlemans (1990). } \\
\text { Present-day accumulation } \\
\text { by Arthern and others } \\
\text { (2006). Ablation from } \\
\text { PDD model (Reeh, 1991) } \\
\text { with factors of } 8 \mathrm{~mm}(\mathrm{Kd})^{-1} \\
\text { for ice melt and } \\
3 \mathrm{~mm}(\mathrm{Kd})^{-1} \text { for snowmelt }\end{array}$ & $\begin{array}{l}\text { Mean annual } \\
\text { temperature (MAT) from } \\
\text { latitudinal and elevation } \\
\text { lapse rates, accumu- } \\
\text { lation from MAT, } \\
\text { ablation from PDD } \\
\text { with latitude-dependent } \\
\text { amplitude around MAT }\end{array}$ \\
\hline
\end{tabular}

Basal sliding Weertman sliding Weertman sliding law

Basal None None

hydrology

\begin{tabular}{|c|c|c|}
\hline Ice shelves & No & No \\
\hline $\begin{array}{l}\text { Advance/ } \\
\text { retreat }\end{array}$ & $\begin{array}{l}\text { Grounding line is } \\
\text { determined by a } \\
\text { floating criterion: } \\
\text { when thickness at } \\
\text { a grid is below } \\
\text { flotation thickness, } \\
\text { then immediately } \\
\text { cut off }\end{array}$ & Grounding line fixed \\
\hline
\end{tabular}
law $(m=3) \quad$ with sub-melt sliding

Weertman sliding law; lubrication factor proportional to basal water amount

Basal water conserved; source calculated from basal melting

No; melting applied at last grounded gridpoint Grounding limit shifts to position where surface falls below flotation height. Longitudinal extension at unbuttressed grounding line yields thinning rate at grounding line added to local mass balance, modified by 'Weertman' parameter (1 - no buttressing, 0 - full buttressing) Saito and Seddik and others (2012) Fastook (1993) Abe-Ouchi (2004, 2005, 2010); Greve and others (2011)
Higher-order (Blatter-Pattyn)

Surface mass balance imposed using the SeaRISE datasets without any correction

iscous sliding law

None

Yes

Fixed calving

front and grounding lines

(n)

.

\footnotetext{
Morlighem and others (2010); Seroussi and others (2011); Larour and others (2012)

Greve and others (2011); Sato and Greve (2012)
}

Shallow ice (Greenland) shallow ice + shallow shelf (Antarctica)

Present-day mean annual and mean summer surface temperatures by Fausto and others (2009) (Greenland) and Fortuin and Oerlemans (1990) (Antarctica). Present-day accumulation by Ettema and others (2009) (Greenland) and Arthern and others (2006) (Antarctica). Ablation from PDD model (Reeh, 1991) with factors of $8 \mathrm{~mm}(\mathrm{Kd})^{-1}$ for ice melt and $3 \mathrm{~mm}(\mathrm{Kd})^{-1}$ for snowmelt

Weertman sliding law with sub-melt sliding

Water content computed in nearbasal temperate ice $(\max .1 \%)$, basal melting rate computed under grounded ice and prescribed under floating ice, no basal water layer

Yes for Antarctica, no for Greenland

Antarctica: Freely evolving grounded ice margin, grounding line and calving front. Grounding line detected by the floating condition. Calving occurs if thickness falls below threshold of $50 \mathrm{~m}$. Greenland: freely evolving grounded ice margin, but limited to present-day extent 
Table 2. continued

\begin{tabular}{|c|c|c|c|c|c|}
\hline \multirow[t]{2}{*}{ Characteristics } & \multicolumn{5}{|c|}{ Model } \\
\hline & PISM & PennState3D & Potsdam & AIF & CISM 2.0 \\
\hline $\begin{array}{l}\text { Numerical } \\
\text { method }\end{array}$ & $\begin{array}{l}\text { Finite difference, } \\
\text { Eulerian }\end{array}$ & $\begin{array}{l}\text { Finite difference, } \\
\text { Eulerian }\end{array}$ & Finite difference, Eulerian & Finite difference, Eulerian & $\begin{array}{l}\text { Finite difference, Eulerian, } \\
\text { explicit mass and tracer } \\
\text { advection (using incremental } \\
\text { remapping) }\end{array}$ \\
\hline Time-step & $\begin{array}{l}\text { Adaptive, typically } \\
\sim 15 \text { days }\end{array}$ & 0.5-1 year & Adaptive & 1 year & $\begin{array}{l}0.1-0.2 \text { year as required for } \\
\text { numerical stability }\end{array}$ \\
\hline $\begin{array}{l}\text { Spin-up/ } \\
\text { initialization }\end{array}$ & $\begin{array}{l}125 \text { ka transient } \\
\text { (from the Eemian } \\
\text { through the last } \\
\text { glacial period } \\
\text { until present) }\end{array}$ & Last $5 \mathrm{Ma}$ & $\begin{array}{l}\text { Quasi-steady-state spin-up } \\
\text { to bring energy and } \\
\text { momentum balance into } \\
\text { approximate equilibrium } \\
\text { with present-day } \\
\text { geometry }\end{array}$ & $\begin{array}{l}\text { Iteration on governing } \\
\text { equations with present- } \\
\text { day ice sheet geometry } \\
\text { and climate forcing. } \\
\text { Balance velocity is used } \\
\text { as the target to tune the } \\
\text { stress configuration } \\
\text { through an adjustable } \\
\text { enhancement factor }\end{array}$ & $\begin{array}{l}\text { Quasi-steady-state spin-up to } \\
\text { bring energy and momentum } \\
\text { balance into approximate } \\
\text { equilibrium with present-day } \\
\text { geometry; basal sliding } \\
\text { parameters tuned to match } \\
\text { balance velocities }\end{array}$ \\
\hline $\begin{array}{l}\text { Ice flow } \\
\text { mechanics }\end{array}$ & $\begin{array}{l}\text { Shallow ice }+ \\
\text { shelfy stream } \\
\text { (hybrid) }\end{array}$ & $\begin{array}{l}\text { Shallow ice }+ \\
\text { shelfy stream } \\
\text { (hybrid) }\end{array}$ & $\begin{array}{l}\text { Shallow ice }+ \text { shelfy } \\
\text { stream (hybrid) }\end{array}$ & $\begin{array}{l}\text { Higher-order with } \\
\text { longitudinal and vertical } \\
\text { shear stresses }\end{array}$ & $\begin{array}{l}\text { First-order (e.g. Blatter- } \\
\text { Pattyn) }\end{array}$ \\
\hline $\begin{array}{l}\text { Surface } \\
\text { mass balance }\end{array}$ & $\begin{array}{l}\text { PDD with } \\
\text { EISMINT } \\
\text { Greenland } \\
\text { parameters }\end{array}$ & $\begin{array}{l}\text { PDD using SeaRISE } \\
\text { modern mean annual } \\
\text { air temperature and } \\
\text { precipitation datasets, } \\
\text { including a sinusoidal } \\
\text { seasonal cycle, lapse } \\
\text { rate corrections (paleo- } \\
\text { spin-up variations } \\
\text { based on deep-sea-core } \\
\delta^{18} \mathrm{O} \text { and orbit) }\end{array}$ & $\begin{array}{l}\text { Surface mass balance } \\
\text { and surface temperature } \\
\text { from SeaRISE-provided } \\
\text { dataset }\end{array}$ & $\begin{array}{l}\text { PDD method using } \\
\text { SeaRISE-provided mean } \\
\text { annual temperature and } \\
\text { suggested parameters }\end{array}$ & PDD or coupled to CESM \\
\hline Basal sliding & Coulomb plastic & $\begin{array}{l}\text { Weertman-type sliding } \\
\text { law with basal } \\
\text { temperature } \\
\text { dependence }\end{array}$ & Coulomb plastic sliding & $\begin{array}{l}\text { Weertman sliding law } \\
\text { depending on the basal } \\
\text { shear stress in a cubic } \\
\text { power (1) or a linear } \\
\text { relation (2) }\end{array}$ & $\begin{array}{l}\text { Linear viscous (using } \\
\text { MacAyeal-type beta-squared } \\
\text { sliding law) }\end{array}$ \\
\hline Basal hydrology & $\begin{array}{l}\text { Basal meltwater } \\
\text { model: controls } \\
\text { bed strength }\end{array}$ & None & $\begin{array}{l}\text { Basal meltwater controls } \\
\text { bed strength }\end{array}$ & None & None \\
\hline Ice shelves & No & Yes & Yes & No & No \\
\hline $\begin{array}{l}\text { Advance/ } \\
\text { retreat }\end{array}$ & $\begin{array}{l}\text { Fixed calving } \\
\text { front }\end{array}$ & $\begin{array}{l}\text { Uses Schoof (2007) } \\
\text { parameterization of ice } \\
\text { flux across grounding } \\
\text { line vs thickness as an } \\
\text { internal boundary } \\
\text { condition. Calving } \\
\text { based on divergence } \\
\text { of large-scale flow }\end{array}$ & $\begin{array}{l}\text { Freely evolving grounded } \\
\text { ice margin, grounding } \\
\text { line and calving front. } \\
\text { Grounding line detected } \\
\text { by the floating condition. } \\
\text { Kinematic first-order } \\
\text { calving law for ice-shelf } \\
\text { fronts using a subgrid } \\
\text { interpolation (Albrecht } \\
\text { and others, 2011; Lever- } \\
\text { mann and others, 2012) }\end{array}$ & $\begin{array}{l}\text { Ice-sheet margin moves } \\
\text { freely. Grounding line } \\
\text { detected by the floating } \\
\text { condition }\end{array}$ & $\begin{array}{l}\text { Calving front and terrestrial } \\
\text { margin allowed to retreat } \\
\text { (if thin to zero) but not } \\
\text { advance past present-day } \\
\text { margin position }\end{array}$ \\
\hline Sources & $\begin{array}{l}\text { Martin and others } \\
(2011) ; \\
\text { Winkelmann and } \\
\text { others (2011) }\end{array}$ & $\begin{array}{l}\text { Pollard and DeConto } \\
(2012)\end{array}$ & $\begin{array}{l}\text { Martin and others (2011); } \\
\text { Winkelmann and others } \\
(2011)\end{array}$ & Wang and others (2012) & $\begin{array}{l}\text { Bougamont and others (2011); } \\
\text { Lemieux and others (2011); } \\
\text { Price and others (2011); } \\
\text { Evans and others (2012) }\end{array}$ \\
\hline
\end{tabular}

sheet and the short spatial scale of large stress gradients all force any model to make assumptions that make each model a unique representation of the ice sheet. SeaRISE embraces this variety and regards each model used as a valuable, though imperfect, simulation of either ice sheet. Characteristics of each model particularly germane to the SeaRISE experiments are presented in Table 2. This is further augmented by brief narrative descriptions of each model in
Appendix A. More complete descriptions appear elsewhere, as cited within these descriptions.

\section{CONTROL RUN}

The standard datasets of ice-sheet shape and flow used by SeaRISE roughly correspond to the 1 January 2004 start date for all experiments. Neither ice sheet was in an 

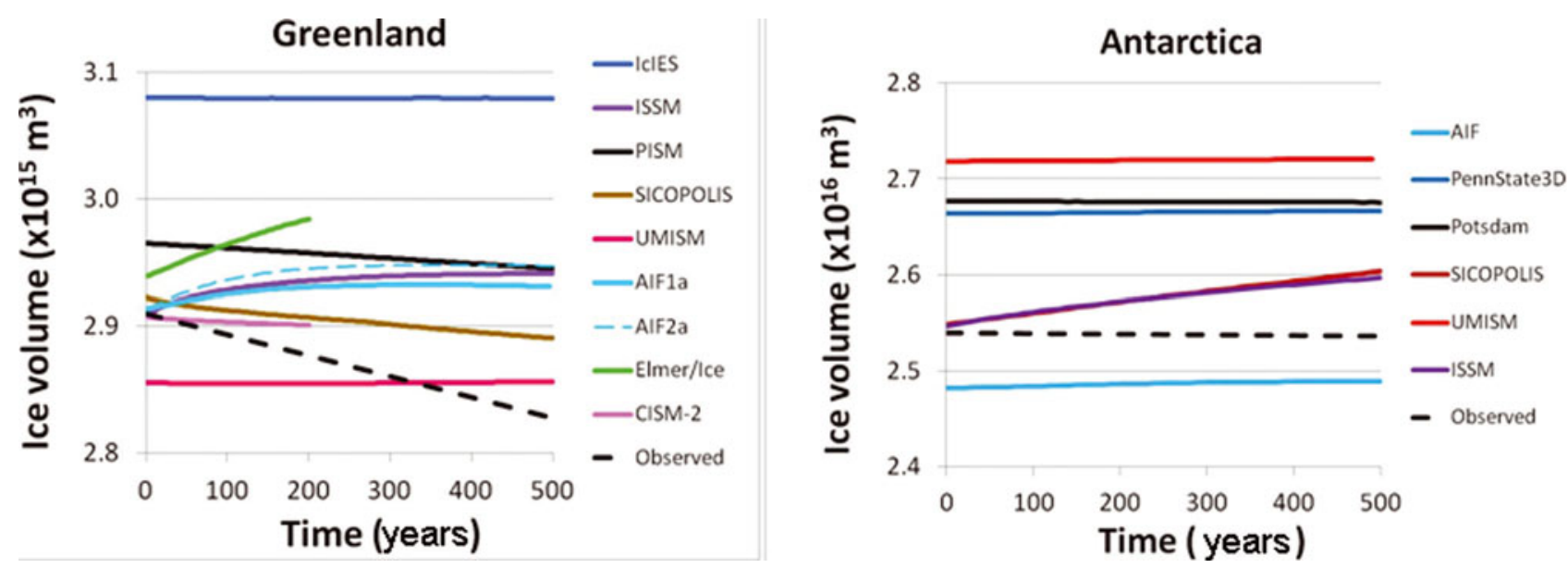

Fig. 1. Change in ice-sheet volume (grounded ice plus ice shelves) for control runs of the Greenland and Antarctic ice sheets for different models. Models are identified and described in Table 2 and Appendix A. Black dashed lines begin with the current volume of each ice sheet at 0 years and apply a recently published rate of ice-sheet mass change (Shepherd and others, 2012).

equilibrium state on that date, so even a perfect numerical model of either ice sheet would calculate changes in shape and flow. Moreover, every model, once initialization is terminated and it begins to calculate the evolving response of the ice sheet to a prescribed experiment, carries the legacy of its initialization process. These calculations usually include a continuing set of adjustments (which are small for a good initialization), but the trends of these adjustments are usually different and sometimes divergent for different models.

To achieve the SeaRISE objective of quantifying and studying the sensitivities of the ice-sheet models to various specified forcing experiments, the effect of ongoing dynamic and geometric changes of the model related to initialization needs to be removed. Fortunately, because these legacy behaviors are contained within each experiment run of each model, the generation of a 'control' run, where no forcing is applied, captures that model's continuing equilibration. By subtracting the results of this control run from the results of any experiment using the same model, the resulting difference isolates the response of that model to the forcing prescribed by the experiment alone.

This approach implicitly assumes that the legacy behavior does not feed back on the experiment and influence the behavior caused by the experiment. Experiments involving small and simple forcing are best suited for ensuring that this non-interference assumption is valid. One specific test of this assumption (using the SICOPOLIS model described below) was performed with a modestly large forcing by generating two very different control runs. The same experiment was then run in combination with each set of conditions used in each of the two control runs, and the experiment outcomes were subtracted from the appropriate control run. The two derived 'experiment minus control' outcomes were identical, supporting the contention that this is an acceptable method for comparing experiment results from different models by examining the respective 'experiment minus control' behaviors.

Control runs for each model were generated by running each model forward 500 years from the starting time (1 January 2004) with a climate that did not change. These control runs are referred to as the 'constant-climate' (CC) run. If the model included any annual variation of temperature or precipitation, the annual cycle corresponding to the last annual cycle before the starting time was reached was imposed over each of the subsequent 500 years. Time-series output from the control run of each model was stored and then subtracted from the output of all subsequent experiments using that same model.

The control run results, expressed as the temporal record of ice-sheet volume (including both grounded and floating ice), are shown in Figure 1. This figure shows that many models continue to evolve, despite the constant climate specified. No model matches both the current volume and the observed rate of present-day volume change. Three of the Greenland models (ISSM, AIF and CISM-2) initialize to the present volume of $2.91 \times 10^{15} \mathrm{~m}^{3}$; the first two then grow slightly, while CISM-2's volume decreases. Two cases of the AIF model are included to correspond with different choices of the basal sliding parameterization (Table 2). Three other models (SICOPOLIS, Elmer/Ice and PISM) begin with volumes slightly too large; Elmer/Ice continues to grow, but PISM and SICOPOLIS shrink at a rate of $\sim 50 \mathrm{Gta}^{-1}$. The remaining two models exhibit temporally stable volumes with ICIES 6\% larger and UMISM $2 \%$ smaller than present.

It is difficult to discern from Figure 1, but rates of volume change diminish with time for all models. By 100 years, the rate of volume change for all but Elmer/Ice and AIF2a is within the range -0.004 to $0.01 \%$ per decade, with Elmer/ Ice growing at a rate of $0.02 \%$ per decade, yet this growth rate is decreasing gradually.

Six models simulate the Antarctic ice sheet. Four are quite stable over the 500 years; however, the vertical scale is $\sim 20$ times larger than the corresponding Greenland plot. The Potsdam, UMISM and PennState3D models all have volumes larger than present. ISSM and SICOPOLIS both closely match the present volume of $2.54 \times 10^{16} \mathrm{~m}^{3}$ and are remarkably similar in their gradual growth over the 500 year run. The AIF model is initialized to match the present Antarctic volume, but because this model does not include ice shelves, the value plotted in Figure 1 is less than the total grounded plus floating volume of the ice sheet.

Rates of volume change for these Antarctic ice-sheet models vary over the 500 years: AIF, PennState3D and UMISM all grow at modest rates below $0.0001 \%$ per decade; ISSM's growth gradually diminishes to $<0.0003 \%$ per decade at 500 years; Potsdam oscillates between rates $+0.0001 \%$ per decade, but with a near-zero mean; and 
SICOPOLIS maintains a relatively high growth rate of $0.0004 \%$ per decade throughout the full 500 year run.

It is incorrect to interpret the temporal response of these control runs as a prediction of actual future behavior of either ice sheet. Generally, the goal of these control runs is to confirm that each model has achieved a high degree of equilibration, expressed as a low rate of volume change. The inclusion in Figure 1 of recently published ice-sheet mass changes (from Shepherd and others, 2012) extrapolated for 500 years helps illustrate the degree of model stability relative to observed volume-change rates. However, even models that indicate a changing volume still provide a useful means of testing their sensitivity to different experiments, albeit with the need for additional caution that the changes calculated in any experiment are not significantly influenced by 'cross-talk' with simultaneous ongoing control-run adjustments.

\section{EXPERIMENTS AND RESULTS}

The heart of the SeaRISE project is the set of experiments designed to examine the sensitivity of the Greenland and Antarctic ice sheets to changes in external forcing. Without direct coupling to models of the surrounding environment, changes at the upper and lower surfaces of the ice sheet and at its perimeter are specified. These are required to be simple enough to have suitable means to apply them to all models of each ice sheet, while still being tied to an actual physical mechanism. The experiments are arranged into four categories. In the first three categories, a single specific change is prescribed at either the upper or lower boundary or perimeter. In each of these three categories, three different experiments are performed to allow the magnitude of the prescribed forcing to cover a wide range and to examine the linearity of the response. The fourth experiment category combines multiple forcings. Below, each experiment is described and the results of predicted ice volume changes are presented and discussed. As mentioned earlier, the presentation and discussion of spatial differences between models for any experiment are contained in companion papers.

Because the focus of SeaRISE is the Greenland or the Antarctic ice sheet's potential contribution to global sea level, the changes in ice volume reported for all experiments include only the portion of lost ice that contributes to sea level. We refer to this as the 'volume above flotation' (VAF). Lost floating ice is not reported. Also not reported is a portion of lost ice grounded on a bed below sea level because some of this lost ice mass converts to water required to fill the same basin without changing sea level. Only that fraction of ice 'above flotation' will change overall sea level. For areas where the bed is below sea level, the ice thickness 'above flotation' can be calculated as

$$
h=H-Z\left(\rho_{\mathrm{w}} / \rho_{\mathrm{i}}\right)
$$

where $h$ is the ice thickness contributing to sea level, $H$ is the full ice thickness, $Z$ is the depth of the marine bed and $\rho_{\mathrm{w}}$ and $\rho_{\mathrm{i}}$ are the densities of sea water and ice, respectively. For Greenland, the difference between the ice lost 'above flotation' and total ice lost is small. For Antarctica, however, there are substantial differences both because large ice shelves are often removed in the scenarios and because there are large areas of grounded ice resting on deep submarine beds.

\subsection{Greenland}

\subsubsection{Surface climate experiment}

The first set of external forcing experiments prescribes a set of changing climate conditions at the upper surface of the ice sheet. Changes in surface air temperature and precipitation were calculated by many global climate models for a number of climate scenarios included in AR4 of the IPCC and made available to the research community. The A1B scenario attempts to simulate rapid economic growth in a more integrated world with a balanced emphasis on all energy sources (Solomon and others, 2007). It increases atmospheric $\mathrm{CO}_{2}$ at slightly less than half the rate of the more fossil-fuel intensive A1F1 scenario. The calculated temperature and precipitation values of the A1B scenario for 18 models were combined into a time series of their monthly mean values and made available to SeaRISE (personal communication from T. Bracegirdle, 2009).

The IPCC model runs began in calendar year 1998 and lasted 100 years. SeaRISE runs begin in calendar year 2004, 6 years later, so these A1B fields apply for the first 94 years of SeaRISE model runs. The SeaRISE project reprojected these averaged A1B outputs onto the SeaRISE grids for Greenland and Antarctica and converted them to anomaly fields of temperature and precipitation for use in the SeaRISE climatesensitivity experiments. These were then applied to whatever scheme each model used to calculate its grid of surface mass-balance values. Most, but not all, models used some form of 'positive degree-day' (PDD) scheme (see Table 2), but even these could vary in necessary scaling parameters, such as lapse rate. The ISSM and CISM-2 models used a simplified surface mass-balance scheme that did not discriminate between solid and liquid precipitation. This simplification would tend to overestimate mass accumulation, reducing mass loss.

Figure 2 illustrates the temporal pattern of these anomalies averaged over the entire Greenland or Antarctic ice sheet. The mean values in 2004 for Greenland are $-18.63^{\circ} \mathrm{C}$ and $0.36 \mathrm{mw}$.e. $\mathrm{a}^{-1}$ and for Antarctica are $-35.53^{\circ} \mathrm{C}$ and $0.16 \mathrm{~m} \mathrm{a}^{-1}$. As expected in a warming climate, both temperature and precipitation increase.

These AR4-A1B scenario-based anomalies form the basis of the climate-forcing experiments. Prescribing them directly defines the first of these experiments (designated C1). Because the IPCC model runs were limited to 100 years and SeaRISE has a later starting date, these anomaly values could be applied for only 94 years. From year 95 to the end of the 500 year simulation, the conditions during year 94 are repeated. The final 6 years of Figure 2 illustrates the beginning of this extensive period of steady climate.

The two additional climate-sensitivity experiments (C2 and C3) amplify these temperature and climate anomalies by an additional $50 \%$ and $100 \%$, respectively, i.e. C2 amplifies the A1B forcing by a factor of 1.5 and $\mathrm{C} 3$ prescribes temperature and precipitation anomalies twice as large as the A1B forcing.

Figure 3 presents the change in VAF of the SeaRISE model simulations of the $\mathrm{C} 1, \mathrm{C} 2$ and $\mathrm{C} 3$ experiments differenced from the control run to remove unrelated adjustments associated with initialization (as discussed earlier). There is a large spread in the response magnitudes, but all models project a decreasing VAF at all times in each experiment. For reference, a loss of $4.0 \times 10^{14} \mathrm{~m}^{3}$ of ice (above flotation) equates to a $1 \mathrm{~m}$ rise in mean global sea level, and all plots (except Fig. 1) use a consistent VAF unit of $10^{14} \mathrm{~m}^{3}$. The 


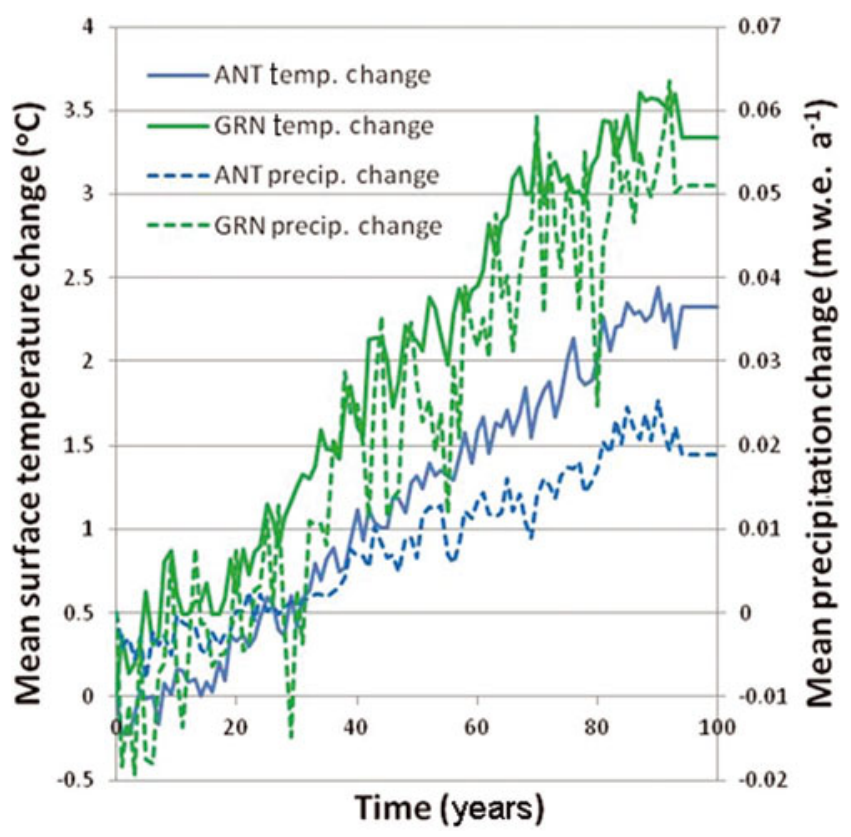

Fig. 2. Anomalies of surface temperature and precipitation averaged over the Greenland and Antarctic ice sheets derived from 18 climate models submitted to the IPCC AR4 running the A1B forcing scenario.

ICIES and PISM models lose the most ice, reaching this $1 \mathrm{~m}$ sea-level contribution $\sim 350$ years after the simulation begins for the doubled A1B scenario (C3). The ISSM model loses the least ice (for the models run for the full 500 years) and projects a sea-level contribution of only $8.5 \mathrm{~cm}$ after 500 years. The CISM-2 model was only run for 200 years, but projects losses less than half that of the ISSM model.
The relative behaviors of the models for each climate experiment are similar. The two models with the least VAF loss (ISSM and CISM-2) are exceptional in not using a PDD scheme to calculate surface melt (Table 2) and it is likely that their inclusion of rain in the surface mass accumulation underestimates the VAF loss. All other models use the prescribed precipitation anomalies in combination with some reference accumulation field and a calculation of surface melting using a PDD scheme driven by the prescribed temperature anomalies to determine the surface mass balance. However, the specific parameters used to translate the temperature change to a melt rate vary between models; this is the likely primary source of the spread of VAF change between models.

The rate of VAF loss increases for all models during the first 94 years, when the magnitude of these changes continues to increase (see Fig. 2). Afterward, the climate changes remain constant (at the final year-94 values) and each model transitions to a more gradual rate of ice loss that slowly decreases. It is important to emphasize that this implies that if the prescribed climate conditions continued to warm, as is the case in most models that project changes beyond 100 years for any realistic emissions scenario, then the projected rates of ice loss would be considerably larger than the cases presented here.

The comparison of model response to the A1B amplification factor (lower panels of Fig. 3) indicates a nearly linear response for those models with the smaller responses (CISM2, ISSM and UMISM), but a nonlinear response for the larger responding models (ICIES and PISM). These response characteristics do not change significantly throughout the 500 year run. The linearity of the VAF change on the A1B amplification factor was examined statistically for every
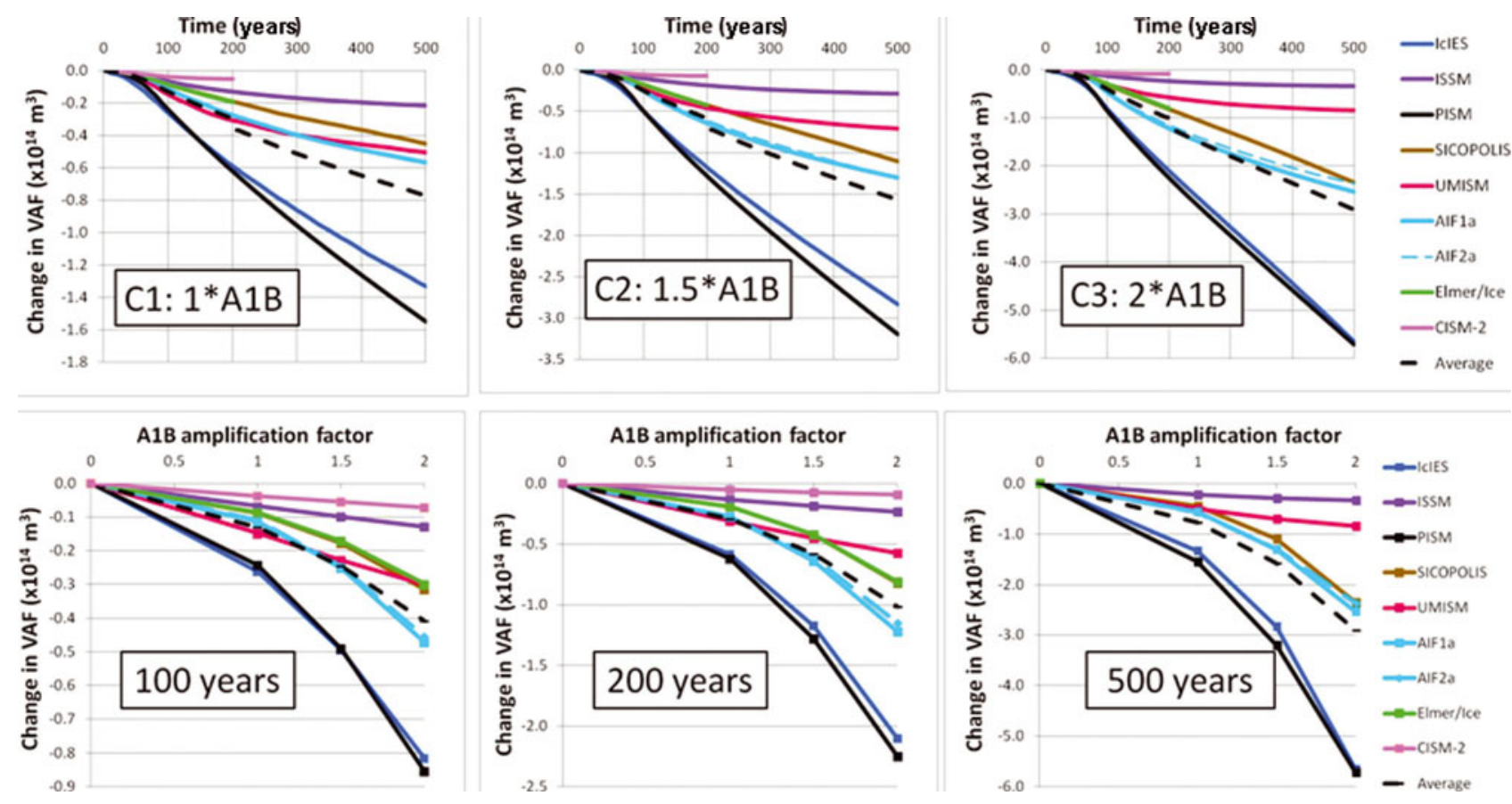

Fig. 3. Results of climate sensitivity experiments for the Greenland ice sheet. Upper panels show calculated change in $\mathrm{VAF}$ for the triplet of cases where prescribed temperature and precipitation changes are taken from the A1B scenarios of the IPCC AR4: left, C1, 100\% of A1B changes applied; middle, C2, 150\% of A1B changes applied; right, C3, 200\% of A1B changes applied. The calculated Average includes AIF1a but ignores AIF2a. Lower panels illustrate the sensitivity of VAF change for the same experiments versus the amplification of the applied A1B climate changes at 100, 200 and 500 years after the simulation start. See Table 2 and Appendix A for descriptions of the various models. Note: all ice volume change plots in this paper use a consistent unit of $10^{14} \mathrm{~m}^{3}$ to facilitate comparisons between plots. 


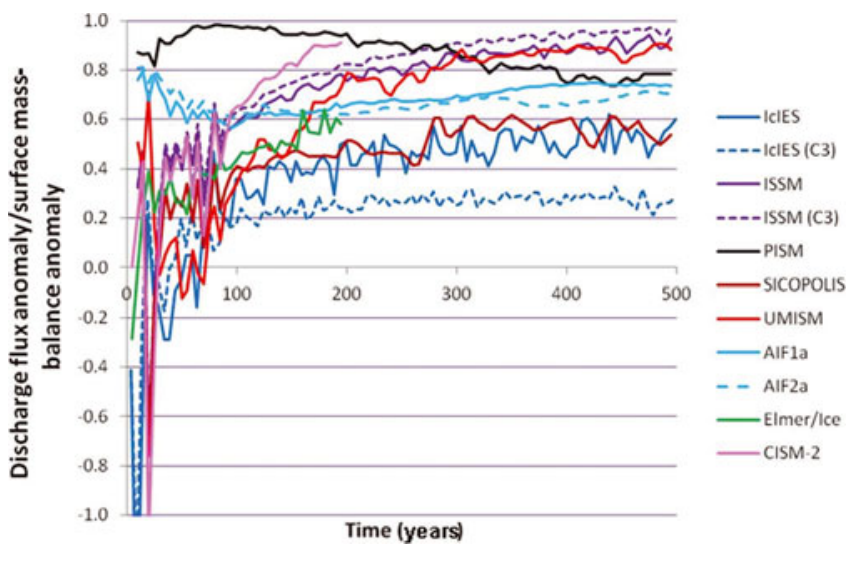

Fig. 4. Ratio of discharge flux anomaly to surface mass-balance anomaly for the $\mathrm{C} 1(1 \times \mathrm{A} 1 \mathrm{~B})$ climate experiment of the Greenland ice sheet. Anomalies are calculated by differencing discharge flux and surface mass-balance values from the respective control experiments. For comparison, the equivalent ratios for the $\mathrm{C} 3$ $(2 \times \mathrm{A} 1 \mathrm{~B})$ experiment for the IcIES and ISSM models are also shown as short-dashed lines.

model at 100, 200 and 500 years. Indeed, CISM-2, ISSM and UMISM have $R^{2}$ values of 0.999 or higher at 100 years, while the lowest $R^{2}$ value of 0.88 occurred for the AIF1a model at 500 years. In general, the $R^{2}$ values for any model gradually decreased with time. This final trend toward slightly less linearity is captured in the $R^{2}$ values of the models' average sensitivity that decreases from 0.95 to 0.93 to 0.91 at 100,200 and 500 years, respectively.

The 100 year change in ice volume expected from the increase in precipitation (Fig. 2) is an increase of $3.7 \times 10^{12} \mathrm{~m}^{3}$, a relatively small volume given the calculated volumes of ice lost. All models lose ice volume during this time, so the combination of increased melting and increased discharge clearly outweighs the volume gained through increased accumulation. For these experiments, the lost volume can be due to either melting, a direct result of warmer temperatures at a given elevation or an indirect result of surfaces lowered to warmer elevations, or increased discharge, driven by increased surface slopes generated by the altered surface mass-balance pattern. To discern the relative magnitudes of these mass loss effects, surface mass balance $(\mathrm{SMB})$ is calculated at each time-step for each model as the area integral over all gridcells that contain ice at that time. Discharge flux is calculated for each model as the difference between total volume change and the timespecific areal integral of surface mass balance. These SMB and discharge values for the $\mathrm{C} 1(1 \times \mathrm{A} 1 \mathrm{~B})$ experiments are then differenced from the control experiment values to produce anomalies of both SMB and discharge, and then the ratio of discharge flux anomaly to the total surface massbalance anomaly is calculated and plotted in Figure 4.

This ratio has several diagnostic characteristics. Positive surface mass-balance anomalies add mass to the ice sheet relative to the control case while positive discharge is taken here as representing mass loss (i.e. increased discharge) relative to the control. In all the experiments considered here, the change in surface mass balance imposes a net mass loss on the ice sheet (compared to the control experiments), so the SMB anomaly is always negative and the interpretation of positive or negative ratios in Figure 4 is unambiguous. Positive anomaly ratios indicate ice is being added by changes in discharge flux (i.e. discharge flux is less in the experiment than in the control run) while it is removed by changes in surface mass balance. The relative contribution of discharge flux anomaly to SMB anomaly is larger the larger the ratio. For a ratio of unity, the two contributions are equal and the ice-sheet volume does not differ from the control run. Negative ratios indicate ice is being lost by changes in both the discharge flux and surface mass balance relative to the control run. The fact that the anomaly ratio never exceeds unity is consistent with the characteristic illustrated in Figure 3 that VAF always decreases for every model.

During the initial 94 year period when temperatures and precipitation are increasing (Fig. 2), the models exhibit a variety of behaviors; IcIES is the only model that generates an anomaly ratio lower than -1 , indicating an increase in discharge flux anomaly exceeding the decrease in SMB anomaly, but many models exhibit negative ratios that signal increasing discharge flux relative to the control. Midway through this initial 94 year period, the ratio for each model is on a persistent trajectory toward a rather steady positive value that is preserved for the last few centuries of the experiment.

Figure 4 also contains the results of the $\mathrm{C} 3(2 \times \mathrm{A} 1 \mathrm{~B})$ case for the ISSM and ICIES models, representing the minimum and the maximum VAF responses, respectively (Fig. 3). Other models fall between these two end cases. There is very little difference in the ratios of the $\mathrm{C} 1$ and $\mathrm{C} 3$ cases for ISSM. On the other hand, the maximally responsive ICIES model exhibits a considerable difference, with anomaly ratios for the $\mathrm{C} 3$ case much lower than the ratios for the $\mathrm{C} 1$ experiment in the later centuries, indicating the equilibration to the larger climate changes takes much longer before the discharge flux adjusts to balance the lower SMB.

\subsubsection{Basal sliding experiment}

Sudden and large changes in ice flow velocity have been observed (e.g. Rignot and Kanagaratnam, 2006; Howat and others, 2008). These changes are inferred to be the result of changes in basal sliding likely caused by changes in the subglacial hydrologic environment (e.g. Joughin and others, 1996; Zwally and others, 2002; Joughin and others, 2008). Their effect on the overall mass balance of the ice sheet is significant and, in some catchments, dominates the rate of volume change (Howat and others, 2008). Many active field studies are underway, but a process-level understanding is probably many years away.

This lack of understanding makes it difficult to incorporate these processes into current ice-sheet models, but the undisputed importance of basal sliding in regulating icesheet discharge through outlet glaciers forces all viable icesheet models to incorporate some means of calculating sometimes large basal sliding rates. Most models include a lubrication factor; however, changing this by a uniform value, say by halving its value, does not always result in a direct doubling of sliding velocity if solution of the sliding velocity involves non-local stresses

The experiment approach taken is to prescribe an increase of the sliding speed by a uniform factor. A trio of sliding experiments set the sliding speed amplification factors as $2 \times, 2.5 \times$ and $3 \times$ for experiments S1, S2 and S3, respectively. Models that employ only local stresses to calculate the basal sliding velocity (ICIES, UMISM, SICOPOLIS and AIF) will maintain this enhanced sliding ratio, but those that use a more complex relationship utilizing both local and regional stresses (e.g. ISSM, PISM, Elmer/lce and 

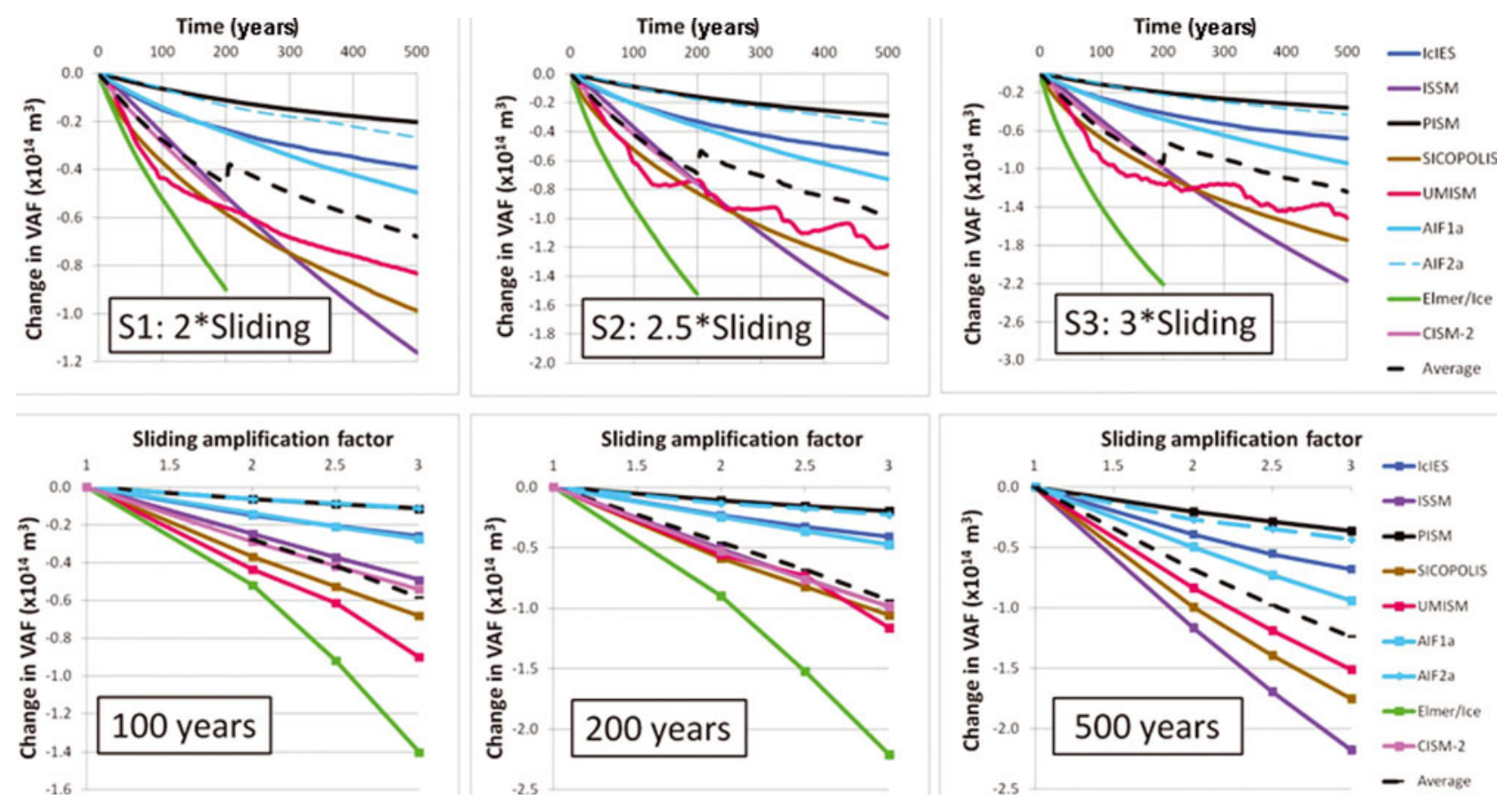

Fig. 5. Results of basal sliding sensitivity experiments for the Greenland ice sheet. Upper panels show calculated change of VAF for the triplet of cases where basal sliding was increased by a constant factor: left, S1, 2×; middle, S2, 2.5×; right, S3, 3×. Lower panels illustrate the sensitivity of ice loss versus the basal sliding amplification factor at 100, 200 and 500 years after the simulation start. The calculated Average includes AIF1a but ignores AIF2a.

CISM-2) will experience sliding ratios that vary from the prescribed ratio; however, the deviations are generally not large. Figure 5 illustrates the results of model runs for this sliding experiment applied to Greenland.

As with the previous set of (climate) experiments, there is a wide range of responses across the different models, but, overall, response magnitudes are not as large as for the set of climate experiments. All models show a gradually decreasing rate of VAF loss over time. The two versions of the AIF model predict larger ice losses when the basal sliding is an exponential function of the basal stress (version AIF1a) as compared to the linear function (AIF2a). The rough response character of the UMISM model is due to details of its treatment of retreat of the ice edge across gridpoints. The largest response is predicted by Elmer/Ice, the only SeaRISE model that incorporates full-Stokes dynamics (i.e. including bridging stresses in addition to longitudinal, lateral and vertical shear), but this model was only run for 200 years and the nature of the model's internal composition resulted in sliding amplifications larger than specified. The shorter duration of Elmer/lce and CISM-2 runs causes the kink at 200 years in the model-Average line in Figure 5. ISSM, using a higher-order set of equations (i.e. including longitudinal, vertical-shear and lateral-shear stresses), predicts the largest ice losses beyond 300 years.

The eight-model average response for experiment $\mathrm{S} 1$ at 100 years is a VAF loss of $2.73 \times 10^{14} \mathrm{~m}^{3}$ which converts to an equivalent sea-level rise of $6.8 \mathrm{~cm}$. This is comparable to the estimate of a $9.3 \mathrm{~cm}$ sea-level contribution by Pfeffer and others (2008) (table 3 and supplementary online material) when the discharge of 33 outlet glaciers was doubled. Their calculation included total volume lost, while ours is limited to the VAF, but, as mentioned earlier, the differences between total volume lost and VAF losses is small for Greenland.
In a manner similar to the climate experiments, the lower panels of Figure 5 show that the response sensitivity to the amplification of basal sliding after 100 years is more linear the smaller the response, tending toward a slightly nonlinear sensitivity for models with larger responses. At 100 years, the $R^{2}$ values of linear fits of VAF loss sensitivity to the sliding amplification factor are all 0.99 or above except for Elmer/Ice $\left(R^{2}=0.98\right)$. At 200 years, only Elmer/lce has a perceptible nonlinear sensitivity (although the $R^{2}$ value is still 0.99) and at 500 years (without Elmer/lce) all models retain $R^{2}$ values above 0.98 , demonstrating the strong linear sensitivity of VAF loss to the basal sliding amplification factor.

\subsubsection{Ice-shelf melting experiment}

The observed spatial pattern of recent ice-sheet changes has been interpreted as suggesting that increased melting at the underside of the fringing ice shelves and floating tongues of outlet glaciers is a key trigger of these changes (Payne and others, 2004; Shepherd and others, 2004; Holland and others, 2008; Joughin and others, 2010). Again, very few whole ice-sheet models incorporate an oceanographic component enabling ocean/ice interaction in a fully coupled manner. Nevertheless, the importance of this interaction led SeaRISE to generate a third set of experiments to gauge the sensitivity of the ice sheets to basal melt rates beneath floating ice.

As with basal sliding calculations, model variation constrained the realism in how this type of experiment could be implemented. PISM has no floating ice at the end of its Greenland spin-up, and melting was not imposed on the tidewater margin of the outlet glaciers, so it was unable to provide meaningful results for this experiment. For similar reasons, Elmer/lce and CISM-2 were not able to perform the ice-shelf melting experiments. Of the remaining models, only one (ISSM) included ice shelves, but the boundary between 

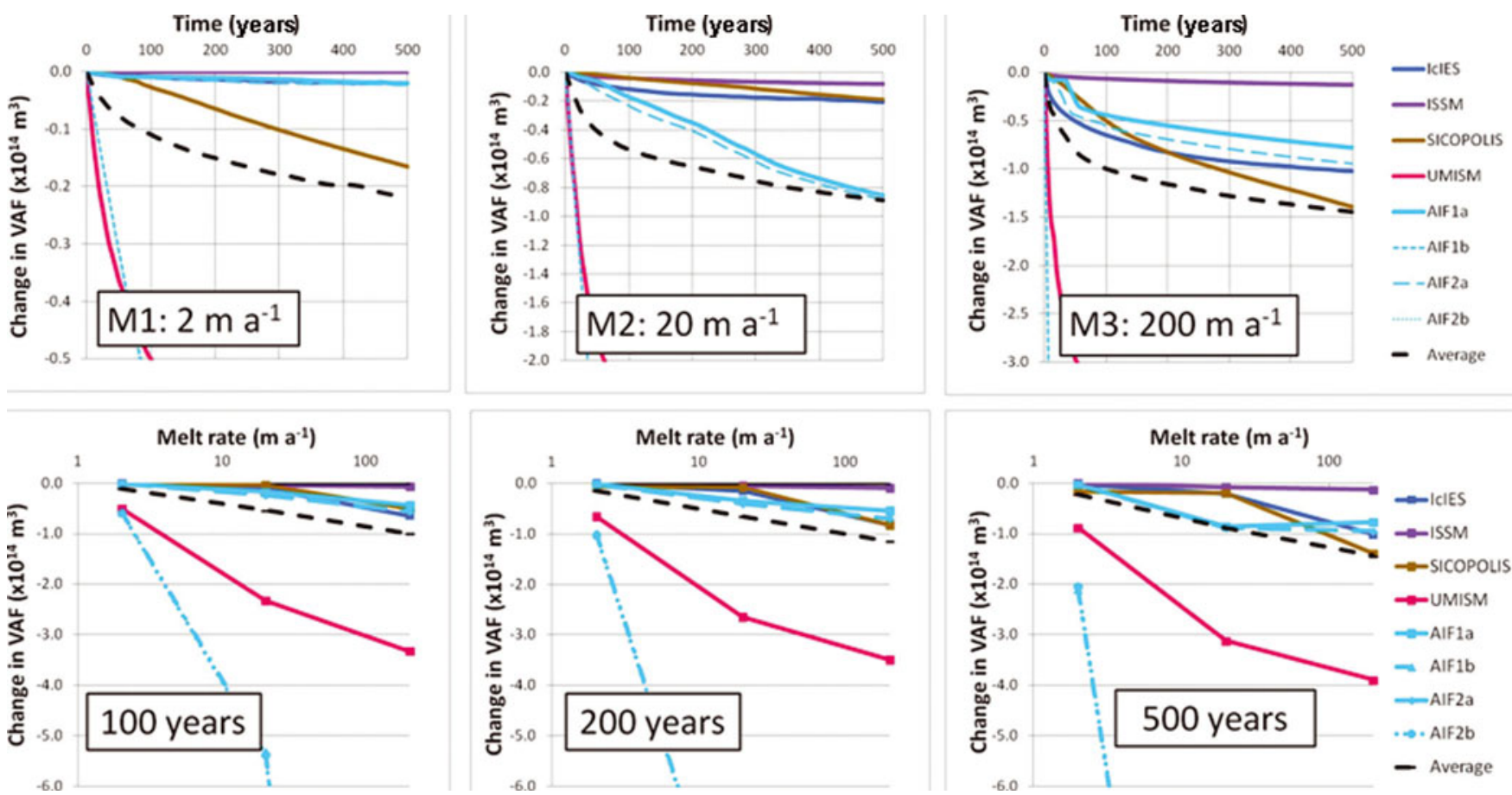

Fig. 6. Results of ocean melting sensitivity experiments for the Greenland ice sheet. Upper panels show calculated ice loss for the triplet of cases where ocean melting was set to constant values: left, $\mathrm{M1}, 2 \mathrm{~m} \mathrm{a}^{-1}$; middle, $\mathrm{M} 2,20 \mathrm{~m} \mathrm{a}^{-1}$; right, M3, $200 \mathrm{~m}^{-1}$. Lower panels illustrate the sensitivity of ice loss vs the three different melt rates at 100, 200 and 500 years after the simulation start. The calculated Average includes only AIF1a and ignores AIF1b, $2 a$ and $2 b$.

the grounded and floating ice remains fixed; the others (ICIES, SICOPOLIS, UMISM and AIF) opt to ignore any ice that floats and apply the basal melt rates at the ocean boundary of grounded ice. The concentration of the prescribed melt rate at the grounding line is a reasonable approximation given the inference that basal melt rates are generally highest near the grounding lines (Williams and others, 2001; Payne and others, 2007). The three SeaRISE experiments in this category set the submarine melt rate at uniform values of 2, 20 and $200 \mathrm{~m} \mathrm{a}^{-1}$ for experiments M1, M2 and M3, respectively. The results of these experiments (again minus the effects of the control runs) are shown in Figure 6.

The range of projected ice loss for these basal melt experiments is larger than for either the climate or basal sliding experiment suites, but much of the variation can be explained by the manner in which the basal melt rates were applied. The most responsive models in all three experiments are the $1 b$ and $2 b$ versions of the AIF model which apply the melt rate along the entire ice-sheet perimeter. This is clearly so unrealistic that these results are not included in the calculated Average. Despite the extreme nature of this assumption, they are useful when interpreted in tandem with the ' $a$ ' scenarios of the AIF model as bracketing the magnitude of Greenland's ocean/ice interaction. The other useful pair of end points is the UMISM and ISSM models. The ISSM model includes ice shelves, but imposes the melt rate only at the front and maintains that front position until melting has removed all the ice there, only then retreating the ice front to the next gridpoint upstream. No melting is ever imposed to initially grounded ice, so no further melting occurs once the ice margin retreats beyond this boundary, severely limiting the ice loss for this suite of experiments. UMISM includes the dynamic effect of ice shelves by imposing a back-stress on the grounded ice according to theoretical formulations (Thomas, 1973) and a large thinning rate at the grounding line according to Weertman (1974). This thinning rate leads to rapid inland erosion of the ice sheet along coastal fjords drawing down the ice within the catchments of marine-based outlet glaciers. The results from the other models fall between the two extremes set by both the AIF ' $a$ ' vs ' $b$ ' versions, ISSM and UMISM. It is possible that the VAF loss for all models is exaggerated by the fact that the $5 \mathrm{~km}$ grid resolution effectively sets a too-large minimum width for many narrow fjords, causing excessive ice loss. Despite the significant approximations these models use to treat this difficult boundary, they are among the best models available at present, and their combined results may be the best approximation of the sensitivity of the ice sheet to basal ice-shelf melting.

An additional insight provided by the extreme case of $200 \mathrm{~m} \mathrm{a}^{-1}$ is that it provides a trajectory of decreasing VAF that helps determine the ice sheet's ultimate vulnerability to oceanic erosion. Because ice loss is continuing even after 500 years, the ocean's effect on the ice sheet is not shortlived. Even after the floating edge of the ice sheet is removed, increased drainage of ice into the ocean will continue for centuries. Extrapolating the Average trajectory many centuries beyond the end of the 500 year experiments, the eventual volume of ice above flotation lost is likely at least $2 \times 10^{14} \mathrm{~m}^{3}$, or $50 \mathrm{~cm}$ of globally averaged sea level.

The widely ranging nature of model responses to the strength of melt rate is also expressed in the sensitivity plots of Figure 6. The VAF changes at 100, 200 and 500 years are plotted on a log scale of the imposed melt rate, making the strength of a linear relation difficult to visualize. At 100 years, ICIES and SICOPOLIS have $R^{2}>0.99$; AIF1a and 2a have linear fits with $R^{2}$ near 0.9 , decreasing to near 0.7 for UMISM and ISSM. By 500 years, ICIES and SICOPOLIS maintain their linear character with $R^{2}>0.99$; AIF1a and 2a have decreased to the overall minimum $R^{2}$ values of 0.36 

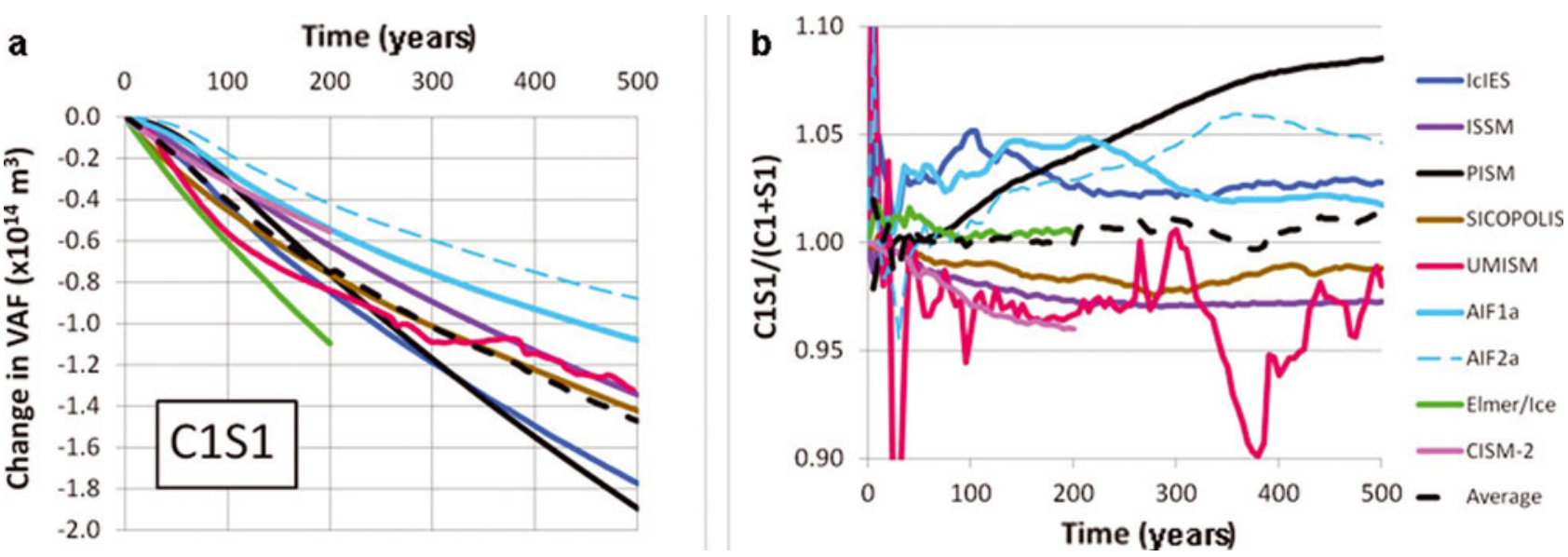

Fig. 7. Results of experiment for Greenland combining the C1 and S1 forcings. (a) Projected change in VAF; (b) the ratio of the VAF loss for the C1S1 combination run divided by the sum of the VAF losses for the C1 and S1 experiments.

and 0.47 , respectively, while UMISM and ISSM have $R^{2}$ values of 0.58 and 0.74 , respectively. The sublinear sensitivity of UMISM (Fig. 6) is probably due to the absence of additional ice available to be removed in the extreme (M3) experiment that was not already removed in the intermediate (M2) experiment.

\subsubsection{Combination experiment}

Each of the above experiments isolates a particular forcing type at prescribed values to measure the sensitivity of the modeled ice sheet to that single forcing. In reality, however, multiple forcings are expected to act simultaneously and it cannot be assumed that these separate sensitivities are additive in determining the total sensitivity to a combination of environmental changes. To examine this subject, a combination experiment was specified which simultaneously imposes the $1 \times \mathrm{A} 1 \mathrm{~B}$ climate change $(\mathrm{C} 1)$ with the $2 \times$ sliding velocity changes (S1) for Greenland. No additional forcing related to the floating-ice melting experiment suite was included, because the implementation of this forcing varied the most across all models.

The results of this combination experiment, labeled C1S1, are shown in Figure 7a. The temporal pattern noted in the C1 experiment, of an increasing rate of ice volume loss over the first 94 years, followed by a gradually decreasing rate of ice loss, is repeated for nearly all models, but is more subdued, presumably because the $\mathrm{S} 1$ experiment lacked a transition at year 94. The only exception is the Elmer/lce model that fails to show a transition at year 94 in the combination experiment, but Figures 3 and 5 show this model's response to the $\mathrm{S} 1$ basal sliding forcing is more than four times stronger than its response to the $\mathrm{C} 1$ climate forcing, so this absence of a change in the trend of VAF loss at 94 years is not surprising.

The issue of how well the sum of the two individual responses matches the response when the two forcings are prescribed in the same experiment is illustrated in Figure $7 \mathrm{~b}$. This plot shows the ratio of the VAF lost in the combination experiment to the sum of the VAF lost separately in the C1 and $\mathrm{S} 1$ experiments. In all cases, this ratio is close to unity. This is true whether the model is more sensitive to the climate experiment than the sliding experiment (like PISM and ICIES) or the reverse (like Elmer/lce and SICOPOLIS). Some models exhibit ratio values less than 1 , indicating the combination run experienced less VAF loss than the sum of the $\mathrm{C} 1$ and S1 runs. This is likely due to the fact that some parcels of ice were lost in both the $\mathrm{C} 1$ and $\mathrm{S} 1$ runs but could only be lost once in the combination run. Other models exhibit ratios greater than 1, indicating an amplified response of the combination experiment where one type of forcing increases the response to the second forcing. One example of how this might manifest is that the A1B climate induces a steeper surface slope that increases basal shear stress and, thus, sliding velocity, which is then amplified by the S1 forcing conditions of doubled basal sliding and delivers more ice either to lower elevations, where it is melted, or to the margins, where it calves into the ocean. These ratios are not constant in time, but are generally stable, lying within $+5 \%$ of unity. PISM is the only model whose ratio continues to increase over the latter half of the experiment, but even it begins to stabilize in the last 150 years. The discovery that linear combinations of individual forcings closely approximate the response of an experiment that applies these forcings simultaneously is significant and is explored further below.

\subsubsection{Summary}

Ten experiments spanning a wide range of prescribed environmental changes have been run by many models that simulate the dynamics of the Greenland ice sheet. In general, the calculated responses illustrate similar behavior but with a range of response magnitudes. Figure 8 includes the model-Average response from each experiment on a common scale to better compare the relative response magnitudes to the different types and magnitudes of forcing. The smallest changes are produced by the $\mathrm{M} 1\left(2 \mathrm{~m} \mathrm{a}^{-1}\right)$ basal melting experiment. The more modest forcings of climate (C1) and basal sliding (S1) produce similar temporal patterns of VAF loss, with their combination (C1S1) doubling the net losses of either individually.

The largest range of model-Average response occurs for the climate experiment trio, with $\mathrm{C} 3(2 \times \mathrm{A} 1 \mathrm{~B})$ producing the largest VAF losses, although the most extreme melt experiment M3 $\left(200 \mathrm{~m} \mathrm{a}^{-1}\right)$ produces the largest initial VAF losses. The suite of experiments with the smallest range of response is that which varied the amplification of basal sliding; however, the full magnitude of this sensitivity may be limited by the models' abilities to adequately represent the basal sliding in narrow outlet glacier fjords.

These results suggest some fundamental characteristics of the Greenland ice sheet's volumetric response to 


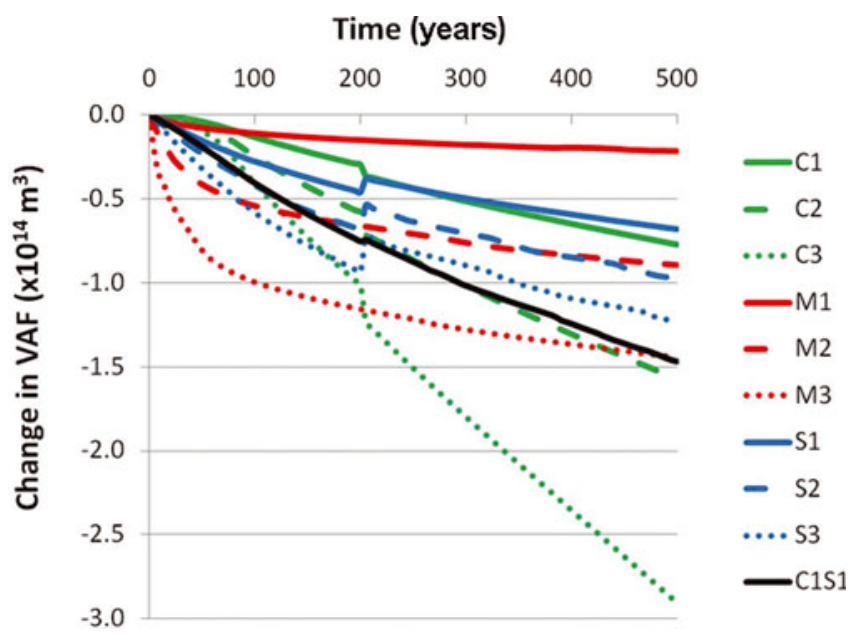

Fig. 8. Results of average response for models for each Greenland experiment. Each suite of experiments is shown in a common color, with the mildest, intermediate and extreme experiments represented by a solid, dashed and dotted line, respectively. A kink appears in the climate, sliding and combination results because the Elmer/lce and CISM-2 runs only lasted 200 years. There is no kink in the melt experiments; neither Elmer/Ice nor CISM-2 ran the melting experiments.

environmental changes. The fastest response can be driven by a sudden and large change to the basal melt rate at the ocean/ice interface; however, the intense initial response lasts only a few decades as the most vulnerable ice is removed, after which the rate of ice loss decreases markedly. Changes in climate (here represented by surface temperature and precipitation changes) can also have a large effect on ice-volume loss, but these losses are achieved through a sustained adjustment of the ice sheet to the altered climate that lasts centuries (and even millennia). The range of climate changes covered in these experiments is arguably more realistic than either the range of basal sliding or ice-shelf melting experiments. To be more realistic, the enhanced sliding may need to be localized to apply more strongly near the outlet glaciers; however, our results do compare well with those of Pfeffer and others (2008), as discussed earlier. Association of basal sliding with surface melt also might improve realism, yet observations of surface lake drainage and ice-flow response underscore the as-yet mysterious nature of basal sliding dynamics (Das and others, 2008; Joughin and others, 2008). More promising is the result that despite the relatively large changes in basal sliding imposed, the range of ice-sheet response is limited. Similar model improvements are required for better simulation of the effects of ice-shelf melt rates on the ice sheet.

\subsection{Antarctica}

The sensitivity of the Antarctic ice-sheet volume to prescribed environmental changes is examined in an equivalent manner to the Greenland ice sheet by running the same set of single-forcing experiments and a similar set of combined forcing experiments. As with Greenland, the results of these sensitivity experiments are extracted by differencing each experiment's results from control runs of the corresponding model. These control runs for the Antarctic ice sheet were discussed earlier (Section 4; Fig. 1). It is important to remember that ice volume changes are reported in terms of only the ice lost that will contribute to sea level, i.e. the VAF.

\subsubsection{Surface climate experiment}

There is no change to the nature of climate-forcing experiments: C1, C2 and C3 refer to the ensemble mean AR4 A1B changes in temperature and precipitation being imposed for 94 years with amplification factors of 1, 1.5 and 2 , respectively, and being held at the year-94 values for the remainder of the 500 year run (Section 5.1.1). The results of the six Antarctic models running these experiments are shown in Figure 9.

As with the Greenland experiments, there is a range of model responses. However, in the case of Antarctica, this range includes projections of increasing VAF, as well as VAF loss, although even for those models that project an overall increase in VAF, there is an initial loss of VAF in the first few decades. Antarctica's ice-sheet area is ten times that of Greenland and the mean temperature is lower, so, unlike in the case of Greenland, increased precipitation has a larger integral effect that is not necessarily offset by rising temperatures increasing both the amount and extent of surface melting.

The additional volume derived exclusively from the increased precipitation can be calculated and is included in Figure 9 as orange circles. Over the first 100 years this additional volume is $1.33 \times 10^{13} \mathrm{~m}^{3}$, a significant amount relative to the total changes predicted by the $1 \times \mathrm{A} 1 \mathrm{~B}$ experiment (C1). The ISSM, AIF and Potsdam models predict a VAF change very close to this amount during the first 100 years; it is only in the later centuries that the dynamic response to the climate changes begins to offset an increasing proportion of this additional volume. (A cautionary note is warranted: because only the VAF is reported here, volume loss on ice shelves and much of the ice lost within deep marine basins, both of which are substantially more extensive in Antarctica than in Greenland, are not included; thus, there may be net ice-sheet volume loss even as VAF increases. Because the ice shelves are at the margins where many of the changes are strongest and first felt, while the deeper marine basins are affected later, it is reasonable to expect a more complex response evolution to the Antarctic experiments than shown in these figures that provide only VAF values; see Nowicki and others, in press a, b, for more spatial details.)

The behavior of the other models is more varied: the PennState3D model increases VAF for two centuries before reversing to a decreasing VAF trend. The UMISM model shows only a very brief increase in VAF and then a decrease, and the SICOPOLIS model produces a more continuously decreasing VAF. This variety implies a complex combination of adjustments including not only the increased precipitation, but melting at the margins and the dynamic adjustments involving not only geometric changes, but interaction of the grounded ice with the ice shelves. The model-Average gradually and monotonically gains VAF.

The temporal pattern of adjustment to these changes, although varied by model, remains consistent for any model regardless of the strength of the climate forcing, i.e. all three panels in the upper row are nearly identical although the magnitude of the response increases with the strength of the forcing. The lower panels of Figure 9 suggest a high degree of linearity of the modeled VAF change to the magnitude of the prescribed forcing. A linear fit to each of these sensitivity plots bears this out: the $R^{2}$ of fits to the AIF, Potsdam, UMISM and ISSM results are always $>0.99$. The $R^{2}$ for the SICOPOLIS model increases from 0.56 at 100 years to 

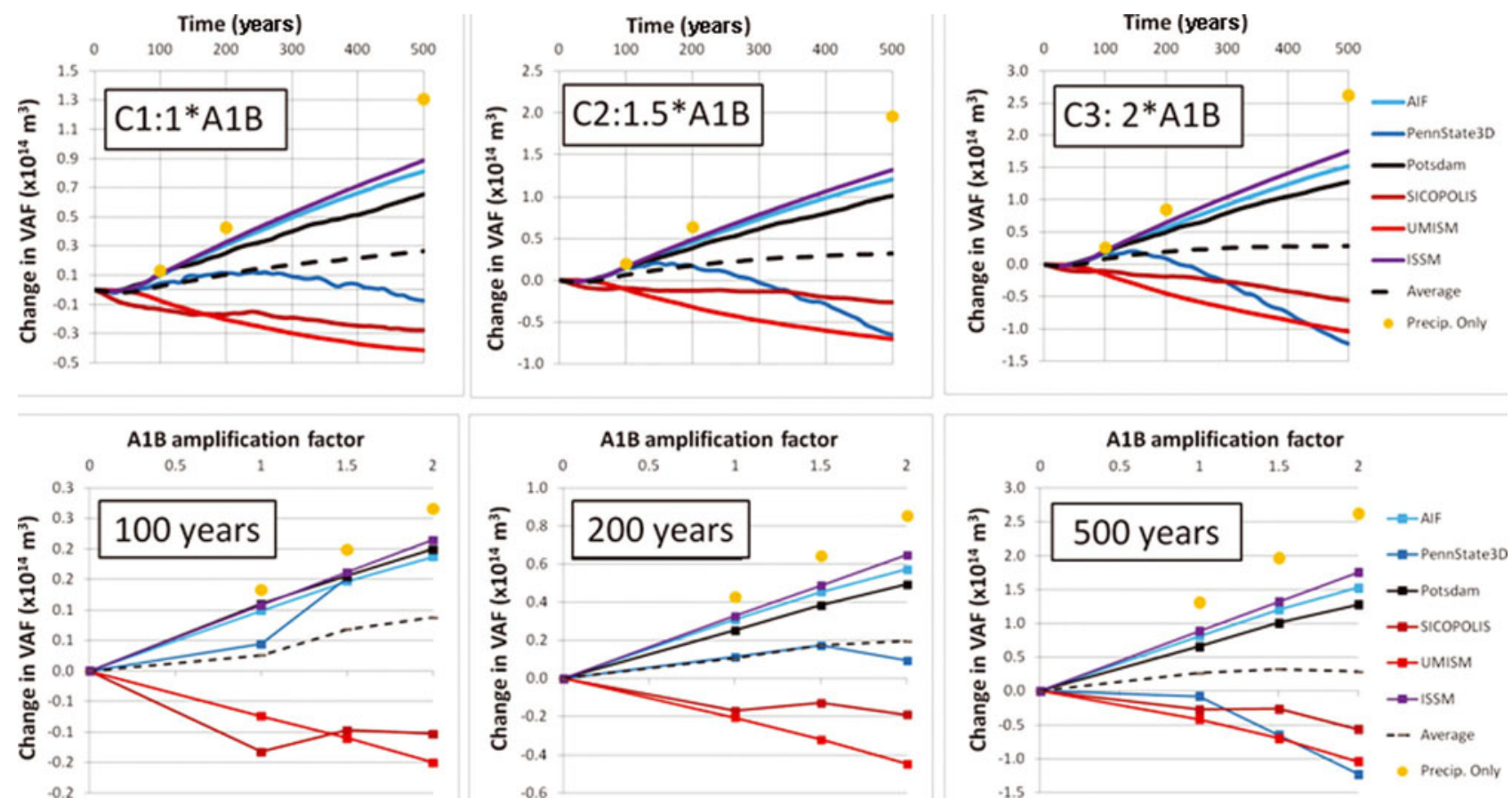

Fig. 9. Change of VAF for the climate sensitivity experiments of the Antarctic ice sheet. Upper panels show calculated VAF change for the triplet of cases where prescribed temperature and precipitation changes are taken from the A1B scenarios of the IPCC AR4: left, C1, 100\% of A1B changes applied; middle, C2, 150\% of A1B changes applied; right, C3, 200\% of A1B changes applied. Lower panels illustrate the sensitivity of VAF change for the same experiments vs the amplification of the applied climate changes at 100, 200 and 500 years after the simulation start. Orange circles indicate the VAF change resulting only from the applied change in precipitation at 100, 200 and 500 years. See Table 2 and Appendix A for descriptions of the various models.

0.89 at 500 years, while the $R^{2}$ for the PennState3D model decreases from 0.90 at 100 years to 0.80 at 500 years.

\subsubsection{Basal sliding experiment}

As in Greenland, the Antarctic ice sheet is drained by many large outlet glaciers with high rates of basal sliding, so the same suite of experiments is used to study the sensitivity of the Antarctic ice sheet to a uniform increase of basal sliding as was used for the Greenland experiments, i.e. the sliding velocity is amplified by 2, 2.5 and 3 for experiments S1, S2 and S3, respectively. It is important to repeat the caveat that not all models calculate sliding velocity in a way that ensures that sliding is enhanced by precisely these amplification factors. Those Antarctic models that do not are Potsdam and ISSM. As an example of the range of sliding amplifications that resulted, for experiment S2 (doubled sliding), ISSM produced sliding velocities that were very close to the desired doubling for most of the ice sheet, but the ratio of altered sliding speed to non-altered sliding deviated from a low of 1.7 to a high of 2.3.

While many of the Antarctic outlet glaciers and ice streams are larger than their Greenland counterparts, so are the total ice-covered area and ice volume. To counter the increased computational demands of the larger domain, the Antarctic models typically use a coarser spatial resolution that is often twice the grid dimension used in Greenland, so the limitations encountered with being able to spatially resolve the dynamic response of outlet glaciers are just as severe. This constraint will only be overcome with finer spatial meshes, nested grids and/or the application of regional models (e.g. Parizek and others, in press).

Figure 10 shows the results from the suite of basal sliding enhancement experiments for Antarctica. In this case, all models lose ice volume above flotation. The temporal pattern of loss among the models is similar while the magnitude of VAF loss increases with sliding amplification. Most models exhibit a decreasing rate of loss with time. The ISSM model stands out as losing VAF at a very nearly constant rate for the entire experiment, thus diverging from the other models at an increasing rate over the latter half of the simulation.

The sensitivity of VAF change can be approximated with a least-squares linear fit with $R^{2}$ values above 0.92 for all models at all three epochs shown in Figure 10 except for the UMISM model. UMISM shows a consistent reverse sensitivity. This might be due to the locations where ice is being lost: as deep marine basins empty, the initial thinning counts as VAF loss, while once the ice thickness reaches the flotation thickness, subsequent ice loss will not add to the values shown in Figure 10. Furthermore, initial thinning and flattening of the ice sheet reduces the local driving stress and therefore outflow, thereby contributing to UMISM's reversed sensitivity. SICOPOLIS's nonlinear sensitivities are not as strong, and overall the model-Average sensitivity has an $R^{2}$ of 0.98 for all times shown in Figure 10.

\subsubsection{Ice-shelf melting experiment}

The largest observed changes in Antarctic mass loss are associated with changes in its fringing ice shelves (e.g. Scambos and others, 2004; Shepherd and others, 2004; Pritchard and others, 2012). Thus, this suite of experiments aimed at examining the possible sensitivity of the Antarctic ice sheet to basal melt of floating ice is particularly germane. Again, repeating the Greenland experiments, the three experiments in this suite set the bottom melt rate for floating ice at uniform values of 2, 20 and $200 \mathrm{ma}^{-1}$. Figure 11 shows the results of the experiments. 

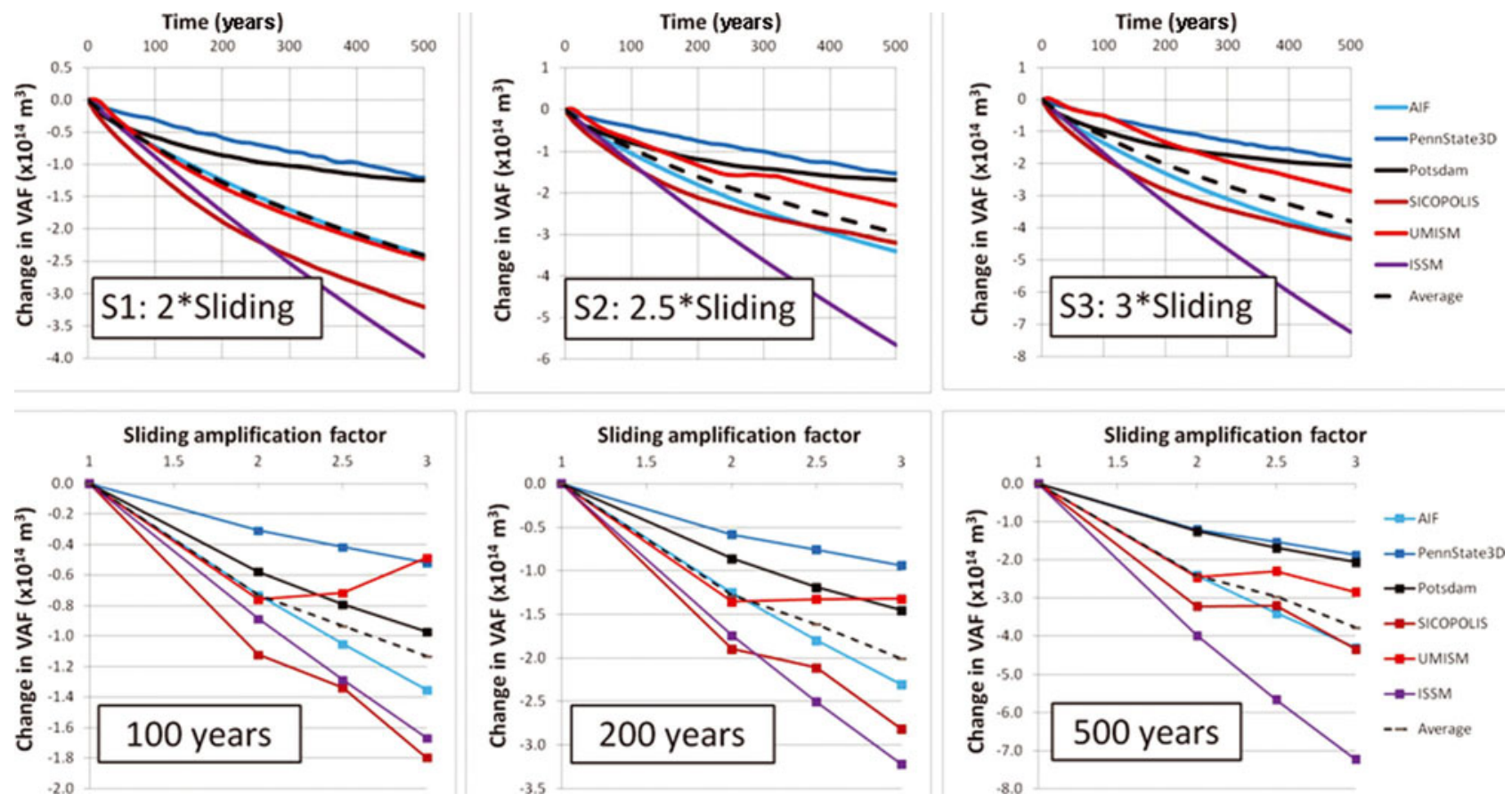

Fig. 10. Results of change in VAF for the basal sliding sensitivity experiments of the Antarctic ice sheet. Upper panels show calculated VAF loss for the triplet of cases where basal sliding was increased by a constant factor: left, S1, $2 \times$; middle, S2, 2.5×; right, S3, $3 \times$. Lower panels illustrate the sensitivity of VAF loss vs the basal sliding amplification factor at 100, 200 and 500 years after the simulation start.

As discussed earlier (Section 5.1.3. and shown in Table 2), there is a variety of approaches to how the ice shelves are treated in the models. Of the Antarctic models, SICOPOLIS, PennState3D and Potsdam include ice shelves. AIF and UMISM do not include ice shelves, instead applying the melt rate at the grounding line, but UMISM does incorporate both a back-stress and a longitudinal thinning rate at the grounding line to include dynamic effects of the ice shelf.
Figure 11 shows that, despite these differences, all models lose VAF when the basal melt of floating ice is increased, even though the direct loss of ice-shelf mass does not appear in the plotted VAF values. Arguably, at 100 and 200 years the scatter among models is less than the same times for the Greenland ice-sheet models (Fig. 6) despite the much larger size of the Antarctic ice sheet. However, unlike the other experiment results for either ice sheet, the relative responses
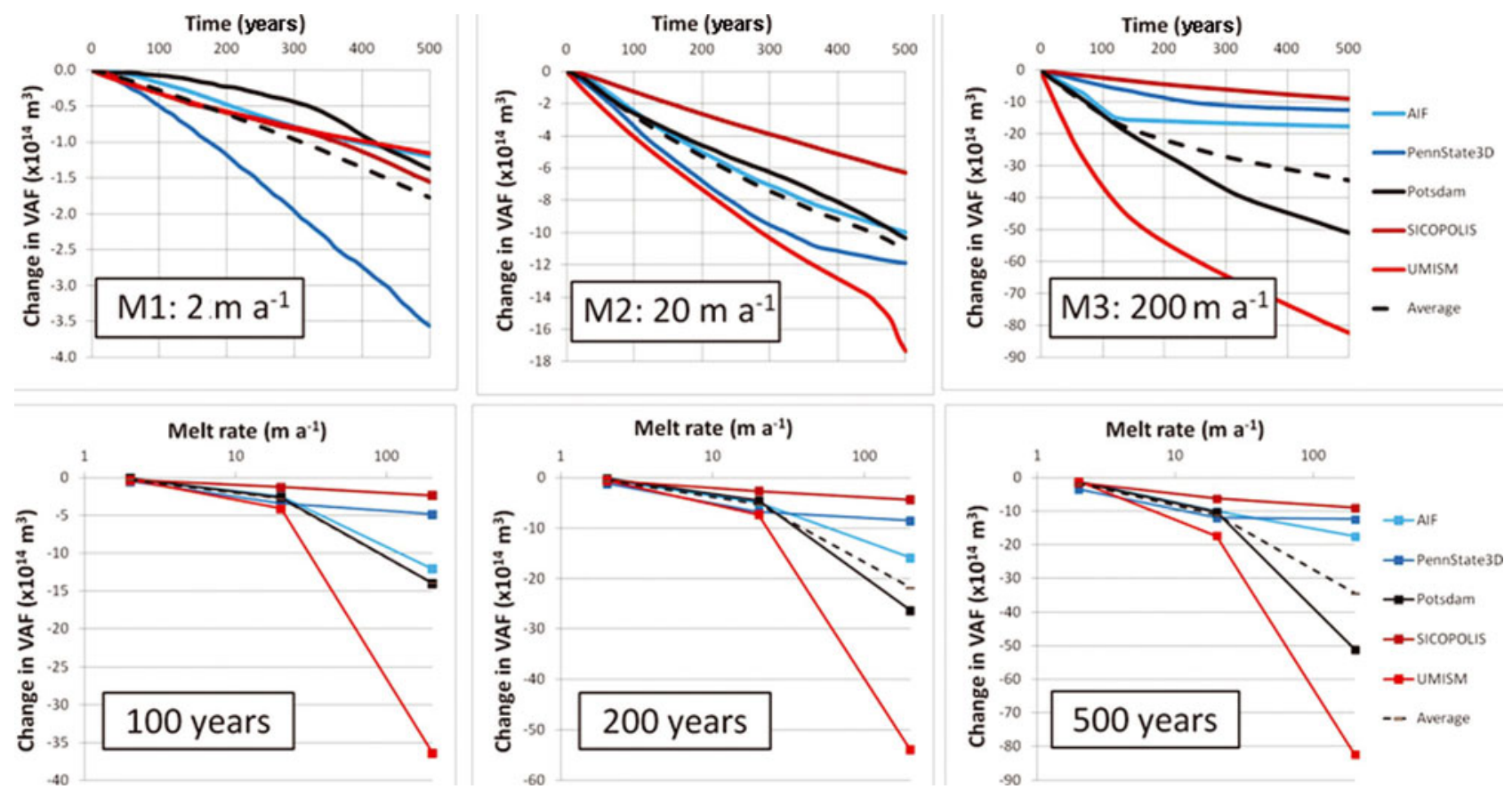

Fig. 11. Results of change in VAF for the ocean melting sensitivity experiments of the Antarctic ice sheet. Upper panels show calculated VAF loss for the triplet of cases where ocean melting was set to constant values: left, M1, $2 \mathrm{ma}^{-1}$; middle, $\mathrm{M}^{2}, 20 \mathrm{ma}^{-1}$; right, $\mathrm{M}_{3}, 200 \mathrm{ma}^{-1}$. Lower panels illustrate the sensitivity of VAF loss vs the three different melt rates at 100, 200 and 500 years after the simulation start. 

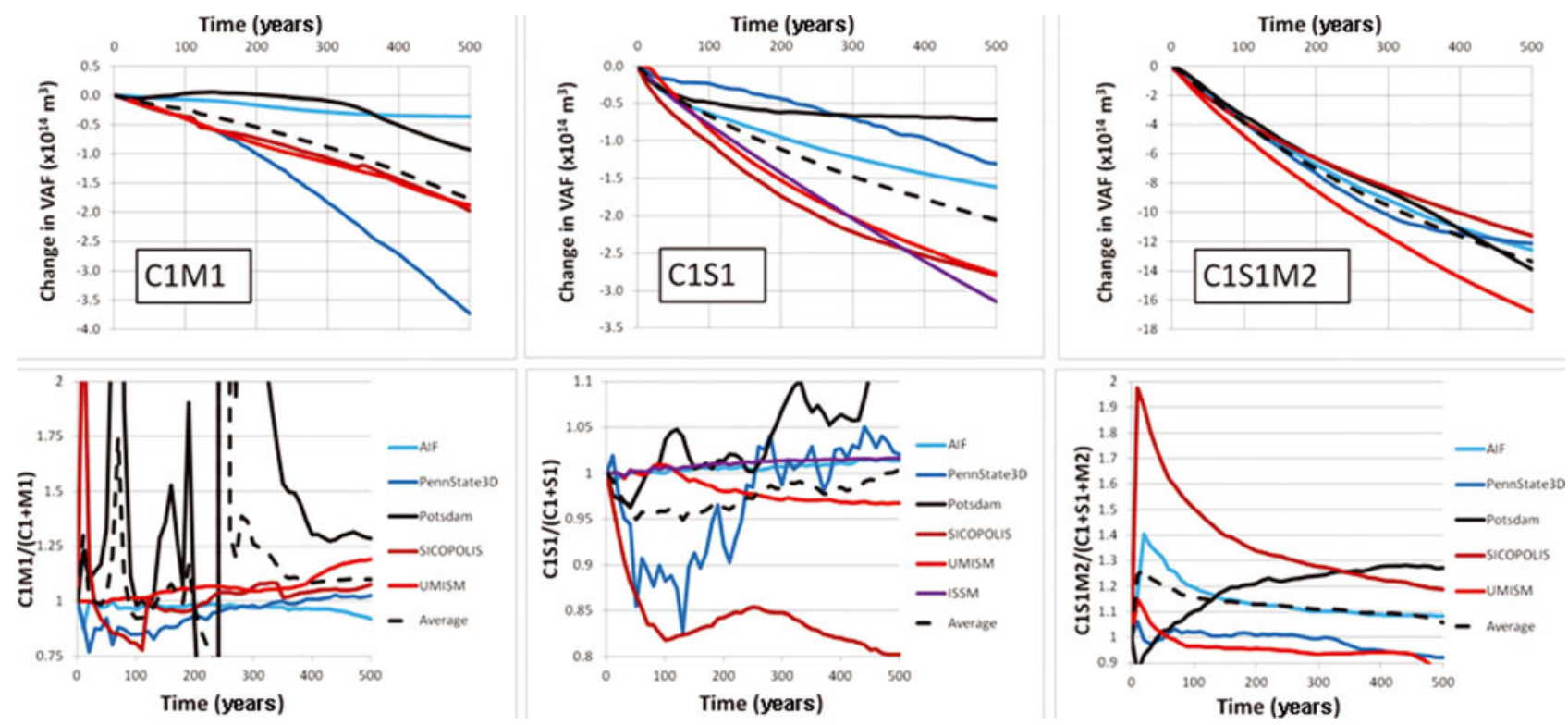

Fig. 12. Results of the three combination experiments of the Antarctic ice sheet: left, A1B climate forcing (C1) combined with $2 \mathrm{ma}^{-1}$ iceshelf basal melt rate (M1); middle, A1B climate (C1) combined with doubled sliding (S1); right, the triple combination of A1B climate (C1), doubled sliding (S1) and $20 \mathrm{~m} \mathrm{a}^{-1}$ ice-shelf basal melting (M2). Upper plots show calculated change in VAF while the lower plots show the ratio of these VAF losses for the combination run divided by the sum of the VAF losses for the individual component runs.

of the models vary significantly more among these three basal melting experiments. For the mildest melt case (M1), the PennState3D model reacts most strongly, while the AIF, SICOPOLIS and UMISM models form a very tight cluster. For the intermediate melt case (M2), the UMISM model is generally consistent with the PennState3D model while the Potsdam and AIF models are also consistent with each other. Finally, in the extreme melt case (M3), the UMISM model produces much higher VAF losses than any other model, and consistent pairs of models are less apparent.

The large experiment-to-experiment variability is understandable given the knowledge that large volumes of floating ice shelves are being rapidly removed along with the evacuation of extensive deep marine basins in the M2 and M3 experiments. As one example of how this affects the results shown in Figure 11, the seemingly modest increase in VAF lost for the PennState3D model from the M2 to the M3 experiment is caused by the fact that most of the marinebased West Antarctic ice sheet is already lost in the M2 experiment; higher melt rates also remove this same ice but only a relatively small amount of additional ice in East Antarctica, an ice sheet less vulnerable to ice-shelf loss. By contrast, the UMISM model, because it applies the prescribed melt rates to the edge of the grounded ice, can erode the edge of the East Antarctic ice sheet, and the very large VAF losses for its M3 experiment reflect the loss of ice in deep marine basins there.

Because only changes in the volume above flotation are reported, the results are influenced by how each model handles the migration of the grounding line. The PennState3D model is the only one that fully employs the transitional stress treatment of Schoof (2007), yet the relative agreement of the models suggests that the details of grounding line migration may be less important than developing means to accurately determine basal melt rates beneath the ice shelves.

The sensitivity diagrams (Fig. 11, lower panels) emphasize the extreme VAF lost in many of the models for the largest basal melt rates. The linearity of the fits is difficult to discern from the log scale. At 100 years, the UMISM, Potsdam and AIF models have $R^{2}$ values of 0.99 or higher, SICOPOLIS is lower with $R^{2}=0.81$, and $R^{2}$ for PennState3D is 0.70 . These relative positions are approximately retained at 500 years, with USISM and Potsdam remaining above 0.99 , but the other values have decreased to $0.79,0.67$ and 0.43 for AIF, SICOPOLIS and PennState3D, respectively.

\subsubsection{Combination experiments}

For the Antarctic, three combination experiments are defined. Each included the A1B climate forcing without amplification (C1). The first experiment added $2 \mathrm{~m} \mathrm{a}^{-1}$ basal melting of ice-shelf ice (M1) to the climate forcing. The second experiment added doubled basal sliding (S1) to the climate forcing (identical to the Greenland combination run). The final combination run added both doubled sliding (S1) and a more ablative $20 \mathrm{~m} \mathrm{a}^{-1}$ ice-shelf basal melt (M2) to the A1B forcing. The labels assigned to each experiment (C1M1, C1S1 and C1S1M2) indicate the forcing scenarios that were combined.

The results of these combination experiments are shown in Figure 12 in which we plot the temporal records of VAF change as well as the ratio of the VAF change from the combination run to the sum of VAF changes for the separate components making up the combination. All combination experiments show progressive VAF losses for all models.

In the first experiment $(\mathrm{C} 1 \mathrm{M} 1)$ the modest melt rate is sufficient to cause net VAF loss for the AIF model, but does not eliminate the Potsdam model's VAF growth in the first two and a half centuries predicted for the $\mathrm{C} 1$ experiment alone. M1 forces a stronger response than $\mathrm{C} 1$ for most models, and the results of this combination experiment are close to the sum of $\mathrm{C} 1$ and $\mathrm{M} 1$, i.e. the ratio of the combination to the sum of the individual runs is close to unity, with this tendency toward unity being particularly strong later in the runs. The Potsdam model shows considerable temporal variability of the VAF ratio, probably 


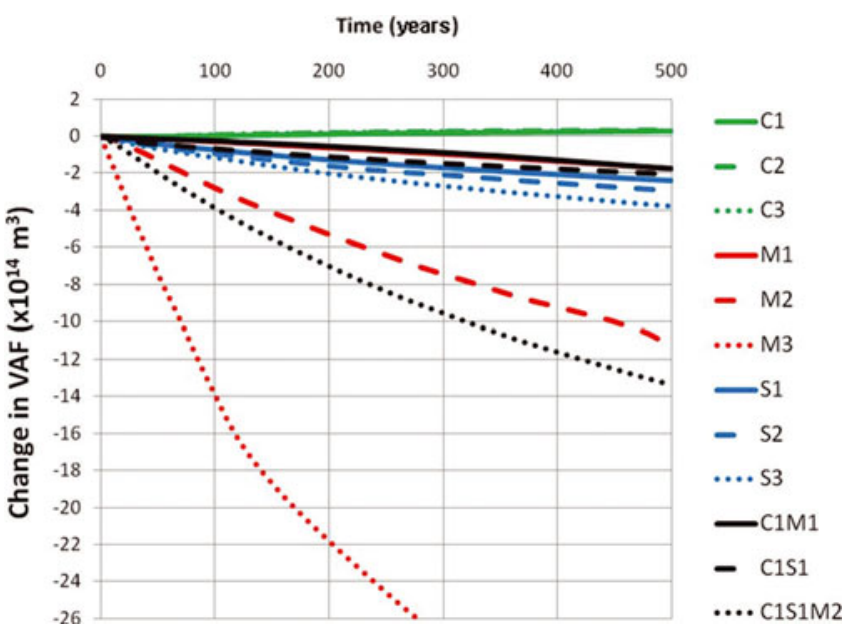

Fig. 13. Results of model-Average VAF change for all Antarctic experiments. Each suite of experiments is shown in a common color, with the mildest, intermediate and extreme experiments represented by a solid, dashed and dotted line, respectively. The average value of the $\mathrm{M} 3$ experiments is $-34.5 \times 10^{14} \mathrm{~m}^{3}$ at 500 years.

because the timing of regional ice loss varies between the individual runs and the combination experiment. UMISM and, to a lesser degree, SICOPOLIS also show some strong temporal variability of this ratio during the first few decades.

The second combination experiment (C1S1) combines doubled basal sliding (S1) with the A1B climate changes (C1). All models again persistently lose VAF. The spread of VAF loss across models is almost identical to that of the C1M1 combination experiment, but the rates of VAF loss for most models decrease with time, rather than increase as in the $\mathrm{C} 1 \mathrm{M} 1$ experiment. The ratios of the combination response to the sum of the individual experiments show temporal variability for some models but with smaller magnitudes than in the C1M1 experiment. Some models have ratio values consistently less than unity, and fewer models converge on unity. A ratio less than unity indicates a weaker combined response than the sum of the individual responses. The tendency of an increasing ratio for the PennState3D model tends to offset the decreasing tendency of the ratio for the SICOPOLIS model, producing an Average result that remains relatively stable.

The third combination experiment $(\mathrm{C} 1 \mathrm{~S} 1 \mathrm{M} 2)$ adds the intermediate ice-shelf basal melt rate of $20 \mathrm{ma}^{-1}$ (M2) to both the doubled basal sliding (S1) and A1B climate changes (C1). The responses among all models are noticeably more consistent than in the other combined experiments, with all producing significant VAF losses at a rate that decreases with time. Considered individually, the melting produces the largest response of these three forcings, and even when combined with the S1 and $\mathrm{C} 1$ forcings all models show VAF losses that are very similar to the M2 case alone (Fig. 11, middle top panel). The SICOPOLIS model exhibits the largest difference between this combination experiment and the $\mathrm{M} 2$ experiment, so it is not surprising that the ratio values of the combination results to the linear sum of the individual experiments for this model are largest (Fig. 12, lower right panel). The temporal patterns of this ratio show a larger VAF loss in the combination run initially which in the SICOPOLIS and AIF models persists for the entire 500 years, but for the UMISM and PennState3D models this larger response is shorter-lived. The Potsdam model exhibits the opposite tendency: a ratio less than unity early in the experiment, growing to values above unity and increasing as time increases. Ratios above unity could well be due to enhanced sliding delivering more ice to the ice shelves where it is rapidly removed through the higher prescribed melt rates. Such an evolution is seen in regional SeaRISE results for Thwaites Glacier (Parizek and others, in press).

The overall conclusion of these three combination experiments is that these forcings produce little, if any, enhancement of VAF loss when they are applied simultaneously. Only in the final experiment (C1S1M2) do the ratios in the SICOPOLIS, Potsdam and AIF models persist well above unity; the other two models (UMISM and PennState3D) display no such enhancement. Indeed, the ratio of these latter models is less than unity, as is SICOPOLIS for the second combination experiment (C1S1) and many models in the first combination experiment (C1M1).

\subsubsection{Summary}

The temporal changes in ice volume above flotation averaged across all the models for each experiment are plotted on a common scale in Figure 13 to assess the relative responses. There are many differences compared to Greenland (Fig. 8), with the largest arguably being that the climateforcing experiments all cause the model-Average response for Antarctica to be an increase in the VAF. The average growth, however, is less than the average VAF loss for Greenland under similar forcing.

For Antarctica, the climate-forcing experiments produce the weakest response, slightly negative in the early decades, reversing to slight VAF gain throughout the remainder of the 500 years. The strongest response is to experiments prescribing the intermediate and extreme increase to the basal melting of ice shelves. For some models without explicit ice shelves, the increased melt rate is imposed at the edge of ice sitting in the ocean. The VAF losses for these strongest response experiments vastly exceed those calculated for the Greenland ice sheet. This is not surprising given the large areal extent of Antarctic ice shelves into which most major outlets discharge. Because the VAF is not affected by loss of ice shelves and less affected by the loss of ice sitting in deep marine basins, it is the inland propagation of thinning triggered and driven by these large melt rates that generates the large losses of VAF.

The magnitudes of changes in VAF for the sliding amplification experiments lie between the average gains of the climate experiments and losses of the melting experiments and are roughly three times larger than those for the sliding experiments for Greenland (Fig. 8).

The VAF lost in the melting and sliding experiments is so much larger than the growth of the climate experiments that net VAF loss is predicted in each of the three combination experiments. Figure 13 strongly suggests that this would be true had even the most extreme of the climate scenarios $(\mathrm{C} 3$ : $2 \times \mathrm{A} 1 \mathrm{~B})$ been used.

The fact that the responses of single-forcing experiments provide a close approximation to the response of the associated combination experiment was discussed in Section 5.2.4 and illustrated in Figure 12. This similarity also holds for the model-Average responses and can be seen in Figure 13: for example, by noting that temporal pattern of increasing ice loss for C1S1M2 in Figure 13 lies beneath the M2 curve by an amount very nearly equal to the sum of the $\mathrm{S} 1$ and $\mathrm{C} 1$ curves. 
Table 3. Global sea-level increase $(\mathrm{cm})$ projected by SeaRISE models for each experiment at 100, 200 and 500 years since model initial time of 1 January 2004

\begin{tabular}{|c|c|c|c|c|c|c|c|c|c|}
\hline & \multicolumn{3}{|c|}{100} & \multicolumn{3}{|c|}{200} & \multicolumn{3}{|c|}{500} \\
\hline & Min & Mean & Max & Min & Mean & Max & Min & Mean & Max \\
\hline \multicolumn{10}{|c|}{ Greenland } \\
\hline $\mathrm{C} 1$ & 0.9 & 3.3 & 6.6 & 1.2 & 7.4 & 15.5 & 5.4 & 19.2 & 38.7 \\
\hline $\mathrm{C} 2$ & 1.3 & 6.1 & 12.4 & 1.8 & 14.5 & 32.0 & 7.2 & 39.2 & 79.8 \\
\hline C3 & 1.8 & 10.2 & 21.4 & 2.3 & 25.3 & 56.2 & 8.5 & 72.6 & 142.6 \\
\hline M1 & 0.0 & 2.7 & 12.5 & 0.0 & 3.1 & 16.6 & -0.1 & 4.5 & 22.0 \\
\hline M2 & 1.0 & 13.5 & 58.2 & 0.0 & 13.7 & 66.2 & -0.1 & 18.5 & 78.1 \\
\hline M3 & 1.6 & 24.9 & 83.3 & -0.1 & 24.1 & 87.5 & -0.2 & 30.1 & 97.5 \\
\hline $\mathrm{S} 1$ & 1.6 & 6.9 & 13.0 & 2.8 & 11.5 & 22.4 & 5.0 & 17.0 & 29.1 \\
\hline $\mathrm{S} 2$ & 2.2 & 10.5 & 22.9 & 3.9 & 17.0 & 38.0 & 7.2 & 24.3 & 42.2 \\
\hline $\mathrm{S} 3$ & 2.9 & 14.6 & 35.0 & 5.0 & 23.4 & 55.2 & 9.0 & 30.9 & 54.3 \\
\hline C1S1 & 6.6 & 10.2 & 15.2 & 13.6 & 18.8 & 27.4 & 26.9 & 36.8 & 47.4 \\
\hline $\mathrm{C} 2$ & -4.1 & -1.7 & 2.8 & -12.2 & -4.4 & 8.0 & -33.0 & -8.0 & 17.5 \\
\hline C3 & -5.4 & -2.2 & 3.8 & -16.2 & -4.9 & 11.2 & -43.8 & -7.2 & 30.7 \\
\hline M1 & 1.8 & 6.9 & 12.4 & 5.7 & 15.3 & 29.5 & 29.0 & 44.2 & 88.9 \\
\hline M2 & 31.8 & 69.3 & 102.0 & 66.4 & 131.9 & 183.1 & 157.5 & 279.4 & 433.5 \\
\hline M3 & 58.0 & 347.66 & 909.4 & 109.8 & 544.8 & 1346.7 & 224.0 & 861.6 & 2059.3 \\
\hline $\mathrm{S} 1$ & 7.7 & 18.3 & 28.0 & 14.6 & 32.0 & 47.4 & 30.0 & 60.4 & 99.4 \\
\hline $\mathrm{S} 2$ & 10.4 & 23.4 & 33.5 & 18.9 & 40.3 & 62.6 & 38.3 & 74.0 & 141.6 \\
\hline $\mathrm{S} 3$ & 12.2 & 28.3 & 44.9 & 23.5 & 50.2 & 80.4 & 46.7 & 94.3 & 180.6 \\
\hline C1M1 & -1.0 & 5.9 & 10.0 & -0.5 & 13.5 & 24.8 & 8.9 & 44.3 & 93.2 \\
\hline C1S1 & 5.8 & 16.7 & 25.6 & 10.9 & 27.9 & 43.5 & 17.8 & 51.4 & 78.6 \\
\hline C1S1M2 & 84.9 & 97.0 & 118.5 & 157.6 & 175.7 & 212.1 & 290.5 & 334.8 & 419.3 \\
\hline
\end{tabular}

\section{SEA-LEVEL IMPLICATIONS}

\subsection{Range of future sea-level changes from sensitivity experiments}

The SeaRISE project was designed to explore the potential future ice-sheet contributions to global sea level using current ice-sheet models. The results in this paper focus on this contribution by consistently reporting only the fraction of projected ice volume change that is above flotation. In Table 3, these results are converted to values of mean global sea-level change for the model ensemble minimum, mean and maximum for every experiment at 100, 200 and 500 years from 1 January 2004 by using the conversion factor of $1 \mathrm{~m}$ of global sea level equals $4 \times 10^{14} \mathrm{~m}^{3}$ of ice lost above flotation. It is important to note that these estimates of sealevel change are in addition to either any ongoing rates of change or any delayed changes caused by forcing occurring prior to the 1 January 2004 start of all SeaRISE experiments.

\subsection{Combination experiment for IPCC AR5}

The experiments presented above provide quantified estimates of the sensitivity of both the Greenland and Antarctic ice sheets to prescribed changes imposed on the ice sheets' upper or lower surfaces and perimeter, but some forcings are either extreme in magnitude and/or unrealistic in their spatial or temporal character. The IPCC Fourth Assessment Report highlighted the difficulties in providing reasonable means and limits for future sea level because dynamic icesheet models neither incorporated processes responsible for recent dramatic ice-sheet changes nor were adequately coupled to global climate models. These limitations led to the SeaRISE project. This subsection addresses these limitations by defining a concluding SeaRISE experiment (R8) relevant to the IPCC Fifth Assessment Report (AR5), reporting the results of running that experiment with the same models, and examining how well the sensitivity experiments presented above can be employed to estimate the results of this concluding experiment.

This final experiment approximates one of the representative concentration pathways (RCPs) being considered by the IPCC AR5 (Meinshausen and others, 2011; Van Vuuren and others, 2011). The RCPs (Fig. 14) represent possible evolutions of global human activity that provide the standard scenarios for global climate models so projections of different models can be compared. This is the same philosophy that SeaRISE has adopted, but, in the case of driving the ice-sheet models with any of the IPCC-specified RCPs, the challenge is to translate those RCP evolutions, expressed in radiative forcing units of $\mathrm{W} \mathrm{m}^{-2}$, into the surface climate, basal sliding and ice-shelf melting forcing conditions employed by SeaRISE.

\subsubsection{Climate conditions}

The connection between the RCPs and the SeaRISE forcings is made through atmospheric temperature and IPCC AR4 scenarios. SeaRISE developed its climate-forcing experiments ( $\mathrm{C} 1, \mathrm{C} 2$ and $\mathrm{C} 3$ ) from the A1B scenario of the IPCC AR4 (see Section 5.1.1). The AR4 scenario A2 is more extreme than $\mathrm{A} 1 \mathrm{~B}$ and most similar to RCP8.5 of the new scenarios, so scenario A2 is used as a proxy for RCP8.5. Based on the IPCC models of the AR4, by 2100 both the Arctic and Antarctic warm $\sim 50 \%$ more in the A2 scenario than in the A1B scenario. Thus, we take the first-century SeaRISE forcing for the R8 experiment as $1.5 \times \mathrm{A} 1 \mathrm{~B}$ (the beginning of the $\mathrm{C} 2$ experiment). For the second century, Figure 14 indicates the radiative forcing increase for 21002200 is about half of the increase from 2000 to 2100 . We 


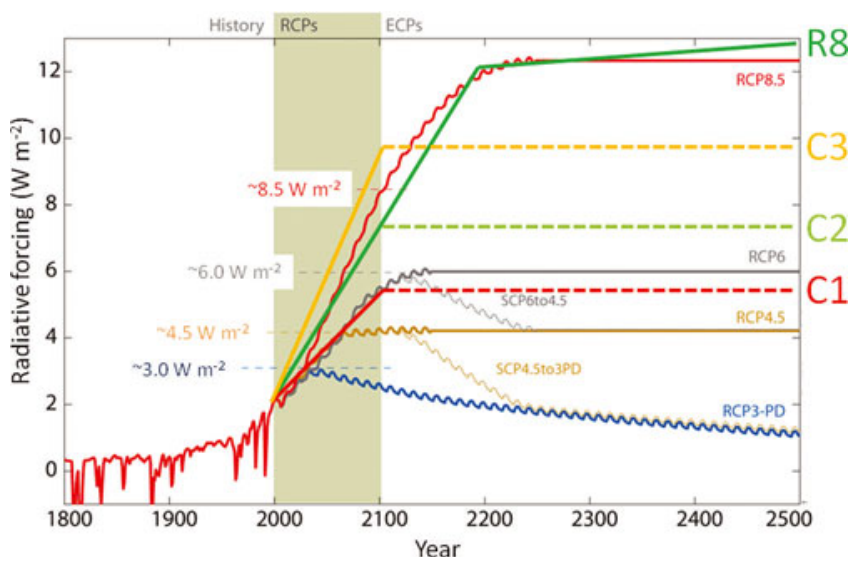

Fig. 14. Representative concentration pathways (RCPs) considered by the IPCC AR5. Included are four temporal profiles of temperature climate forcing used in the SeaRISE experiments C1, C2, C3 and R8. The scaling of the temperature profiles is adjusted so that the R8 profile matches RCP8.5 based on the conversion described in the text. Adapted from Meinshausen and others (2011).

chose to repeat the $1.5 \times \mathrm{A} 1 \mathrm{~B}$ forcing through this century (rather than reduce it to $1 / 2 \times 1.5 \times \mathrm{A} 1 \mathrm{~B}$ ) to capture some of the delayed warming from the first century's radiative input that will occur during the second century. For the final three centuries of the 500 year run, RCP8.5 is flat (Fig. 14), but modest delayed warming from the second century's radiative forcing increase is included by gradually increasing the temperature another modest increment.

For Greenland, the mean temperature increase in A1B over the final 10 years is $3.5^{\circ} \mathrm{C}$ (Fig. 2), so this final SeaRISE experiment imposes a $5.25^{\circ} \mathrm{C}$ increase in temperature in the first century, another $5.25^{\circ} \mathrm{C}$ increase in the second century, concluding with a final $0.75^{\circ} \mathrm{C}$ increase over the final 300 years for a total of $11.25^{\circ} \mathrm{C}$. The temporal profile of the warming for the R8 experiment is illustrated in Figure 14, superimposed on the RCP8.5 profile of radiative forcing. It is also worth noting that Figure 14 shows that experiment $\mathrm{C} 1$ roughly approximates RCP6, with only a slight underestimate of forcing after 2100.

For Antarctica, the mean temperature increase in $\mathrm{A} 1 \mathrm{~B}$ is $2.29^{\circ} \mathrm{C}$ over the final 10 years (Fig. 2), so a $3.4^{\circ} \mathrm{C}$ increase in temperature (i.e. $1.5 \times \mathrm{A} 1 \mathrm{~B}$ ) is imposed in the first century of experiment R8, followed by another $3.4^{\circ} \mathrm{C}$ increase in the second century. The final 300 years of the experiment includes an additional temperature increase of $0.5^{\circ} \mathrm{C}$ : less than the gradual $0.75^{\circ} \mathrm{C}$ applied to Greenland but consistent with Antarctica's reduced temperature increases during the first two centuries. The resulting total temperature increase for Antarctica is $7.4^{\circ} \mathrm{C}$.

Amplification factors to apply to the $\mathrm{A} 1 \mathrm{~B}$ record of temperatures (Fig. 2) were calculated to prescribe this forcing for all SeaRISE models. The same amplification factors were used to modify the A1B precipitation values for the R8 experiment.

\subsubsection{Basal sliding conditions}

Changes in basal sliding are also expected to occur as part of the RCP8.5 scenario because there is an observed link between changes in surface meltwater penetrating the Greenland ice sheet and ice flow speed (Zwally and others, 2002; Joughin and others, 2008). A quantifiable relationship between surface changes and basal speed, however, is not firmly established. In advance of a time when global climate model output can prescribe such changes in basal sliding, a rather ad hoc forcing is used drawing from the nature of the basal sliding sensitivity experiments already completed and described earlier. Basal sliding for Greenland is prescribed by setting the sliding amplification to a factor of 1.5 , i.e. halfway between the control experiment (CC) and the doubled-sliding experiment (S1). This amplification remains constant for the entire R8 experiment.

For Antarctica, the basal sliding prescription is more complex. No sliding amplification is applied for the first century to incorporate the observation that there is, as yet, no warming-triggered acceleration of Antarctic outlet glaciers. After 100 years, the sliding is increased linearly at a rate of $20 \%$ of its original value per century, but only in the coastal regions because enhanced sliding due to melting from higher temperatures is expected to occur there first. Thus, at the coast, the amplification factor remains at unity for 100 years and eventually rises to 1.8 after 500 years. Inland, the sliding amplification factor decreases linearly as a function of surface elevation such that no sliding enhancement is applied above $1200 \mathrm{~m}$ elevation. The $1200 \mathrm{~m}$ threshold is derived by applying the maximum warming of the climate forcing $\left(7.4^{\circ} \mathrm{C}\right.$; see above) to a summer lapse rate of $-0.692^{\circ} \mathrm{C}$ per $100 \mathrm{~m}$ elevation (Huybrechts and de Wolde, 1999).

\subsubsection{Ice-shelf basal melting}

Finally, ice-shelf basal melting forcings for the R8 experiment are specified. These are tied to temperature change using Rignot and Jacobs' (2002) relation of $10 \mathrm{~m} \mathrm{a}^{-1}{ }^{\circ} \mathrm{C}^{-1}$ melt. An early modeling result of the future warming of circum-Antarctic waters predicts a $3{ }^{\circ} \mathrm{C}$ increase $(77 \%$ of the global mean) in the cavity temperatures of the Amundsen Sea within 80 years for the RCP8.5 scenario (Winkelmann and others, 2012). Adding two decades of delay, because time is required for increased air temperatures to warm the upper mixed layer and/or drive increased upwelling of deep water onto the continental shelf, and converting to basal melt rate suggests melt rates might increase by $30 \mathrm{ma}^{-1}$ by the end of a century. The R8 experiment prescribed a linear increase in basal melt rates from an initial value of zero (i.e. the control run values) to $30 \mathrm{~m} \mathrm{a}^{-1}$ at the end of the first century. Because temperatures continue to rise in the R8 experiment, this linear rate continues for an additional century, reaching $60 \mathrm{~m} \mathrm{a}^{-1}$ by 2200 . After 2200, temperatures still rise, but more gradually, causing an additional $10 \mathrm{~m} \mathrm{a}^{-1}$ melt extending over the next 300 years to reach a total of $70 \mathrm{ma}^{-1}$ by the end of the 500 year run. These conditions are applied only to the Amundsen Sea (90$\left.120^{\circ} \mathrm{W}\right)$ and the Amery Ice Shelf $\left(60-75^{\circ} \mathrm{E}\right)$, not to the Weddell and Ross Seas where the very large Ronne and Ross Ice Shelves buttress large reservoirs of grounded ice.

For Greenland, the temperature increases are larger than for Antarctica, but the impact of the ocean/ice interaction might be lessened by the limited extent and thickness of Greenland ice shelves and the effect might not reach all outlets. Without a simple quantitative guide to follow, the melting increases are prescribed to mirror those in the Antarctic, but without any longitudinal limits.

\subsubsection{Results}

The results of the R8 experiment for both the Greenland and Antarctic ice sheets are shown in Figure 15; Table 4 presents 

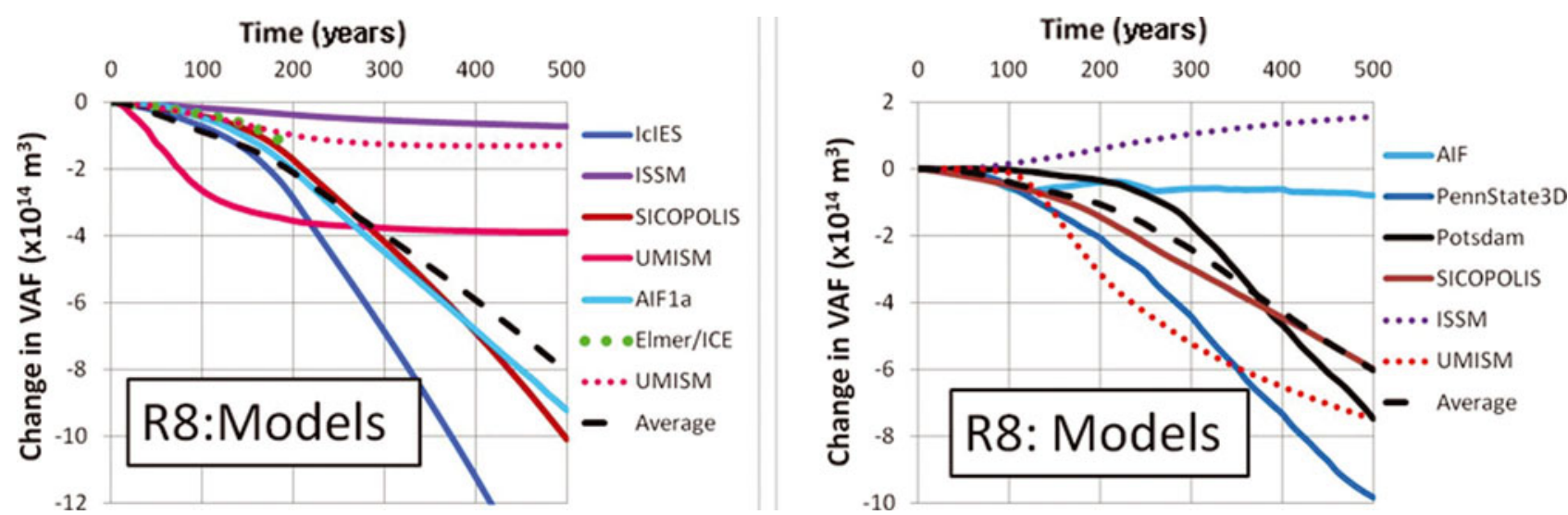

Fig. 15. Model predictions of change in VAF for the R8 combination experiment for the Greenland (left) and Antarctic (right) ice sheets. Two cases for the UMISM Greenland model are included: one with all forcings and one where basal melting changes were not applied. Dotted lines represent model results where basal melt changes were not included. None of the dotted results are included in the Average.

the global mean sea-level equivalents for the end of the first, second and fifth centuries of the experiment. Considering Greenland first, all models project a decrease in the ice volume above flotation. The smallest VAF loss comes from the ISSM model, a model that has ice shelves but applies the melt rate only to the calving front and does not allow melting of ice initially grounded (Table 2). At the other extreme, the UMISM model does not have ice shelves and applies the melting directly to at the grounded edge of submarine ice and predicts the most rapid loss of VAF. To evaluate the impact of the UMISM model's approach, this experiment was run separately with the UMISM but without any melting applied; its predictions are similar to the ISSM model (dotted red line in Fig. 15) but are not included in the computed Average or Table 4. Results for the IcIES, SICOPOLIS and AIF models lie between these two other models for the first 200 years and display a similar evolution, with a rapid transition to increasing VAF loss in the middle of the second century. No change in the prescribed forcing occurs at this time, so the cause likely is a delayed response to earlier forcing. The Elmer/lce model, which also does not include melting (and thus is not included in either the computed Average curve or Table 4), agrees well with this final model trio through its abbreviated 200 year run, suggesting that the cause of this delayed response is not melting, but rather either the climate or basal sliding forcing. Because the doubled basal sliding experiment (S1, Fig. 5) did not exhibit this type of response, the cause of the increasing rate of VAF loss is most likely the prescribed climate forcing.

Table 4 reflects the widening spread with time of the model projections expressed as sea-level equivalent. A mean contribution to increased sea level of $22.3 \mathrm{~cm}$ from ice loss in Greenland is projected after 100 years. The singularly large VAF loss predicted by the UMISM model at 100 years is responsible for the relatively high maximum value at that epoch; all other models are tightly clustered about a slightly smaller value of $11.4 \mathrm{~cm}$. By 200 years, the UMISM model's predictions are more in line with the other models, most of which have begun to dramatically increase their loss of VAF, so that with a very similar spread, the mean sea-level contribution has increased to $53.2 \mathrm{~cm}$. At 200 years, the pace of climate forcing and the rate at which melt rates increase both reduce considerably. Following this transition, the UMISM model markedly decreases its rate of VAF loss; however the ICIES, AIF and SICOPOLIS models do not respond similarly, maintaining relatively high rates of VAF loss for the remaining three centuries. By the end of the experiment at 500 years, the spread has grown to a sea-level equivalent of nearly $4 \mathrm{~m}$, bounded by the unresponsive ISSM and very responsive IcIES models. The mean loss of VAF at the experiment's conclusion is $>2 \mathrm{~m}$ of sea-level equivalent. We repeat the caveat that these estimates of sea-level change are in addition to either any ongoing rates of change or any delayed changes caused by changes occurring prior to the 1 January 2004 start of the R8 experiments.

For Antarctica, the model projections define VAF changes that are broadly similar in magnitude and range to Greenland, but there are important differences. The R8 climate changes in Antarctica encourage ice-sheet growth, delaying the eventual increase in VAF losses driven by the increased ice-shelf melting and the delayed increase in basal sliding. A universal caveat in interpreting the Antarctic results is that because we have demonstrated (Fig. 13) that melt is the strongest of the three environmental forcings for the Antarctic ice sheet, the validity of the Antarctic ice sheet's near-term contribution to future sea level depends very

Table 4. Projections of ice-sheet contributions to global mean sea level $(\mathrm{m})$ from the R8 experiment at 100, 200 and 500 years in the future. Models that do not include all three forcings (specified in the text) are not included

\begin{tabular}{|c|c|c|c|c|c|c|c|c|c|}
\hline & \multicolumn{3}{|c|}{100} & \multicolumn{3}{|c|}{200} & \multicolumn{3}{|c|}{500} \\
\hline & Min & Mean & Max & Min & Mean & Max & Min & Mean & Max \\
\hline Greenland & 0.045 & 0.223 & 0.663 & 0.096 & 0.532 & 0.889 & 0.181 & 2.016 & 4.097 \\
\hline Antarctica & 0.000 & 0.081 & 0.144 & 0.087 & 0.267 & 0.520 & 0.195 & 1.505 & 2.456 \\
\hline
\end{tabular}



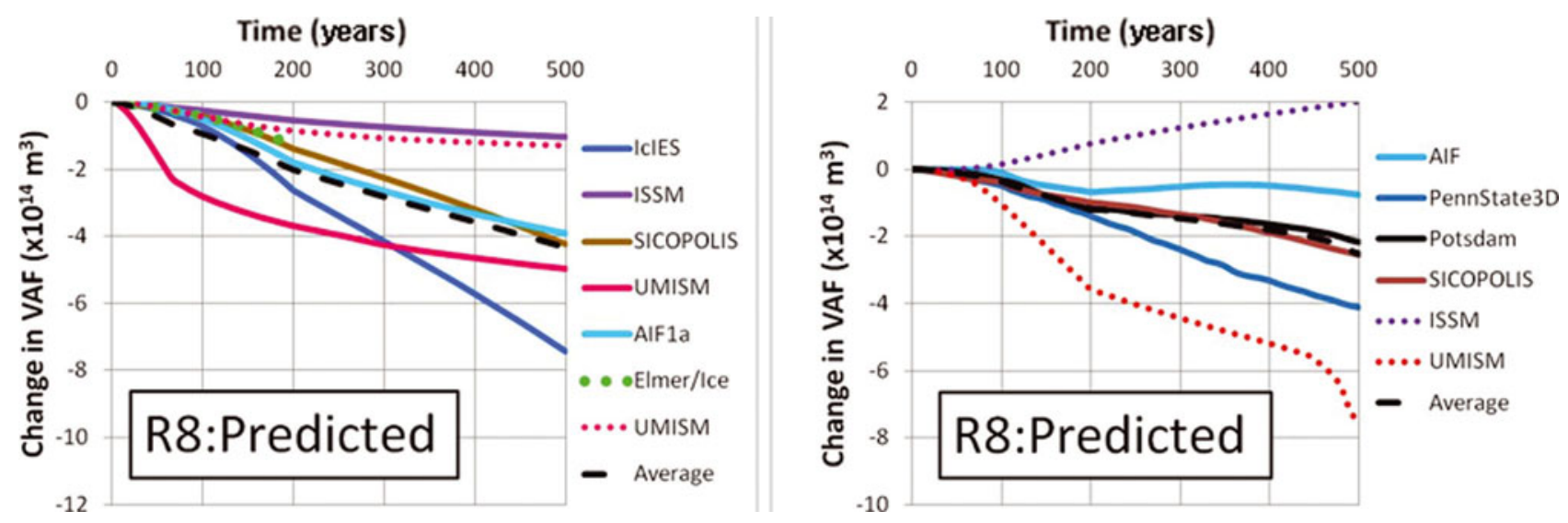

Fig. 16. Calculations of predicted model results for the R8 combination experiment based on the linear interpolation approach: Greenland (left) and Antarctica (right). Vertical scales are identical to the model results (Fig. 15) to facilitate comparison.

much on an accurate assessment of how basal melting beneath the ice sheets will evolve in the next few decades. We have linked this forcing to the radiative foundation of the RCP 8.5 scenario, but without fully coupled climate models capable of extending their reach to include the intrusion of circumpolar deep water onto the Antarctic continental shelf, the timing and magnitude of our basal melting link to RCP 8.5 remains uncertain.

The UMISM and ISSM models in this experiment do not include basal melting beneath ice shelves, so (as with the models that do not include all forcing components for Greenland) dotted lines are used to represent the results of these models in Figure 15 and their results are not included in either the computed model-Average or in Table 4. The first century's changes of gradually increasing temperatures, increasing precipitation and sub-ice-shelf melting cause only modest changes of VAF for all the models with a mean contribution to sea-level rise of $8.1 \mathrm{~cm}$. A contributing factor to the modest average VAF loss is the slow response of the Potsdam model. Stronger VAF losses by the PennState3D and SICOPOLIS models begin early in the second century and are maintained through the remainder of the experiment.

By the end of 200 years, losses of VAF intensify and the mean contribution to sea level increases to $26.7 \mathrm{~cm}$. Beyond 200 years, the Potsdam model begins to parallel the VAF losses of the PennState3D model, with both eventually exceeding the VAF losses calculated by SICOPOLIS. The AIF model never matches the VAF losses of these other three models. At the end of the experiment, the mean predicted contribution to sea level at 500 years is an increase of $1.505 \mathrm{~m}$ ), with a wide range of more than $2 \mathrm{~m}$ (due mainly to the low VAF losses of the AIF model).

\subsection{Prediction of future sea level using a linear response concept}

In the discussion of the sensitivity experiments, we noted that many of the models displayed a nearly linear dependence of VAF change on the strength of the forcing parameter (i.e. A1B climate amplification, sliding amplification or basal melting rate). In addition, many of the combination experiments support this linear dependence by exhibiting VAF changes that are often closely approximated by a linear sum of the individual contributing forcings. This linearity may be influenced by the focus here on the bulk behavior of VAF change; studies of individual drainage basins indicate stronger occurrences of dynamic feedbacks (e.g. Parizek and others, in press). Nevertheless, our hypothesis is that a linear application of the sensitivity characteristics of each model (or of the average of all models) can provide an alternate means of calculating the results to a wide range of forcing scenarios, including combinations of forcings. If established and verified, the use of such a methodology is potentially extremely powerful.

If valid, this method would also allow the identification of the relative magnitudes of the separate contributing forcings to the net change in VAF predicted by a model, a discrimination that is not possible from the model run alone. This approach has been explored elsewhere to project the possible separate contributions of oceanic thermal expansion and of the Greenland and Antarctic ice sheets to future sea level (Winkelmann and others, 2012). Here a less sophisticated interpolation methodology is applied using the sensitivity experiment results and testing against the R8 experiment results. In essence, the sensitivity experiments provide known responses for a small set of forcing values, the gradually changing forcing magnitudes of the R8 experiment are then used to interpolate the incremental VAF changes between the known values, and the separate incremental responses for each forcing component are then integrated along time and summed to calculate the predicted total response. Details of the interpolation method are presented and discussed in Appendix B.

Figure 16 shows the results of applying this linear interpolation methodology for the prescribed forcings of the R8 experiment. The scales are identical to Figure 15 (the actual model results) to facilitate comparison. Model results can be predicted even for the cases where melting or some other forcing is excluded in the model run (e.g. the UMISM no-melt model results) by not including that particular factor in the interpolation prediction. There are some sudden changes in the rates of VAF change shown in Figure 16 that can be tied to specific times when the interpolation shifts from using one pair of sensitivity results to another (e.g. at 67 years for the UMISM interpolation of Greenland, when the basal melt interpolation shifts, and at 200 years for both the ICIES interpolation of Greenland and the UMISM interpolation of Antarctica, when the melt rate changes; see Appendix B).

Overall, the temporal pattern of the responses is similar and the relative position of any model among the group is usually preserved. However, the envelope is wider in the 

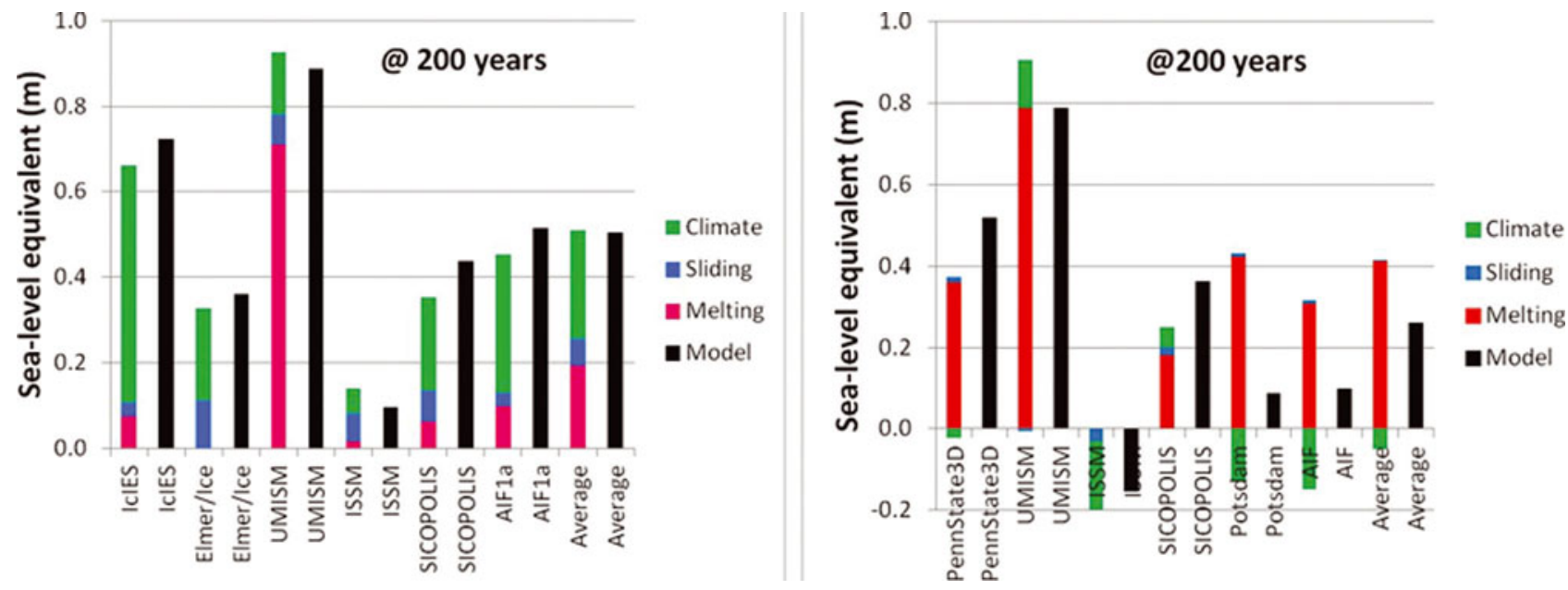

Fig. 17. Comparison of interpolated predictions of model response, partitioned among the three separate forcings (multicolored bars), with actual model results (black bars) for the R8 experiment at 200 years: Greenland (left) and Antarctica (right). Results are given in units of global sea-level equivalent.

actual model case, indicating a general tendency of the interpolation method to under-predict the response.

For Greenland specifically, the interpolations predict progressive VAF loss, in agreement with the model results. For the first 200 years, the evolution and magnitude of the models' VAF losses are very well matched by the interpolation method, generally within $10 \%$. After 200 years, the more rapid VAF losses of the AIF1a, SICOPOLIS and ICIES models are not well predicted and the agreement of the results with the interpolated predictions becomes increasingly poor.

A similar result is seen when comparing the interpolated predictions of the Antarctic models with those actually produced. Initially there is little VAF change because the forcing is not strong. The VAF growth of the ISSM model is overestimated by $\sim 10 \%$ for most of the 500 years. All other models lose VAF throughout the experiment (i.e. PennState3D, SICOPOLIS, UMISM, AIF and Potsdam) and although, as with Greenland, the predictions match the sign of modeled VAF change, the interpolations increasingly under-predict the magnitude of the models with larger VAF losses (i.e. PennState3D, SICOPOLIS and UMISM), so that by the end of the experiment most of the predictions are approximately half of what these models produce. The worst agreement occurs with the Potsdam model where the prediction fails to match the modeled modest VAF loss through the first half of the experiment followed by a more rapid and sustained pace of VAF loss. This might be due to the loss early in the experiment of ice in deep, submarine embayments that do not contribute to VAF loss as much as later losses of more firmly grounded ice (that contribute more substantially to the calculated VAF change). The PennState3D model illustrates a similar but more subdued example of this difference between the model and predicted response.

Because the comparison of the predicted output and the actual output is quite good up to 200 years, Figure 17 compares the sea-level-equivalent values at year 200 including a partitioning of the predicted response among the three separate forcings (climate, sliding and basal melting). In most cases, the prediction is within $20 \%$ of the actual result, with Greenland models comparing generally better than Antarctica models.
The partitioning among the individual forcing components reveals a stark difference between the nature of the Greenland and Antarctic responses to the R8 experiment. For the Greenland ice sheet, the climate forcing dominates for nearly every model (ISSM and UMISM being the exceptions) and accounts for an average of $57 \%$ of the total response. For the Antarctic ice sheet, basal melting clearly dominates, being responsible for $>90 \%$ of the VAF loss.

\section{DISCUSSION AND CONCLUSIONS}

The IPCC AR4 clearly stated the importance of improving projections of the ice sheets' future contributions to sea level, while noting major hurdles in accomplishing the task. The most apparent limitations include a lack of: (1) understanding of key interactive and internal processes that can produce rapid ice loss, (2) large-scale ice-sheet models with grids that can adequately capture the flow transitions from slow sheet flow to relatively small-scale, fast-moving outlet glaciers prevalent along the ice-sheet margins, and (3) coupling between these ice-sheet models and climate models that include atmospheric and oceanic interactions within the environment that surrounds the ice sheets.

Progress is being made in all these areas, but with a view to informing the next IPCC report, the SeaRISE project was formed to contribute additional insight into the potential sea-level contributions of the ice sheets using the current generation of ice-sheet models. Because all existing ice-sheet models have both strengths and weaknesses, a multiple-model ensemble approach was adopted, standard datasets were prepared to limit potential differences in fields defining the physical setting, and coupling to the environment was simplified. The resulting suite of sensitivity experiments serves to illuminate the variety of ice-sheet model responses to even simple forcing. An important discovery is that in a majority of the cases, the response, measured in terms of the change in the ice volume above flotation, is nearly linearly related to the strength of the forcing even when the forcing varies over a wide range.

Perhaps even more significant than the linearity of the modeled responses to single forcing experiments is the fact that model results for experiments that combined two or 
three forcings simultaneously could be accurately predicted by the linear combination of results from experiments with single forcings (Figs 7 and 12). This indicates only limited positive or negative feedbacks acting within the ice sheet when subjected to multiple forcings. The importance of this characteristic becomes clear when considering semi-empirical studies of climate/ice-sheet interaction (e.g. Vermeer and Rahmstort, 2009) that employ simple relationships to project future sea level and suggest that simpler couplings between ice sheets and global climate models might prove entirely adequate.

Differences in the modeled response for Greenland and Antarctica are revealed by this study. The Greenland ice sheet's modeled contribution to sea level due to only the atmospheric changes in temperature and precipitation expected in the next century (i.e. ignoring changes in either basal sliding or basal melt rates of ice shelves) is much greater than Antarctica's modeled contribution despite Greenland's smaller size. On the other hand, the Antarctic ice sheet's modeled contribution to sea level is vastly more sensitive to the melt rate beneath floating ice shelves than is Greenland's. The Antarctic ice sheet is predicted to produce a greater sea-level contribution for the same increase in basal sliding (by about a factor of 2-3; Table 3 and Figs 8 and 13), but the likelihood of such an increase is probably greater in Greenland.

The trio of climate, sliding and basal melting forcings provide enough scope that a proxy simulation of RCP 8.5 could be generated to provide the most direct tie between this work and the IPCC's next report. The model averages project an additional $22.3 \mathrm{~cm}$ rise of sea level from the Greenland ice sheet and a smaller rise of $8.1 \mathrm{~cm}$ from the Antarctic ice sheet in 100 years. These projected rates increase significantly in the second century (Fig. 15), with the total 200 year contributions being 53.2 and $26.7 \mathrm{~cm}$ for Greenland and Antarctica, respectively. These projections are in addition to either any ongoing rates of change or any delayed changes caused by changes occurring prior to the 1 January 2004 start of all SeaRISE experiments. An additional caveat is that the timing and magnitude of changes in basal melt beneath the fringing floating ice used in this study (particularly important for the large Antarctic ice shelves) are speculative, but are tied in a reasonable manner to the RCP8.5 scenario.

The models' results for the R8 experiment were also estimated by interpolating the results of the sensitivity experiments. This method produced not only the same relative pattern of model responses, but magnitudes of VAF change were generally within $20 \%$ of the actual model results for the first 200 years. This finding provides a relatively simple means of estimating ice-sheet contributions to sea level for a wide range of different climate scenarios once those climate scenarios are converted to the forcing categories used herein.

We conclude this work by repeating the caveats noted by the IPCC AR4. This current generation of ice-sheet models has many limitations that restrict their ability to simulate the more dynamic changes recently observed. Thus, our results of potential future sea-level rise should be viewed as only an estimate of ice-sheet response to environmental forcing. Ongoing research, including regional studies utilizing multiple models (similar to the investigation described in this paper) will bring additional, and much needed, refinement to the estimates made here.

\section{ACKNOWLEDGEMENTS}

A project of this magnitude and scope required extensive support from many persons not listed as authors. Datasets, both published and in pre-publication forms, were contributed by A. Le Brocq, H. Pritchard, B. Csatho, T. Bracegirdle, CReSIS and NASA's IceBridge mission and posted on the University of Montana CISM website to be available to all SeaRISE modelers. This website also served as a discussion forum for SeaRISE during its early stages of model initialization and experiment design. The Los Alamos National Laboratory also offered use of a website that became the repository of all communication files (telecom notes and meeting presentations of SeaRISE).

Participation in SeaRISE remained voluntary and, in most cases, came without financial support. Thus participants had to leverage off existing funding activities with objectives that overlapped with SeaRISE goals.

R. Greve, H. Seddik and T. Sato were supported by a Grant-in-Aid for Scientific Research A (No. 22244058) from the Japan Society for the Promotion of Science (JSPS).

$U$. Herzfeld was supported by a NASA Cryospheric Sciences Award (NNX11AP39G).

B. Parizek was supported by the US National Science Foundation (NSF) under grants 0531211, 0758274, 0909335 and the Center for Remote Sensing of Ice Sheets (CReSIS) 0424589 and by NASA under grants NNX-09-AV94G and NNX-10-AI04G.

D. Pollard was supported by NSF under grants ANT0424589, 1043018, 25-0550-0001 and OCE-1202632.

S.F. Price and W.H. Lipscomb were supported by the US Department of Energy (DOE) Office of Science Office of Biological and Environmental Research. Simulations were conducted at the National Energy Research Scientific Computing Center (supported by DOE's Office of Science under contract No. DE-AC02-05CH11231) using time awarded through DOE's ASCR Leadership Computing Challenge allocation to the project 'Projections of Ice Sheet Evolution Using Advanced Ice and Ocean Models'. Model development and simulations were also conducted the Oak Ridge Leadership Computing Facility at the Oak Ridge National Laboratory, supported by DOE's Office of Science under contract No. DE-AC05-00OR22725. CISM development and simulations relied on additional support by K.J. Evans, P.H. Worley and J.A. Nichols (all of Oak Ridge National Laboratory) and A.G. Salinger (Sandia National Laboratories).

$H$. Seroussi and M. Morlighem are supported by the NASA Cryospheric Sciences Program and Modeling Analysis and Prediction Program, and a contract with the Jet Propulsion Laboratory (JPL) Research Technology and Development Program. H. Seroussi was also supported by an appointment to the NASA Postdoctoral Program at JPL, administered by Oak Ridge Associated Universities through a contract with NASA. Resources supporting this work were provided by the NASA High-End Computing (HEC) Program through the NASA Advanced Supercomputing (NAS) Division at Ames Research Center. E. Larour and E. Rignot further enabled their participation on SeaRISE.

R. Walker was supported by NSF through grants 0909335 and CReSIS 0424589, by NASA under grants NNX-09AV94G and NNX-10-AI04G, and by the Gary Comer Science and Education Foundation.

W. Wang was supported by the NASA Cryospheric Science program (grant 281945.02.53.02.19). 
R. Bindschadler and S. Nowicki wish to gratefully acknowledge the unwavering encouragement and financial support from the NASA Cryospheric Science program for the core funding enabling SeaRISE to reach a successful conclusion. Two anonymous reviewers also supplied very thoughtful comments to the original draft that led to a more constructive final manuscript.

\section{REFERENCES}

Abe-Ouchi A and Blatter H (1993) On the initiation of ice sheets. Ann. Glaciol., 18, 203-207

Abe-Ouchi A, Segawa T and Saito F (2007) Climatic conditions for modelling the Northern Hemisphere ice sheets throughout the ice age cycle. Climate Past, 3(3), 423-438 (doi: 10.5194/cp-3423-2007)

Albrecht T, Martin M, Haseloff M, Winkelmann R and Levermann A (2011) Parameterization for subgrid-scale motion of ice-shelf calving-fronts. Cryosphere, 5(1), 35-44 (doi: 10.5194/tc-5-352011)

Amestoy PR, Duff IS, Koster J and L'Excellent JY (2001) A fully asynchronous multifrontal solver using distributed dynamic scheduling. SIAM J. Matrix Anal. Appl., 23(1), 15-41 (doi: 10.1137/S0895479899358194)

Amestoy PR, Guermouche A, L'Excellent J-Y and Pralet S (2006) Hybrid scheduling for the parallel solution of linear systems. Parallel Comput., 32(2), 136-156 (doi: 10.1016/j.parco. 2005.07.004)

Arthern RJ, Winebrenner DP and Vaughan DG (2006) Antarctic snow accumulation mapped using polarization of $4.3 \mathrm{~cm}$ wavelength microwave emission. J. Geophys. Res., 111(D6), D06107 (doi: 10.1029/2004JD005667)

Aschwanden A, Bueler E, Khroulev C and Blatter H (2012) An enthalpy formulation for glaciers and ice sheets. J. Glaciol., 58(209), 441-457 (doi: 10.3189/2012JoG11J088)

Bamber JL, Layberry RL and Gogineni SP (2001) A new ice thickness and bed dataset for the Greenland ice sheet. 1.Measurement, data reduction, and errors. J. Geophys. Res., 106(D24), 33 773-33 780 (doi: 10.1029/2001JD900054)

Bamber JL, Gomez-Dans JL and Griggs JA (2009) A new $1 \mathrm{~km}$ digital elevation model of the Antarctic derived from combined satellite radar and laser data - Part 1: data and methods. Cryosphere, 3(1), 101-111

Blatter H (1995) Velocity and stress fields in grounded glaciers: a simple algorithm for including deviatoric stress gradients. J. Glaciol., 41(138), 333-344

Bohlander J and Scambos TA (2007) Antarctic coastlines and grounding line derived from MODIS Mosaic of Antarctica (MOA). National Snow and Ice Data Center, Boulder, CO. Digital media: http://nsidc.org/data/moa/

Bougamont M, Price S, Christoffersen P and Payne AJ (2011) Dynamic patterns of ice stream flow in a 3-D higher-order ice sheet model with plastic bed and simplified hydrology. J. Geophys. Res., 116(F4), F04018 (doi: 10.1029/2011JF002025)

Bueler E and Brown J (2009) Shallow shelf approximation as a 'sliding law' in a thermomechanically coupled ice sheet model. J. Geophys. Res., 114(F3), F03008 (doi: 10.1029/2008JF001179)

Comiso JC (2000) Variability and trends in Antarctic surface temperatures from in situ and satellite infrared measurements. J. Climate, 13(10), 1674-1696 (doi: 10.1175/1520-0442(2000) $013<1674$ :VATIAS $>2.0 . \mathrm{CO} ; 2)$

Das SB and 6 others (2008) Fracture propagation to the base of the Greenland Ice Sheet during supraglacial lake drainage. Science, 320(5877), 778-781 (doi: 10.1126/science.1153360)

Dukowicz JK and Baumgardner JR (2000) Incremental remapping as a transport/advection algorithm. J. Comput. Phys., 160(1), 318-335 (doi: 10.1006/jcph.2000.6465)

Dukowicz JK, Price SF and Lipscomb WH (2010) Consistent approximations and boundary conditions for ice-sheet dynamics from a principle of least action. J. Glaciol., 56(197), 480-496 (doi: 10.3189/002214310792447851)

Dupont TK and Alley RB (2005) Assessment of the importance of ice-shelf buttressing to ice-sheet flow. Geophys. Res. Lett., 32(4), L04503 (doi: 10.1029/2004GL022024)

Ettema J and 6 others (2009) Higher surface mass balance of the Greenland ice sheet revealed by high-resolution climate modelling. Geophys. Res. Lett., 36(12), L12501 (doi: 10.1029/ 2009GL038110)

Evans KJ and 10 others (2012) A modern solver interface to manage solution algorithms in the Community Earth System Model. Int. J. High Perform. Comput. Appl., 26(1), 54-62 (doi: 10.1177/ 1094342011435159)

Fastook JL (1990) A map-plane finite-element program for ice sheet reconstruction: a steady-state calibration with Antarctica and a reconstruction of the Laurentide ice sheet. In Brown HU ed. Computer assisted analysis and modelling on the IBM 3090. IBM Scientific and Technical Computing Department, White Plains, NY, 45-80

Fastook JL (1993) The finite-element method for solving conservation equations in glaciology. Comp. Sci. Eng., 1(1), 55-67

Fastook JL and Hughes TJ (1990) Changing ice loads on the earth's surface during the last glacial cycle. In Sabadini R, Lambeck K and Boschi E eds. Glacial isostasy, sea-level, and mantle rheology. (NATO Science Series C: Mathematical and Physical Sciences 334). Kluwer Academic, Dordrecht

Fastook JL and Prentice M (1994) A finite-element model of Antarctica: sensitivity test for meteorological mass-balance relationship. J. Glaciol., 40(134), 167-175

Fausto RS, Ahlstrøm AP, Van As D, Bøggild CE and Johnsen SJ (2009) A new present-day temperature parameterization for Greenland. J. Glaciol., 55(189), 95-105 (doi: 10.3189/ 002214309788608985)

Fortuin JPF and Oerlemans J (1990) Parameterization of the annual surface temperature and mass balance of Antarctica. Ann. Glaciol., 14, 78-84

Fox Maule C, Purucker ME, Olsen N and Mosegaard K (2005) Heat flux anomalies in Antarctica revealed by satellite magnetic data. Science, 309(5733), 464-467 (doi: 10.1126/science.1106888)

Franca LP and Frey S (1992) Stabilized finite element methods. II. The incompressible Navier-Stokes equations. Comput. Meth. Appl. Mech. Eng., 99(2-3), 209-233 (doi: 10.1016/00457825(92)90041-H)

Franca LP, Frey S and Hughes TJR (1992) Stabilized finite element methods. I. Application to the advective-diffusive model. Comput. Meth. Appl. Mech. Eng., 95(2), 221-242

Greve R (1997) A continuum-mechanical formulation for shallow polythermal ice sheets. Philos. Trans. R. Soc. London, Ser. A, 355(1726), 921-974 (doi: 10.1098/rsta.1997.0050)

Greve R, Saito F and Abe-Ouchi A (2011) Initial results of the SeaRISE numerical experiments with the models SICOPOLIS and ICIES for the Greenland ice sheet. Ann. Glaciol., 52(58), 23-30 (doi: 10.3189/172756411797252068)

Griggs JA and Bamber JL (2009) A new 1 km digital elevation model of Antarctica derived from combined radar and laser data - Part 2: validation and error estimates. Cryosphere, 3(1), 113-123 (doi: 10.5194/tc-3-113-2009)

Griggs JA and Bamber JL (2011) Antarctic ice-shelf thickness from satellite radar altimetry. J. Glaciol., 57(203), 485-498 (doi: 10.3189/002214311796905659)

Heroux HA and 15 others (2005) An overview of the Trilinos project. ACM Trans. Math. Softw., 31(3), 397-423

Herzfeld UC, Wallin BF, Leuschen CJ and Plummer J (2011) An algorithm for generalizing topography to grids while preserving subscale morphologic characteristics - creating a glacier bed DEM for Jakobshavn trough as low-resolution input for dynamic ice-sheet models. Comput. Geosci., 37(11), 1793-1801 (doi: 10.1016/j.cageo.2011.02.021)

Herzfeld UC, Fastook J, Greve R, McDonald B, Wallin BF and Chen PA (2012) On the influence of outlet glaciers in Greenland bed 
topography on results from dynamic ice sheet models. Ann. Glaciol., 53(60 Pt 2), 281-293 (doi: 10.3189/2012AoG60A061)

Holland DM, Thomas RH, de Young B, Ribergaard MH and Lyberth B (2008) Acceleration of Jakobshavn Isbræ triggered by warm subsurface ocean waters. Nature Geosci., 1(10), 659-664 (doi: 10.1038/ngeo316)

Howat IM, Smith BE, Joughin I and Scambos TA (2008) Rates of southeast Greenland ice volume loss from combined ICESat and ASTER observations. Geophys. Res. Lett., 35(17), L17505 (doi: 10.1029/2008GL034496)

Hutter K (1983) Theretical glaciology; material science of ice and the mechanics of glaciers and ice sheets. D. Reidel Publishing Co., Dordrecht; Terra Scientific Publishing Co., Tokyo

Huybrechts P (2008) Report of the Third EISMINT Workshop on Model Intercomparison. EISMINT Intercomparison Group, Grindelwald

Huybrechts P and de Wolde J (1999) The dynamic response of the Greenland and Antarctic ice sheets to multiple-century climatic warming. J. Climate, 12(8), 2169-2188 (doi: 10.1175/15200442(1999)012<2169:TDROTG>2.0.CO;2)

Jakobsson $M$ and 7 others (2008) An improved bathymetric portrayal of the Arctic Ocean: implications for ocean modeling and geological, geophysical and oceanographic analyses. Geophys. Res. Lett., 35(7), L07602 (doi: 10.1029/ 2008GL033520)

Johnson J and Fastook J (2002) Northern Hemisphere glaciation and its sensitivity to basal melt water. Quat. Int., 95-6, 65-74

Joughin I, Tulaczyk S, Fahnestock M and Kwok R (1996) A minisurge on the Ryder Glacier, Greenland, observed by satellite radar interferometry. Science, 274(5285), 228-230

Joughin I, Das SB, King MA, Smith BE, Howat IM and Moon T (2008) Seasonal speedup along the western flank of the Greenland Ice Sheet. Science, 320(5877), 781-783 (doi: 10.1126/science.1153288)

Joughin I, Smith BE, Howat IM, Scambos $\mathrm{T}$ and Moon T (2010) Greenland flow variability from ice-sheet-wide velocity mapping. J. Glaciol., 56(197), 415-430 (doi: 10.3189/ 002214310792447734)

Joughin I, Smith BE and Holland DM (2010) Sensitivity of 21st century sea level to ocean-induced thinning of Pine Island Glacier, Antarctica. Geophys. Res. Lett., 37(20), L20502 (doi: 10.1029/2010GL044819)

Kleman J, Fastook J and Stroeven AP (2002) Geologically and geomorphologically-constrained numerical model of Laurentide Ice Sheet inception and build-up. Quat. Int., 95-96, 87-98 (doi: 10.1016/S1040-6182(02)00030-7)

Larour E, Seroussi H, Morlighem M and Rignot E (2012) Continental scale, high order, high spatial resolution, ice sheet modeling using the Ice Sheet System Model (ISSM). J. Geophys. Res., 117(F1), F01022 (doi: 10.1029/2011JF002140)

Le Brocq AM, Payne AJ and Vieli A (2010) An improved Antarctic dataset for high resolution numerical ice sheet models (ALBMAP v1). Earth Syst. Sci. Data, 2(2), 247-260 (doi: 10.5194/essdd-3195-2010)

Lemieux J-F and 6 others (2011) Implementation of the Jacobianfree Newton-Krylov method for solving the first-order ice sheet momentum balance. J. Comput. Phys., 230(17), 6531-6545 (doi: 10.1016/j.jcp.2011.04.037)

Levermann A, Albrecht T, Winkelmann R, Martin MA, Haseloff M and Joughin I (2012) Kinematic first-order calving law implies potential for abrupt ice-shelf retreat. Cryosphere, 6(2), 273-286 (doi: 10.5194/tc-6-273-2012)

Lipscomb WH, Bindschadler R, Bueler E, Holland D, Johnson J and Price S (2009) A Community Ice Sheet Model for sea level prediction. EOS, 90(3), 23

Little CM and 21 others (2007) Toward a new generation of ice sheet models. EOS, 88(52), 578-579

MacAyeal DR (1989) Large-scale ice flow over a viscous basal sediment: theory and application to Ice Stream B, Antarctica. J. Geophys. Res., 94(B4), 4071-4087
Martin MA and 6 others (2011) The Potsdam Parallel Ice Sheet Model (PISM-PIK) - Part 2: Dynamic equilibrium simulation of the Antarctic ice sheet. Cryosphere, 5(3), 727-740 (doi: 10.5194/tc-5-727-2011)

Meinshausen $M$ and 9 others (2011) The RCP greenhouse gas concentrations and their extensions from 1765 to 2300 . Climatic Change, 109(1-2), 213-241 (doi: 10.1007/s10584-011-0156-z)

Morland LW (1984) Thermo-mechanical balances of ice sheet flow. Geophys. Astrophys. Fluid Dyn., 29, 237-266

Morland LW (1987) Unconfined ice-shelf flow. In Van der Veen CJ and Oerlemans J eds. Dynamics of the West Antarctic Ice Sheet. D. Reidel, Dordrecht, 99-116

Morlighem M, Rignot E, Seroussi H, Larour E, Ben Dhia H and Aubry D (2010) Spatial patterns of basal drag inferred using control methods from a full-Stokes and simpler models for Pine Island Glacier, West Antarctica. Geophys. Res. Lett., 37(14), L14502 (doi: 10.1029/2010GL043853)

Näslund JO, Rodhe L, Fastook JL and Holmlund P (2003) New ways of studying ice sheet flow directions and glacial erosion by computer modelling - examples from Fennoscandia. Quat. Sci. Rev., 22(2-4), 245-258 (doi: 10.1016/S0277-3791(02)00079-3)

Nitsche FO, Jacobs SS, Larter RD and Gohl K (2007) Bathymetry of the Amundsen Sea continental shelf: implications for geology, oceanography, and glaciology. Geochem. Geophys. Geosyst., 8(Q10), Q10009 (doi: 10.1029/2007GC001694)

Nowicki S and 30 others (2013a) Insights into spatial sensitivities of ice mass response to environmental changes from the SeaRISE ice sheet modeling project I: Antarctica. J. Geophys. Res. Earth Surf., in press

Nowicki S and 30 others (2013b) Insights into spatial sensitivities of ice mass response to environmental changes from the SeaRISE ice sheet modeling project II: Greenland. J. Geophys. Res. Earth Surf., in press

Oppenheimer M and 23 others (2007) Report of the Workshop on Ice Sheet Modeling at the NOAA Geophysical Fluid Dynamics Laboratory, 8 January 2007. National Oceanic and Atmospheric Administration with Princeton University, Washington DC http:// www.scar.org/researchgroups/physicalscience/icesheetrpt.pdf

Parizek BR and Alley RB (2004) Implications of increased Greenland surface melt under global-warming scenarios: ice-sheet simulations. Quat. Sci. Rev., 23(9-10), 1013-1027 (doi: 10.1016/j.quascirev.2003.12.024)

Parizek BR and 10 others (in press) Dynamic (in)stability of Thwaites Glacier, West Antarctica. J. Geophys. Res.

Pattyn F (2003) A new three-dimensional higher-order thermomechanical ice-sheet model: basic sensitivity, ice stream development, and ice flow across subglacial lakes. J. Geophys. Res., 108(B8), 2382 (doi: 10.1029/2002JB002329)

Payne AJ, Vieli A, Shepherd A, Wingham DJ and Rignot E (2004) Recent dramatic thinning of largest West Antarctic ice stream triggered by oceans. Geophys. Res. Lett., 31(23), L23401 (doi: 10.1029/2004GL021284)

Payne AJ, Holland PR, Shepherd AP, Rutt IC, Jenkins A and Joughin I (2007) Numerical modeling of ocean-ice interactions under Pine Island Bay's ice shelf. J. Geophys. Res., 112(C10), C10019 (doi: 10.1029/2006JC003733)

Pfeffer WT, Harper JT and O'Neel S (2008) Kinematic constraints on glacier contributions to 21 st-century sea-level rise. Science, 321(5894), 1340-1343 (doi: 10.1126/science.1159099)

Pollard D and DeConto RM (2012) Description of a hybrid ice sheetshelf model, and application to Antarctica. Geosci. Model Dev. Discuss., 5(2), 1077-1134 (doi: 10.5194/gmdd-5-1077-2012)

Price SF, Payne AJ, Howat IM and Smith BE (2011) Committed sealevel rise for the next century from Greenland ice sheet dynamics during the past decade. Proc. Natl Acad. Sci. USA (PNAS), 108(22), 8978-8983 (doi: 10.1073/pnas.1017313108)

Pritchard HD, Ligtenberg SRM, Fricker HA, Vaughan DG, Van den Broeke MR and Padman L (2012) Antarctic ice-sheet loss driven by basal melting of ice shelves. Nature, 484(7395), 502-505 (doi: 10.1038/nature10968) 
Reeh N (1991) Parameterization of melt rate and surface temperature on the Greenland ice sheet. Polarforschung, 59(3), 113-128

Rignot E, Casassa G, Gogineni P, Krabill W, Rivera A and Thomas R (2004) Accelerated ice discharge from the Antarctic Peninsula following the collapse of Larsen B ice shelf. Geophys. Res. Lett., 31(18), L18401 (doi: 10.1029/2004GL020697)

Rignot E and Jacobs SS (2002) Rapid bottom melting widespread near Antarctic ice sheet grounding lines. Science, 296(5575), 2020-2023 (doi: 10.1126/science.1070942)

Rignot E and Kanagaratnam P (2006) Changes in the velocity structure of the Greenland Ice Sheet. Science, 311(5673), 986-990 (doi: 10.1126/science.1121381)

Saito F and Abe-Ouchi A (2004) Thermal structure of Dome Fuji and east Dronning Maud Land, Antarctica, simulated by a threedimensional ice-sheet model. Ann. Glaciol., 39, 433-438 (doi: 10.3189/172756404781814258)

Saito F and Abe-Ouchi A (2005) Sensitivity of Greenland ice sheet simulation to the numerical procedure employed for ice-sheet dynamics. Ann. Glaciol., 42, 331-336 (doi: 10.3189/ 172756405781813069)

Saito F and Abe-Ouchi A (2010) Modelled response of the volume and thickness of the Antarctic ice sheet to the advance of the grounded area. Ann. Glaciol., 51(55), 41-48 (doi: 10.3189/ 172756410791392808)

Sato T and Greve R (2012) Sensitivity experiments for the Antarctic ice sheet with varied sub-ice-shelf melting rates. Ann. Glaciol., 53(60 Pt 2), 221-228 (doi: 10.3189/2012AoG60A042)

Scambos TA, Bohlander JA, Shuman CA and Skvarca P (2004) Glacier acceleration and thinning after ice shelf collapse in the Larsen B embayment, Antarctica. Geophys. Res. Lett., 31(18), L18402 (doi: 10.1029/2004GL020670)

Schoof C (2007) Ice sheet grounding line dynamics: steady states, stability, and hysteresis. J. Geophys. Res., 112(F3), F03S28 (doi: 10.1029/2006JF000664)

Seddik H, Greve R, Zwinger T, Gillet-Chaulet F and Gagliardini $O$ (2012) Simulations of the Greenland ice sheet 100 years into the future with the full Stokes model Elmer/lce. J. Glaciol., 58(209), 427-440 (doi: 10.3189/2012JoG11J177)

Seroussi $\mathrm{H}$ and 6 others (2011) Ice flux divergence anomalies on 79north Glacier, Greenland. Geophys. Res. Lett., 38(9), L09501 (doi: 10.1029/2011GL047338)

Shapiro NM and Ritzwoller MH (2004) Inferring surface heat flux distribution guided by a global seismic model: particular application to Antarctica. Earth Planet. Sci. Lett., 223(1-2), 213-224 (doi: 10.1016/j.epsl.2004.04.011)

Shepherd A, Wingham D and Rignot E (2004) Warm ocean is eroding West Antarctic Ice Sheet. Geophys. Res. Lett., 31(23), L23404 (doi: 10.1029/2004GL021106)

Shepherd A and 46 others (2012) A reconciled estimate of ice sheet mass balance. Science, 338(6111), 1183-1189

Solomon S and 7 others eds (2007) Climate change 2007: the physical science basis. Contribution of Working Group I to the Fourth Assessment Report of the Intergovernmental Panel on Climate Change. Cambridge University Press, Cambridge

Tarasov L and Peltier WR (2002) Greenland glacial history and local geodynamic consequences. Geophys. J. Int., 150(1), 198-229 (doi: 10.1046/j.1365-246X.2002.01702.x)

Thomas RH (1973) The creep of ice shelves: theory. J. Glaciol., 12,(64), 45-53

Van de Berg WJ, Van den Broeke MR, Reijmer $\mathrm{CH}$ and Van Meijgaard E (2006) Reassessment of the Antarctic surface mass balance using calibrated output of a regional atmospheric climate model. J. Geophys. Res., 111(D11), D11104 (doi: 10.1029/2005JD006495)

Van der Veen CJ and ISMASS (2010) Ice sheet mass balance and sea level: a science plan. SCAR Rep. 38

Van Vuuren DP and 14 others (2011) The representative concentration pathways: an overview. Climatic Change, 109(1-2), 5-31 (doi: 10.1007/s10584-011-0148-z)
Vaughan, D. G., J. W. Holt, and D. D. Blankenship (2007), West Antarctic links to sea level estimation, Eos Trans. AGU, 88(46), 485485 (doi:10.1029/2007EO460001)

Vermeer M and Rahmstort S (2009) Global sea level linked to global temperature. Proc. Natl Acad. Sci. USA (PNAS), 106(51), 21 527-21532 (doi: 10.1073/pnas.0907765106)

Wang W, Li J and Zwally HJ (2012) Dynamic inland propagation of thinning due to ice loss at the margins of the Greenland ice sheet. J. Glaciol., 58(210), 734-740 (doi: 10.3189/2012JoG11J187)

Weertman J (1974) Stability of the junction of an ice sheet and an ice shelf. J. Glaciol., 13(67), 3-11

Williams MJM, Grosfeld K, Warner RC, Gerdes R and Determann J (2001) Ocean circulation and ice-ocean interaction beneath the Amery Ice Shelf, Antarctica. J. Geophys. Res., 106(C10), 22 383-22 399 (doi: 10.1029/2000JC000236)

Winkelmann R and 6 others (2011) The Potsdam Parallel Ice Sheet Model (PISM-PIK) - Part 1: Model description. Cryosphere, 5(3), 715-726 (doi: 10.5194/tc-5-715-2011)

Winkelmann R, Levermann A, Frieler K and Martin MA (2012) Uncertainty in future solid ice discharge from Antarctica. Cryos. Discuss., 6(1), 673-714 (doi: 10.5194/tcd-6-673-2012)

Zwally HJ, Abdalati W, Herring T, Larson K, Saba J and Steffen K (2002) Surface melt-induced acceleration of Greenland icesheet flow. Science, 297(5579), 218-222 (doi: 10.1126/ science.1072708)

\section{APPENDIX A: MODEL DESCRIPTIONS}

\section{A.1. PennState3D}

The PennState3D ice-sheet/shelf model is designed for longterm continental-scale applications in paleoclimatic studies. Much of the ice-sheet model is a standard 3-D finitedifference implementation on polar stereographic or longitude-latitude grids. Ice dynamics is a hybrid combination of the scaled shallow-ice-approximation (SIA) equations for interior grounded (vertically shearing) flow, and the shallowshelf (or shelfy-stream) approximation (SSA) equations for stream or shelf (longitudinal stretching) flow. Floating ice shelves and migrating grounding lines are included. The Schoof (2007) parameterization is imposed to set ice fluxes across grounding lines, which enables grounding-line migration to be simulated without the need for higherresolution treatments at this interface. Standard prognostic finite-difference equations predict ice thickness, internal ice temperatures, and the bedrock response under the ice load. An optional coupling with a sediment model, with explicit quarrying/abrasion, transport and deposition of deformable sediment under the ice, is available. There is no explicit basal hydrologic component in the current model.

\section{A.2. UMISM}

The University of Maine Ice Sheet Model (UMISM) consists of a time-dependent finite-element solution of the coupled mass, momentum and energy conservation equations (Fastook, 1990, 1993; Fastook and Hughes, 1990; Fastook and Prentice, 1994) with a broad range of applications. This SIA model works in the map-plane, with the primary input consisting of the present bedrock topography, the surface mean annual temperature, the geothermal heat flux and the annual net mass balance, all defined as functions of position. The solution consists of ice thicknesses, surface elevations, column-integrated ice velocities, the temperature field within the ice sheet, the amount of water at the bed resulting from basal melting, and the amount of bed depression resulting from the ice load. 
The primary solution is of the mass conservation equation. The required column-integrated ice velocities at each point in the map-plane are obtained by numerically integrating the momentum equation through the depth of the ice. Stress is a function of depth and related to strain rates through the flow law of ice. The temperature, on which the flow law ice hardness depends, is obtained from a onedimensional finite-element solution of the energy conservation equation. This calculation includes vertical diffusion and advection, but neglects horizontal movement of heat. Internal heat generation produced by shear with depth and sliding at the bed is also included.

Areas of basal sliding can be specified if known, or internally determined by the model for regions where the bed reaches the pressure-melting point and lubricating water is available. A two-dimensional solution for conservation of water at the bed allows for movement of the basal water down the hydrostatic pressure gradient (Johnson and Fastook, 2002).

With surface temperature and mass balance obtained from a climatological parameterization, the model can be run with no more input than the specified bedrock topography. However, it can also be tightly constrained by climatological, geological and glaciological data when such data are available (Kleman and others, 2002; Naslund and others, 2003).

\section{A.3. Potsdam}

The Potsdam ice-sheet model is based on the Parallel Ice Sheet Model (PISM, www.pism-docs.org), version stable 0.4 which is described separately in this appendix.

This version of PISM has been merged with the Potsdam Parallel Ice Sheet Model (PISM-PIK; Martin and others, 2011; Winkelmann and others, 2011). Ice flow is approximated by a hybrid scheme incorporating both the SIA and the SSA (Bueler and Brown, 2009). An enthalpy formulation (Aschwanden and others, 2012) is used for thermodynamics, and the model employs a physical stress-boundary condition to the SSA at ice fronts, in combination with a subgrid interpolation (Albrecht and others, 2011) and a kinematic first-order calving law (Levermann and others, 2012) at iceshelf fronts. Geothermal heat flux values use the SeaRISErecommended values of Shapiro and Ritzwoller (2004). Surface melting is not modeled for the climate experiments (C1-C3). The grid is non-adaptive, but adjustable; for resolutions used here see Table 2 .

\section{A.4. CISM-2.0}

The Community Ice Sheet Model (CISM) version 2.0 includes improvements to all existing components of the original, SIA-based Glimmer-CISM model. The momentum balance is based on the 3-D first-order approximation to the Stokes equations (Blatter, 1995; Pattyn, 2003; Dukowicz and others, 2010). Energy conservation is expressed through the standard advective-diffusive temperature equation for ice sheets, where the vertical diffusive and advective components are treated separately for purposes of efficient parallelization. Mass, temperature and general 'tracer' advection take advantage of incremental remapping, a high-order, explicit, conservative, upwinding scheme (Dukowicz and Baumgardner, 2000). The governing equations are discretized on a regular grid using second-order accurate, mixed centered (inside the domain) and one-sided (at boundaries) finite-difference stencils. All model components are fully parallel and scale to order $\sim 1000$ processors (Evans and others, 2012). Model numerics, including nonlinear (Picard- and Newton-based) solution methods, are discussed in Lemieux and others (2011) and use the Trilinos solver library (Heroux and others, 2005). Sliding, which is generally treated using a linear-viscous sliding law, is tuned to match balance velocities (Price and others, 2011). Other available options include sliding over a plastic till, for which a basal processes sub-model describes the evolution of till yield strength as a function of basal water content (Bougamont and others, 2011).

\section{A.5. SICOPOLIS}

SICOPOLIS (SImulation COde for POLythermal Ice Sheets) is a 3-D, polythermal ice-sheet model that was originally created by Greve (1997) in a version for the Greenland ice sheet, and has been developed continuously since then. The open-source version 3.0 used here can be found at sicopolis.greveweb.net. It is based on finite-difference solutions of the SIA for grounded ice (Hutter, 1983; Morland, 1984) and the SSA for floating ice (Morland, 1987; MacAyeal, 1989); the latter is not relevant for the Greenland ice sheet. Special attention is paid to basal temperate layers (i.e. regions with a temperature at the pressure-melting point), which are positioned by fulfilling a Stefan-type jump condition at the interface to the cold ice regions. Within the temperate layers, the water content is computed, and its influence on the ice viscosity is taken into account. Glacial isostasy is modeled by the elastic-lithosphere/relaxingasthenosphere (ELRA) approach. SICOPOLIS is coded in Fortran 90, based on the philosophy of keeping all structures as simple as possible; advanced coding techniques are only employed where it is deemed appropriate. The use of external libraries is kept to an absolute minimum and SICOPOLIS can be run without external libraries at all, which makes the installation very easy and fast. Details of the implementations for Antarctica and Greenland are included in Table 2.

\section{A.6. ICIES (AAB)}

The Ice-sheet model for Integrated Earth-system Studies (ICIES) is an extension to three dimensions from a 2-D icesheet model developed by Abe-Ouchi and Blatter (1993). The model is a thermodynamic ice-sheet model with SIA dynamics. Two different options of higher-order flow dynamics are available, but not used in the SeaRISE experiments. The model has been applied for the Greenland ice sheet (Saito and Abe-Ouchi 2005; Greve and others, 2011), the Antarctic ice sheet (Saito and Abe-Ouchi 2004, 2010) as well as past Northern Hemisphere ice sheets (AbeOuchi and others, 2007).

\section{A.7. Elmer/Ice}

Elmer/lce is a full-Stokes thermomechanically coupled model which employs the finite-element method to solve the full-Stokes equations, the temperature evolution equation and the evolution equation of the free surface. A mesh of the computational domain is created using an initial $5 \mathrm{~km}$ horizontal resolution grid. To limit the eventual number of elements while maximizing the spatial resolution, an anisotropic mesh adaptation scheme is employed based on the Hessian matrix of the observed surface velocities (Joughin and others, 2010), with gaps filled with balance velocities (Bamber and others, 2001). The final mesh of horizontal 
elements is vertically extruded to form a 3-D mesh of 320880 elements with 17 equidistant, terrain-following layers.

The boundary conditions are such that at the lateral boundaries of the domain, the stress-free condition is applied with a vanishing horizontal temperature gradient. At the base, a nonlinear Weertman law with sub-melt sliding is used for the basal sliding. At the surface, the mass balance is computed using the positive degree-day (PDD) method. A Picard iteration scheme is used to deal with the nonlinearity of the model equations, and stabilization methods (Franca and Frey, 1992; Franca and others, 1992) are applied to the finite-element discretization. The resulting system of linear equations is solved with a direct method using the MUltifrontal Massively Parallel sparse direct Solver (MUMPS; Amestoy and others, 2001, 2006).

\section{A.8. ISSM}

The Ice Sheet System Model (ISSM, http://issm.jpl.nasa.gov; Morlighem and others, 2010; Seroussi and others, 2011; Larour and others, 2012) is an open-source, massively parallelized, finite-element software dedicated to thermomechanical simulations of continental-scale ice sheets, developed in partnership between the Jet Propulsion Laboratory (JPL) and the University of California Irvine $(\mathrm{UCl})$. ISSM includes several approximations of the fullStokes equations and data assimilation capabilities. A 3-D higher-order flow approximation (Pattyn, 2003) is employed here to run the SeaRISE experiments, with an anisotropic mesh, the resolution of which varies between $3 \mathrm{~km}$ along the coasts and fast ice streams and $15 \mathrm{~km}$ in the interior. The final Greenland mesh has $\sim 450000$ elements, and the Antarctic mesh $\sim 825000$ elements with 14 vertical layers.

Initialization of the model is based on inverse modeling: Present-day geometry (i.e. ice thickness, surface elevation, ice front position) is used to infer the basal friction to bestmatch inferometric synthetic aperture radar (InSAR)-derived observed surface velocities. To ensure compatibility between temperatures and velocities, the thermomechanical steady state is computed. This procedure allows starting with a configuration close to present-day conditions. For the time-dependent simulations, a semi-implicit mass conservation is used. The ice front is kept at its initial position. Timesteps of $\sim 2$ months are used. The arbitrary Lagrangian Eulerian method is applied, and only the vertical positions of the nodes change with time to reflect the geometry evolution (see Table 2).

\section{A.9. PISM}

The Parallel Ice Sheet Model (PISM; www.pism-docs.org) is a well-documented open-source ice-sheet model. PISM uses a hybrid stress balance (Bueler and Brown, 2009) and an enthalpy-based conservation-of-energy scheme (Aschwanden and others, 2012), making the model polythermal. Grid spacing is $5 \mathrm{~km}$ (horizontal) and $10 \mathrm{~m}$ (vertical). At the upper surface, a PDD model converts air temperature and precipitation into surface mass balance, with parameters from EISMINT Greenland (Huybrechts, 2008). At the base, a pseudo-plastic power law relates basal shear stress and sliding velocity. At the ocean boundary, ice is calved off at the initial calving position.

During the last $5 \mathrm{ka}$ of the paleoclimate initialization, a flux correction is applied to the surface mass balance to obtain ice-sheet geometry close to the observed present-day geometry. To avoid model drift, the same flux correction is also applied in all experiments.

\section{A.10. AIF}

The Anisotropic Ice-Flow (AIF) model is a 3-D ice-sheet model (without ice shelves) incorporating anisotropic ice flow, longitudinal and vertical stresses and fully coupling dynamics and thermodynamics (Wang and others, 2012). It calculates ice-sheet geometry including isostatic bedrock adjustment, 3-D distributions of shear and longitudinal strain rates, and enhancement factors which account for the effect of ice anisotropy, temperatures, horizontal and vertical velocities, and shear and longitudinal stresses.

Greenland experiments were addressed with four different implementations of the AIF model. Versions ' 1 ' or ' 2 ' refer to use of a sliding law based on either a cubic (' 1 ') or linear $\left('{ }^{\prime}\right)$ power relation of the basal stress. Model versions ' $a$ ' or ' $b$ ' refer to whether the basal melting at the ice-sheet perimeter is applied to only the perimeter gridpoints with a bed below sea level ('a'), or to the entire perimeter of the ice sheet $(' b$ '). Results from all versions are shown on the Greenland results, but only version ' $1 \mathrm{a}^{\prime}$ (linear-power sliding and basal melt only at submarine perimeter gridpoints) is used in the calculated average and sea-level equivalent values reported in this paper.

\section{APPENDIX B: INTERPOLATION METHODS}

The interpolation approach used here reduces to identifying the proper interpolation point between the associated experiment run results for each forcing type (i.e. climate, sliding or melting) and then summing the results for the total response. The interpolation point is identified at each reported time (every 5 years for Greenland and every 10 years for Antarctica).

Interpolation of the R8 experiment climate forcing is straightforward and, thus, a good choice to illustrate the approach. The climate forcing for the R8 experiment begins by following the $\mathrm{C} 2$ experiment climate forcing of $1.5 \times \mathrm{A} 1 \mathrm{~B}$ for the first 94 years, so no interpolation is used for the climate forcing until the next reported time at 95 years. From this time until the end of the second century, the climate forcing continues to increase linearly with time using a gradient averaged over the first 94 years. From 200 to 500 years the forcing continues to increase linearly, but the rate of increase over these last three centuries is much smaller. Equations that represent how the temperature, $T$, changes with time, $t$, are

$$
\begin{aligned}
& 0<t \leq 94, \quad T(t)= T(t) \text { of } \mathrm{C} 2(1.5 \times \text { AIB }) \text { experiment; } \\
& 95 \leq t<200, \quad T(t)=1.5 \times\left[T_{94} / 94\right] \times t \\
& 200 \leq t \leq 500, \quad T(t)=1.5 \times\left[200 \times T_{94} / 94\right] \\
&+0.07 \times\left[T_{94} / 94\right] \times[t-200]
\end{aligned}
$$

where $t$ is in years and $T_{94}$ is the temperature of the A1B experiment $(\mathrm{C} 1)$ at year $94\left(3.33^{\circ} \mathrm{C}\right.$ for Greenland and $2.32^{\circ} \mathrm{C}$ for Antarctica). The factor 0.07 expresses the slower warming rate after year 200.

The R8 climate forcing initially repeats the C2 forcing, then lies between the $\mathrm{C} 2$ and $\mathrm{C} 3$ forcing conditions and eventually exceeds the C3 forcing (Fig. 14), so it is best to use the $\mathrm{C} 2$ and $\mathrm{C} 3$ experiment results for the interpolation. The R8 temperatures from the above equations provide the interpolation point to be used. By comparing its value to the 
$\mathrm{C} 2$ and $\mathrm{C} 3$ temperatures at the same time $\left(1.5 T_{94}\right.$ and $2.0 T_{94}$, respectively, for all times beyond 94 years), the predicted R8 volume change, $V$, can be interpolated from the volume change values of the $\mathrm{C} 2$ and $\mathrm{C} 3$ experiments, $V_{\mathrm{C} 2}$ and $V_{\mathrm{C} 3}$, at the same time; thus

$$
V(t)=f_{\mathrm{C}} \times\left[V_{\mathrm{C} 3}(t)-V_{\mathrm{C} 2}(t)\right]+V_{\mathrm{C} 2}(t)
$$

where

$$
f_{\mathrm{c}}=\left[T(t)-1.5 T_{94}\right] /\left[2 T_{94}-1.5 T_{94}\right]
$$

All volume changes expressed here are assumed to already be relative to the control experiment.

Melting is described next. The R8 basal melting forcing can be expressed in equation form as

$$
\begin{aligned}
0<t<200, & M(t)=30 \times t / 100 \\
200 \leq t \leq 500, & M(t)=60+10 \times(t-200) / 300
\end{aligned}
$$

where $M(t)$ is the melt rate at time $t$.

For melt rates below $20 \mathrm{ma}^{-1}$ (experiment M2), the interpolation uses results from the $M 1$ and $M 2$ experiments, while for higher melt rates the interpolation uses results from the $\mathrm{M} 2$ and $\mathrm{M} 3$ experiments. A melt rate of $20 \mathrm{~m} \mathrm{a}^{-1}$ occurs at $t=67$ years, so the time interval must be considered in two sub-intervals on which the interpolation equations are

$$
\begin{aligned}
0<t<67, \quad V(t) & =f_{M} \times\left[V_{M 2}(t)-V_{M 1}(t)\right]+V_{M 1}(t) \\
\text { where } f_{M} & =[M(t)-2] /[20-2] \\
67 \leq t \leq 500, \quad V(t) & =f_{M} \times\left[V_{M 3}(t)-V_{M 2}(t)\right]+V_{M 2}(t) \\
\text { where } f_{M} & =[M(t)-20] /[200-20]
\end{aligned}
$$

An alternate interpolation was investigated based on the log of the melt rate, but it performed no better.

The longitudinal dependence applied to the Antarctic ice sheet is treated by first identifying the catchments that fed the ice discharging between $60-75^{\circ} \mathrm{E}$ and $90-120^{\circ} \mathrm{W}$ and masking out all other areas of the ice sheet. Then the above interpolation equations are applied to only the catchments outside this mask.

Sliding is the third component of environmental forcing. For Greenland, predicting the R8 experiment sliding results uses a straightforward interpolation between the CC (noenhanced-sliding) and the S1 (doubled-sliding) experiment. Thus, for all times, $t$,

$$
V(t)=0.5 V_{S 1}
$$

remembering that all volume changes are already referenced to the control volumes.

For the Antarctic ice sheet, the R8 experiment prescribes no sliding enhancement for the first 100 years, but then both a temporal and spatial variation of the sliding amplification factor thereafter. This enhancement factor, $e_{x y}$ can be written

$$
\begin{aligned}
0<t<100, \quad e_{x y}=1 & \\
100<t<500, \quad e_{x y}= & \left\{1+0.2 \times\left[1200-Z^{*}{ }_{x y} / 1200\right]\right. \\
& \times[(t-100) / 100]\}, \\
\text { only if } Z^{*}{ }_{x y}<1200 &
\end{aligned}
$$

where $Z^{*}{ }_{x y}$ is the surface elevation at gridpoint $(x, y)$. Up to year 100 , the sliding contribution to volume change is identically zero because there is no sliding enhancement, so the ice-sheet descriptions exactly match those of the control (CC) run. However, beginning after year 100, sliding amplification is introduced. The subscript on the enhancement factor indicates that amplification varies spatially but it also requires knowledge of the elevation, which changes over time. Interpolation must begin at year 110 (next reported time-step after year 100). The sliding enhancement factor is calculated from the elevation grid at the previous time-step (modified from the elevations from the control and S1 experiments for times after 100 years). The modified elevations are calculated by applying the following equation at every gridpoint:

$Z_{x y}(t)=\left[e_{x y}-1\right] \times\left[Z^{*}{ }_{x y}(t)-Z^{*}{ }_{x y}(t-10)\right]+Z_{x y}(t-10)$

where $Z$ is the modified elevation and $Z^{*}{ }_{x y}$ are the values from the S1 experiment. 